\title{
Aleocharinae della Sottoregione Africana Orientale al Museo di Ginevra (Coleoptera, Staphylinidae) Parte II *
}

\author{
Roberto PACE \\ Via Vittorio Veneto, 13. 37032 Monteforte d'Alpone (Verona), Italia.
}

\begin{abstract}
Aleocharinae from the Eastern African Subregion in the Geneva Museum (Coleoptera, Staphylinidae). Part II. - Based on the study of 80 species of the tribes Tachyusini and Athetini, 54 species are described as new. A key to the species of the genus Alomacrotona Pace is given. Illustrations for fifteen holotypes or lectotypes of species described by Fauvel, Bernhauer, Eichelbaum and Cameron are given. One species, Atheta mombassana Bernhauer, 1934, is newly synonymised with Atheta paludosa Bernhauer, 1931. Three species are transferred to other genera. The new genus Charicera is described and illustrated, based on a new species. It is related to Pelioptera Kraatz. The new genus Askeptoxenia, erected for Atheta acuticollis Fauvel (= A. fauveli Fenyes) is illustrated.
\end{abstract}

Key-words: Coleoptera - Staphylinidae - Aleocharinae - Taxonomy - East Africa.

\section{INTRODUZIONE}

La prima parte dello studio sulle Aleocharinae dell'Africa orientale raccolte nel corso di missioni di ricerca, promosse dal Museo di Storia Naturale di Ginevra, è stata da me pubblicata sulla presente "Revue suisse de Zoologie" nel 1994. Il presente lavoro è la sua prosecuzione e riguarda due tribù: Tachyusini e Athetini.

La seconda di queste tribù comprende qui un maggior numero di specie, dato che le Aleocharinae della tribù Athetini prediligono il clima temperato e il clima temperato freddo e le ricerche del Museo di Ginevra si sono svolte prevalentemente in zone d'alta quota dei maggiori massicci dell'Africa orientale.

Anche nella presente Parte II, come nella Parte I, pubblico e illustro i tipi delle specie di Aleocharinae relative alle due tribù trattate e designo il lectotypus, quando necessario. Mi sono limitato a pubblicare solo quindici tipi: la pubblicazione di tutti i tipi di Atheta dell'Africa da me esaminati, avrebbe comportato un notevole aumento di pagine e avrebbe un po' fuorviato il fine principale del presente lavoro, quello cioè di

* $126^{\circ}$ Contributo alla conoscenza delle Aleocharinae.

Manoscritto accettato il 23.12.1994. 
rendere noto e mettere in ordine sistematico quanto scoperto nel corso delle ricerche promosse dal Museo di Ginevra.

Al materiale affidatomi in studio dal Museo di Ginevra ho aggiunto alcune specie datemi in esame dal Museo di Storia Naturale di Genova, dal D.E.I. di Eberswalde e dal Museo di Erfurt.

Gli holotypi delle nuove specie si conservano nel Museo di Storia Naturale di Ginevra (MG), nel Museo di Storia Naturale di Genova (MGE) e nel D.E.I. di Eberswalde. Paratypi sono custoditi nel Museo di Ginevra, in mia collezione e nel Museo di Erfurt.

\section{ELENCO SISTEMATICO DEI GENERI E DELLE SPECIE E DESCRIZIONI}

\section{TACHUSINI}

Amanota externa (Fauvel, 1907)

(Figg. 1-2)

Tachyusa externa FAUVEL, 1907: 59.

Amanota externa, PACE, 1986: 95, 109.

Materiale esaminato: Lectotypus + , Nakuro (Rift-Valley), externa FVL, Tachyusa, presente designazione; 3 paralectotypi, stessa provenienza (Mus. Roy. Bruxelles).

La specie è qui illustrata per la prima volta.

Amanota interna sp. $\mathrm{n}$.

(Figg. 3-4)

Holotypus + , Kenya, Embu, pr. Ishiara, 900 m, 14.X.1977 (Mahnert \& Perret leg., MG).

Descrizione. Lungh. 2,1 mm. Corpo lucido e bruno-rossiccio con uriti liberi $4^{\circ} \mathrm{e}$ $5^{\circ}$ bruni; antenne bruno-rossicce con antennomero basale rossiccio e $11^{\circ}$ giallo; zampe bruno-rossicce con base dei femori e tarsi giallo-rossicci. La punteggiatura del capo è quasi indistinta, su un fondo non reticolato. Tubercoletti fini e ben salienti sono presenti solo sulla metà posteriore del pronoto. La punteggiatura e la reticolazione delle elitre sono distinte. Gli uroterghi sono privi di reticolazione e hanno una punteggiatura superficiale. Spermateca fig. 4.

Comparazioni. E' da escludere che la nuova specie sia identica ad A. eastopi Tottenham, 1957 del Kenya o ad A. albicornis Tottenham, 1957 dell'Urundi, perché queste specie presentano $\mathrm{l}^{\prime} 11^{\circ}$ antennomero e i due uriti liberi basali colorati di giallo pallido e le elitre sono più lunghe del pronoto, e non un po' più corte come quelle della nuova specie. Per il colore delle antenne e dell'addome, come per la forma della spermateca, la nuova specie sembra sistematicamente vicina ad A. externa (Fauvel, 1907) (Figg. 1-2) della "Rift-Valley", ma la spermateca nettamente più corta, le elitre più lunghe del pronoto e il pronoto più largo osservabili in externa, sono caratteri sufficienti a distinguere externa da interna sp. n.

Etimologia. Il nome della specie è dato in contrapposizione alla specie $A$. externa (Fauvel).

ATHETINI

Amischa kaszabi Pace, 1986

Amischa kaszabi PACE, 1986: 96. 


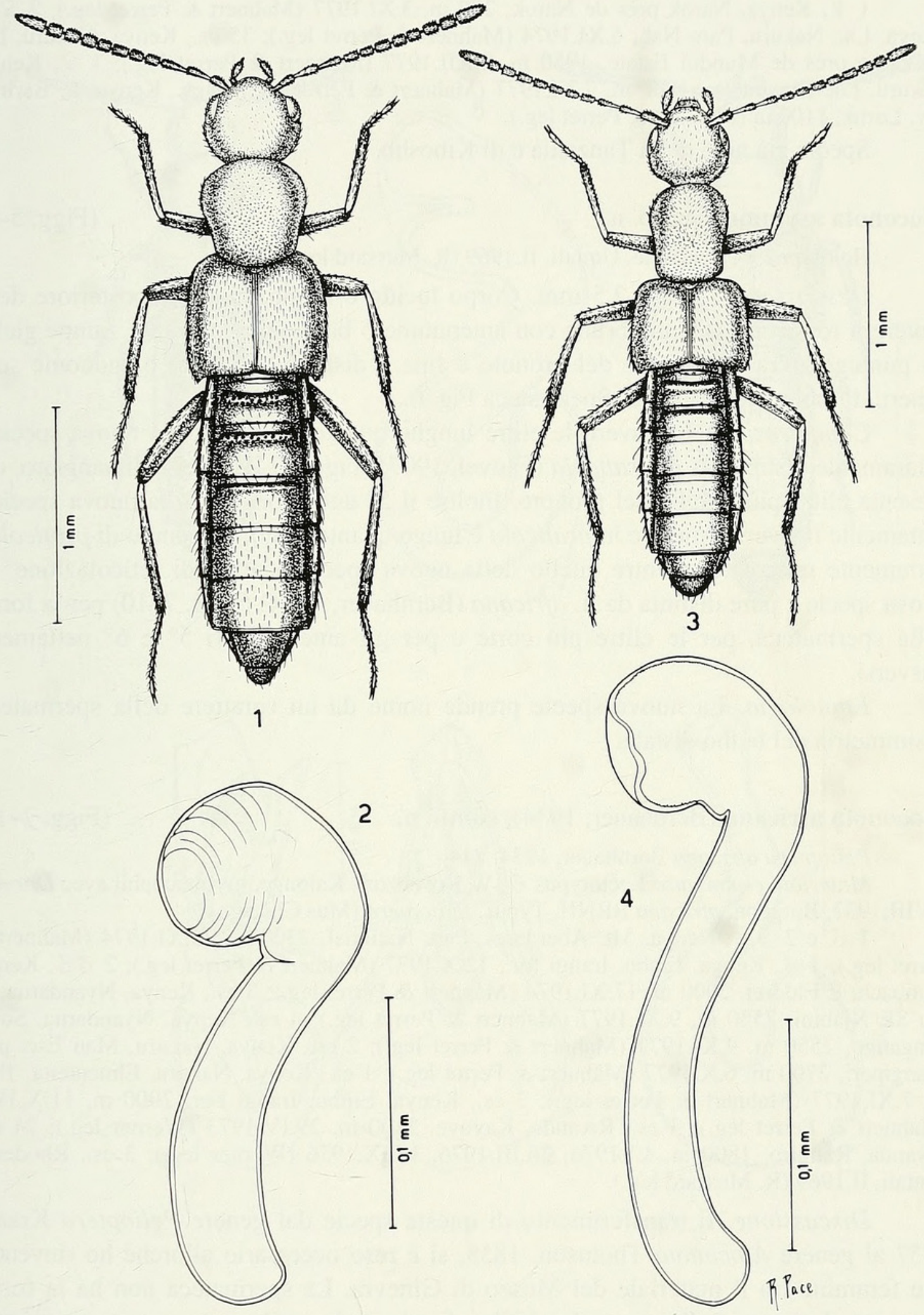

FIGG. 1-4

Habitus e spermateca. 1-2: Amanota externa (Fauvel), lectotypus; 3-4: Amanota interna sp. n. 
1 q. Kenya, Narok près de Narok, 200 m, 3.XI.1977 (Mahnert \& Perret leg.); 2 q $q$, Kenya, Lac Nakuru, Parc Nat., 6.XI.1974 (Mahnert \& Perret leg.); 35 es., Kenya, Nakuru, Lac Naivasha près de Mundui Estate, 1950 m, 8.XII.1977 (Mahnert \& Perret leg.); 1 q, Kenya, Nakuru, Lac Elmenteita, 1800 m, 7.XI.1977 (Mahnert \& Perret leg.); 1 es., Kenya, L. Baringo env. Loruk, $1100 \mathrm{~m}$ (Mahnert \& Perret leg.).

Specie già nota della Tanzania e di Kibosho.

\section{Aloconota asymmetrica sp. $\mathrm{n}$.}

(Figg. 5-6)

Holotypus + , Rhodésie, Umtali, II.1969 (R. Mussard leg., MG).

Descrizione. Lungh. 2,5 mm. Corpo lucido e bruno; margine posteriore degli uroterghi rossiccio; antenne brune con antennomero basale giallo-bruno; zampe gialle. La punteggiatura del capo e del pronoto è fine e distinta. Le elitre e l'addome sono coperti di tubercoletti distinti. Spermateca Fig. 6.

Comparazioni. Per avere le elitre lunghe quanto il pronoto, la nuova specie è chiaramente distinta da A. praticola (Fauvel, 1907) (Figg. 17-19) del Kilimangiaro, che presenta elitre più lunghe del pronoto. Inoltre il $5^{\circ}$ antennomero della nuova specie è nettamente trasverso, mentre in praticola è lungo quanto largo; il pronoto di praticola è nettamente reticolato, mentre quello della nuova specie è privo di reticolazione. La nuova specie è pure distinta da A. africana (Bernhauer, 1934) (Figg. 7-10) per la forma della spermateca, per le elitre più corte e per gli antennomeri $5^{\circ}$ e $6^{\circ}$ nettamente trasversi.

Etimologia. La nuova specie prende nome da un carattere della spermateca: l'asimmetria del bulbo distale.

Aloconota africana (Bernhauer, 1934), comb. n.

(Figg. 7-10)

Pelioptera africana Bernhauer, 1934: 214.

Materiale esaminato: Lectotypus oे, W Riwenzori, Kalonge, myrmecophil avec Dorylus, 8.VIII.1932, Burgeon, africana BRNH, Typus, Pelioptera (Mus Chicago).

1 ot e 2 q q. Kenya, Mt. Aberdares, Parc National, 2300 m, 25.XI.1974 (Mahnert \& Perret leg.); 1 oे, Kenya, Embu, Irangi for., 12.X.1977 (Mahnert \& Perret leg.); 2 oे ơ, Kenya, Tambach, E Eldoret, 2000 m, 17.XI.1974 (Mahnert \& Perret leg.); 3 es., Kenya, Nyandarua, 10 km SE Njabini, 2550 m, 9.XI.1977 (Mahnert \& Perret leg.); 4 es., Kenya, Nyandarua, South Kingango, 2550 m, 9.XI.1977 (Mahnert \& Perret leg.); 2 es., Kenya, Nakuru, Mau Esc. près Erangiperi, 2700 m, 6.X.1977 (Mahnert \& Perret leg.); 1 es., Kenya, Nakuru, Elmenteita, 1800 m, 7.XI.1977 (Mahnert \& Perret leg.); 3 es., Kenya, Embu, Irangi For. 2000 m, 11.X.1977 (Mahnert \& Perret leg.); 3 es., Rwanda, Kayove, 2100 m, 29.IV.1973 (Werner leg.); 24 es., Rwanda, Rangiro, 1800 m, 1.I.1976, 26.III.1976, 14.IX.1976 (Werner leg.); 3 es., Rhodésie, Umtali, II.1969 (R. Mussard leg.).

Discussione. Il transferimento di questa specie dal genere Pelioptera Kraatz, 1857 al genere Aloconota Thomson, 1858, si è reso necessario allorché ho rinvenuto due femmine tra il materiale del Museo di Ginevra. La spermateca non ha la forma consueta al genere Pelioptera, cioè bulbo distale molto sviluppato e parte prossimale della spermateca stessa fortemente ricurva al lato sinistro e molto assottigliata, cioè al contrario di quanto è osservabile sulla spermateca di africana (fig.10). Effettivamente le mesocoxe in africana sono un po' scostate tra loro, carattere questo riconducibile a Pelioptera e che ha probabimente indotto Bernhauer all'attribuzione a Pelioptera. 


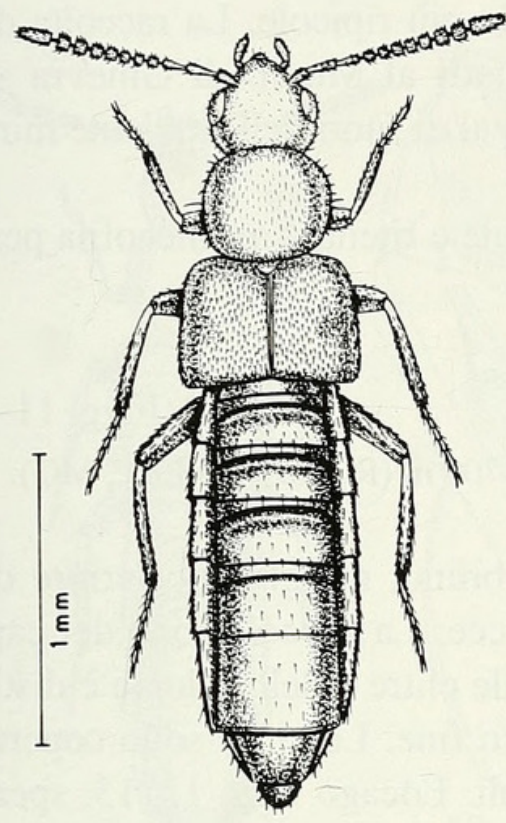

5

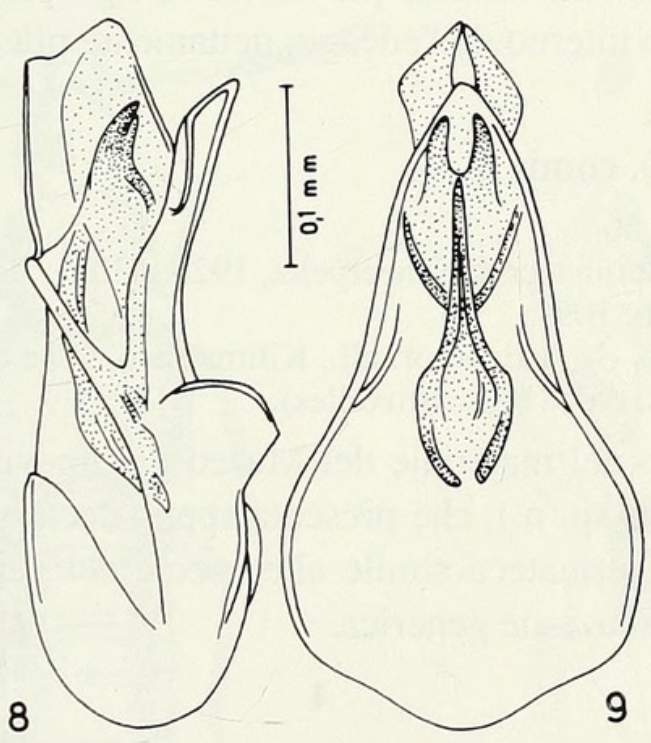

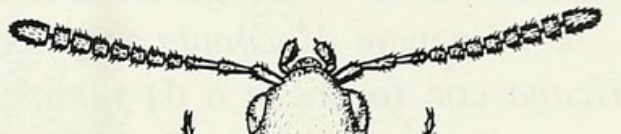
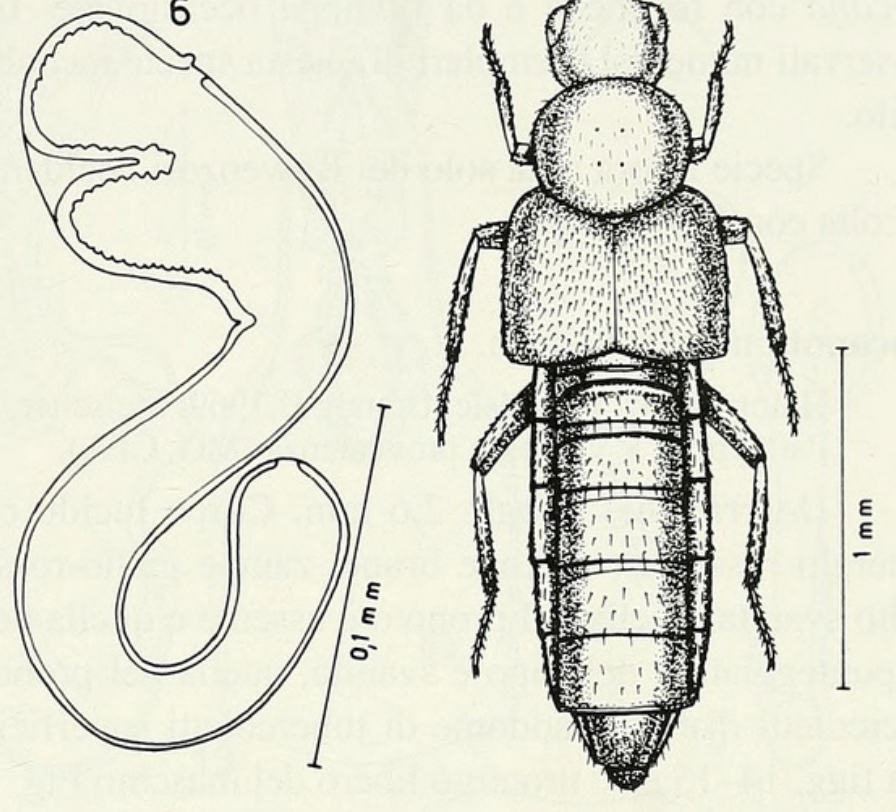

7

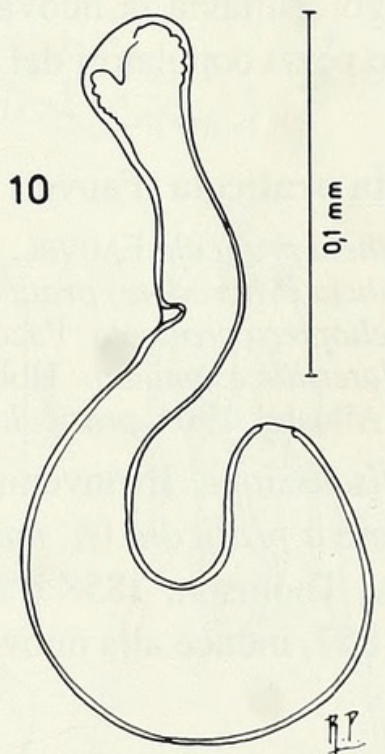

FIGG. 5-10

Habitus, spermateca ed edeago in visione laterale e ventrale. 5-6: Aloconota asymmetrica sp. n.; 7-10: Aloconota africana (Bernhauer), lectotypus ô. 
Tuttavia non sempre questo carattere è costante nell'ambito di un genere, come ho constatato anche in altri generi di Athetini.

$\mathrm{Al}$ genere Aloconota appartengono specie per lo più ripicole. La raccolta di $A$. africana con formiche è da ritenersi occasionale. Infatti al Museo di Ginevra sono conservati numerosi esemplari di questa specie raccolti al di fuori dell'ambiente mirmecofilo.

Specie finora nota solo del Ruwenzori occidentale e ritenuta mirmecofila perché raccolta con Dorylus sp.

\section{Aloconota mussardi sp. n.}

(Figg. 11-16)

Holotypus đ̊, Rhodésie, Umtali, II.1969, Melsetter, 1700 m (R. Mussard Leg., MG).

Paratypi: 2 $q$, stessa provenienza (MG, CPA).

Descrizione. Lungh. 2,6 mm. Corpo lucido e bruno; margine posteriore degli uroterghi rossiccio; antenne brune; zampe giallo-rossicce. La reticolazione del capo è molto svanita, quella del pronoto è assente e quella delle elitre e dell'addome è distinta. La punteggiatura del capo è svanita, quella del pronoto fine. Le elitre sono coperte di tubercoletti distinti, l'addome di tubercoletti superficiali. Edeago figg. 12-13, spermateca figg. $14-15$ e $6^{\circ}$ urotergo libero del maschio Fig. 16.

Comparizioni. Specie simile ad A. africana (Bernhauer, 1934) (Figg. 7-10) del Kenya e del Ruwenzori, a motivo delle elitre più lunghe del pronoto e della forma dell'edeago. Tuttavia la nuova specie ha antenna più corte, edeago più ricurvo al lato ventrale e pezzi copulatori del sacco interno dell'edeago, nettamente più robusti.

Aloconota praticola (Fauvel, 1907), comb. n.

(Figg. 17-19)

Atheta praticola FAUvel, 1907: 56.

Atheta (Microdota) praticola, Bernhauer \& Scheerpeltz, 1926: 630.

Pelioptera praticola; Pace, 1986: 109.

Materiale esaminato: Holotypus ơ, Afrique or. all., Kilimanjaro, zone des prairies, 3200 altit., Ch. Alluaud, 1904, praticola FVL, type (Mus. Bruxelles).

Discussione. Il rinvenimento nel materiale del Museo di Ginevra di una specie assai affine a praticola (A. mauensis sp. n.), che presenta spermateca tipica del genere Aloconota Thomson, 1858 e non spermateca simile alle specie del genere Pelioptera Kraatz, 1857, induce alla nuova attribuzione generica.

\section{Aloconata mauensis sp. n.}

(Figg. 20-23)

Holotypus ô, Kenya, Nakuru Mau Escarpment, S East Mau, 2850 m, 6.XI.1977 (Mahnert \& Perret leg., MG).

Paratypus, 1 \& , stessa provenienza.

Descrizione. Lungh. 2,9 mm. Corpo lucido e bruno con elitre e addome rossicci; antenne brune con antennomero basale bruno-rossiccio; rampe giallo-rossicce. La punteggiatura del capo è distinta, su un fondo non reticolato. Sul pronoto sono presenti tubercoletti salienti, sulle elitre tubercoletti molto salienti e sull'addome tubercoletti distinti. La reticolazione del pronoto è distinta. Edeago figg. 21-22, spermateca Fig. 23. 


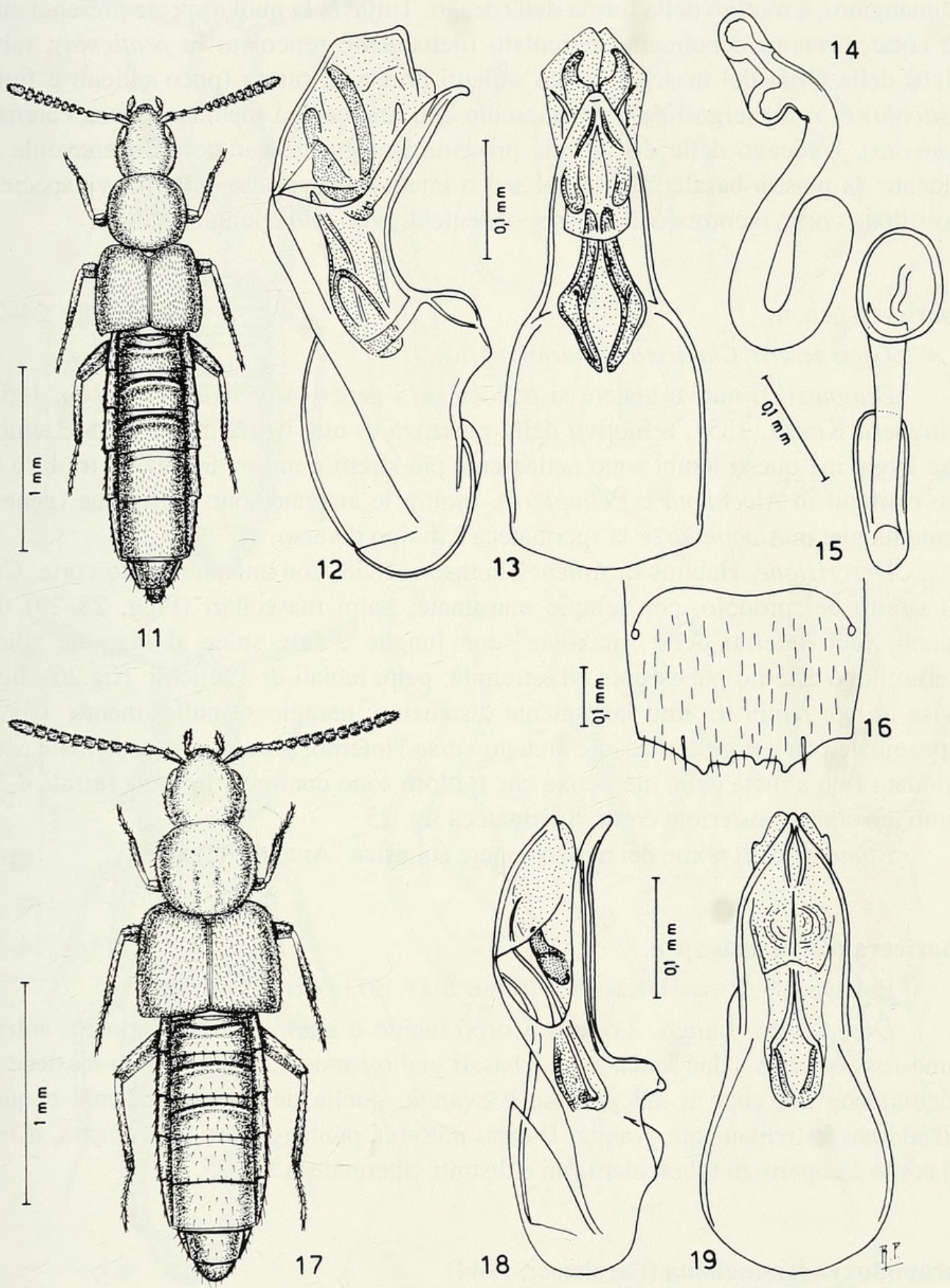

FIGG. 11-19

Habitus, edeago in visione laterale e ventrale, spermateca e $6^{\circ}$ urotergo libero del maschio. 11-16: Aloconota mussardi sp. n.; 17-19: Aloconota praticola (Fauvel), Holotypus ô. 
Comparazioni. Specie affine ad A. praticola (Fauvel, 1907) (Figg. 17-19), del Kilimangiaro, a motivo della forma dell'edeago. Tuttavia la nuova specie presenta elitre più corte, pronoto debolmente reticolato (nettamente reticolato in praticola); tubercoletti delle elitre del maschio molto salienti presso la sutura (poco salienti e fini in praticola) e $5^{\circ}$ urotergo libero del maschio con una carena mediana (senza carena in praticola). L'edeago delle due specie presenta il seguente carattere differenziale più evidente: la piastra basale interna del sacco interno dell'edeago della nuova specie ha uno stiletto corto, mentre quello corrispondente di praticola è lunghissimo.

\section{Charicera gen. $n$.}

(Figg. 24-29)

Typus generis. Charicera ruandensis sp. n.

Diagnosi. Il nuovo genere si colloca tra i generi Aloconota Thomson, 1858 e Pelioptera Kraatz, 1857, a motivo della presenza di una ligula divisa in due lembi a base larga, ma questi lembi sono nettamente più stretti e molto distanziati tra loro (tra loro contigui in Aloconota e Pelioptera). Inoltre le antenne sono cortissime (generalmente lunghe in Aloconota) e la spermateca è di tipo diverso.

Descrizione. Habitus di Atheta Thomson, 1858, con antenne molto corte. Capo più stretto del pronoto, con tempie marginate; palpi mascellari (Figg. 28-29) di 4 articoli; lobo interno delle "maxillae" con lunghe e fitte spine al margine apicale interno; lobo esterno pubescente all'estremità; palpi labiali di 3 articoli (fig.26); ligula divisa in due lembi tra loro largamente distanziati; paraglosse nulle; mento (fig.27) trapezoidale con margine anteriore arcuato verso l'interno; processo mesosternale acuto, insinuato fino a metà delle mesocoxe che tra loro sono contigue; formula tarsale 4-5-5; primo tarsomero posteriore corto. Spermateca fig. 25.

Etimologia. Il nome del nuovo genere significa "Antenne graziose".

Charicera ruandensis sp. $\mathrm{n}$.

(Figg. 24-29)

Holotypus \&, Rwanda, Kayove, 2100 m, 29.IV.1973 (Werner leg., MG).

Descrizione. Lungh. 2,6 mm. Corpo lucido e giallo-rossiccio sporco; antenne bruno-rossicce con i due antennomeri basali giallo-rossicci; zampe giallo-rossicce. La reticolazione del capo e del pronoto è svanita, quella delle elitre assente e quella dell'addome estremamente svanita. Il capo presenta punteggiatura fine e netta, il resto del corpo è coperto di tubercoletti fini e distinti. Spermateca fig. 25.

Parapodoxya jeanneliana (Bernhauer, 1944)

Oxypoda (Podoxya) jeanneliana Bernhauer, 1944: 20.

Oxypoda (Parapodoxya) jeanneliana, Jeannel \& PaUlian, 1945: 96.

Parapodoxya jeanneliana, PACE, 1986: 109.

23 es., Kenya, Mt. Elgon, env. 2650 m, 14.XI.1974 (Mahnert \& Perret leg.).

Specie già nota del Mt. Elgon (località tipica) (JEAnnel \& PAUlian, 1944) e del Mt. Meru (PACE, 1986). Specie infeudata nei nidi di Tachyorictes splendens. 


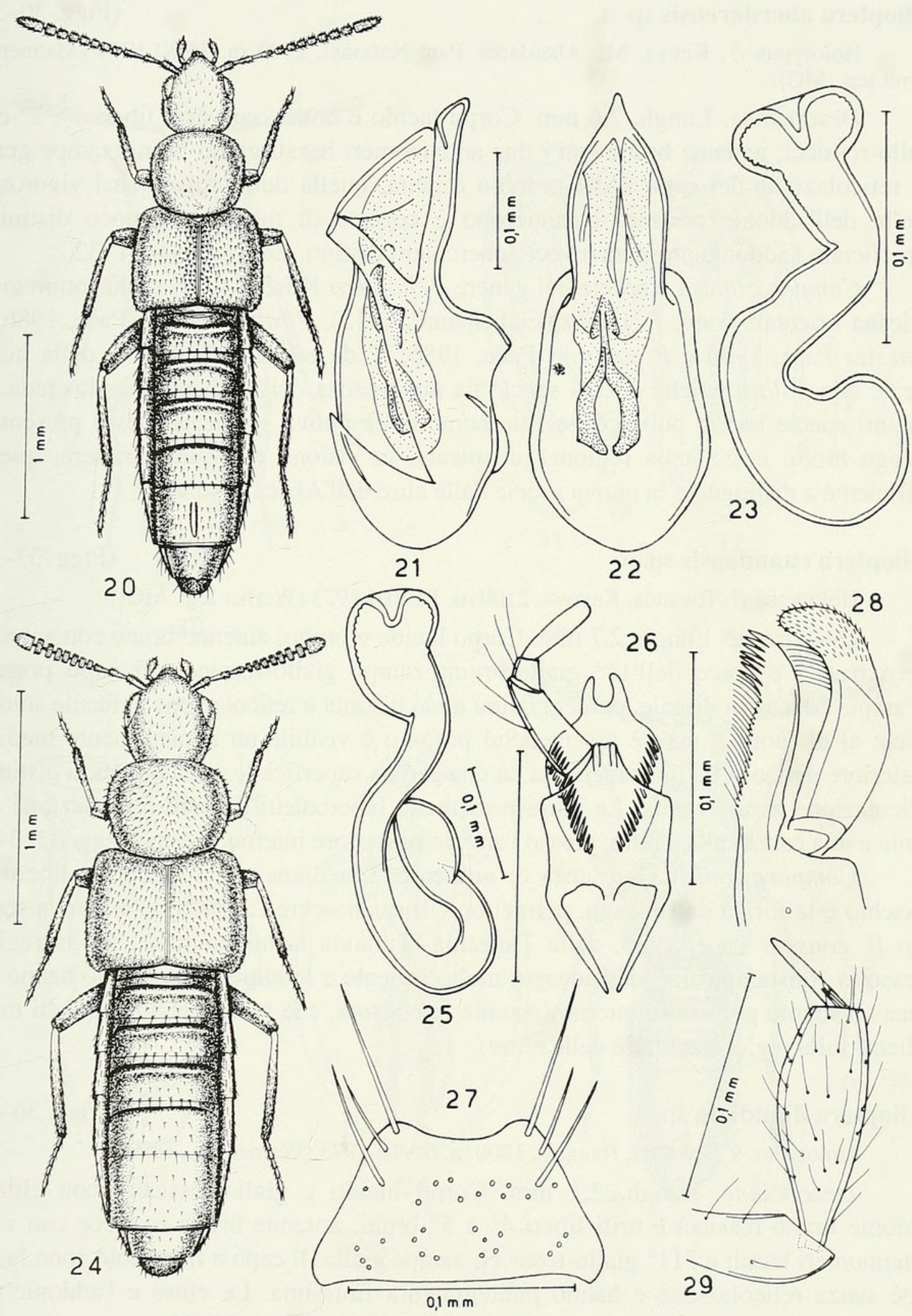

FIGG. 20-29

Habitus, edeago in visione laterale e ventrale, spermateca, labio con palpo labiale, maxilla, palpo mascellare e mento. 20-23: Aloconota mauensis sp. n.; 24-29: Charicera ruandensis gen. n., sp. n. 


\section{Pelioptera aberdarensis sp. $\mathrm{n}$.}

(Figg. 30-32)

Holotypus đ̊, Kenya, Mt. Aberdares, Parc National, 2300 m, 25.XI.1974 (Mahnert \& Perret leg., MG).

Descrizione. Lungh. 2,6 mm. Corpo lucido e bruno, con uriti liberi $1^{\circ}, 2^{\circ}$ e $6^{\circ}$ giallo-rossicci; antenne brune con i due antennomeri basali giallo-bruni; zampe gialle. La reticolazione del capo e del pronoto è netta, quella delle elitre quasi vigorosa e quella dell'addome assente. L'avancorpo è coperto di tubercoletti poco distinti o superficiali, l'addome presenta invece tubercoletti distinti. Edeago figg. 31-32.

Comparazioni. Le specie del genere Pelioptera Kraatz, 1857, della sottoregione africana orientale sono: P. polita (Eichelbaum, 1913), P abyssinorum Pace, 1986, $P$. quaesita Pace, 1986 e $P$. consors Pace, 1986. E' da escludere l'affinità della nuova specie con polita, poiché questa specie ha pubescenza dell'avancorpo molto rada. La restanti specie hanno pubescenza fitta come della nuova specie, ma esse presentano edeago molto largo nella regione subapicale, in visione ventrale, carattere, questo, sufficiente a distinguere la nuova specie dalle altre dell'Africa orientale.

\section{Pelioptera ruandensis sp. $\mathrm{n}$.}

(Figg. 33-35)

Holotypus ơ, Rwanda, Kayove, 2100 m, 12.VIII.1973 (Werner leg., MG).

Descrizione. Lungh. $2,7 \mathrm{~mm}$. Corpo lucido e bruno; antenne brune con antennomero basale e apice dell' $11^{\circ}$ giallo-bruni; zampe giallo-rossicce. Il capo presenta un'ampia concavità discale, punteggiatura assai distinta e reticolazione evidente solo sul disco: al di fuori di esso è assente. Sul pronoto è visibile un appiattimento mediano posteriore diviso sulla linea mediana da una carena superficiale, punteggiatura distinta e reticolazione assai svanita. Le elitre presentano tubercoletti distinti, reticolazione evidente e una carena alla sutura, presso l'angolo posteriore interno. Edeago figg. 33-34.

Comparazioni. La presenza di una carena mediana sul $5^{\circ}$ urotergo libero del maschio e la forma dell'edeago, permettono di riconoscere l'affinità della nuova specie con $P$. consors Pace, 1986, della Tanzania. Tuttavia la nuova specie ha la regione presso la "crista apicalis" dell'adeago, molto saliente e le elitre del maschio hanno una plica all'angolo posteriore interno (assente in consors, che ha invece tubercoletti molto salienti sulla regione suturale delle elitre).

Pelioptera dimidiata sp. $n$.

(Figg. 36-38)

Holotypus + , Rwanda, Rangiro, 1800 m, 6.VIII.1973 (Werner leg., MG).

Descrizione. Lungh. 2,1 mm. Corpo lucido e giallo-rossiccio con elitre e addome bruno-rossicci e uriti liberi $4^{\circ}$ e $5^{\circ}$ bruni; antenne bruno-rossicce con i due antennomeri basali e l'$^{\prime} 11^{\circ}$ giallo-rossicci; zampe gialle. Il capo e il pronoto sono lucidi, cioè senza reticolazione e hanno punteggiatura finissima. Le elitre e l'addome presentano tubercoletti distinti e non sono reticolati. Edeago figg. 37-38.

Comparazioni. La forma dell'edeago della nuova specie appare un po' simile a quella di $P$. abyssinorum Pace, 1986. Infatti entrambe le specie presentano una plica presso la "crista apicalis" dell'edeago e l'apice dell'edeago termina a punta di lancia. La più vistosa differenza tra le due specie consiste nella presenza di un flagello lungamente 


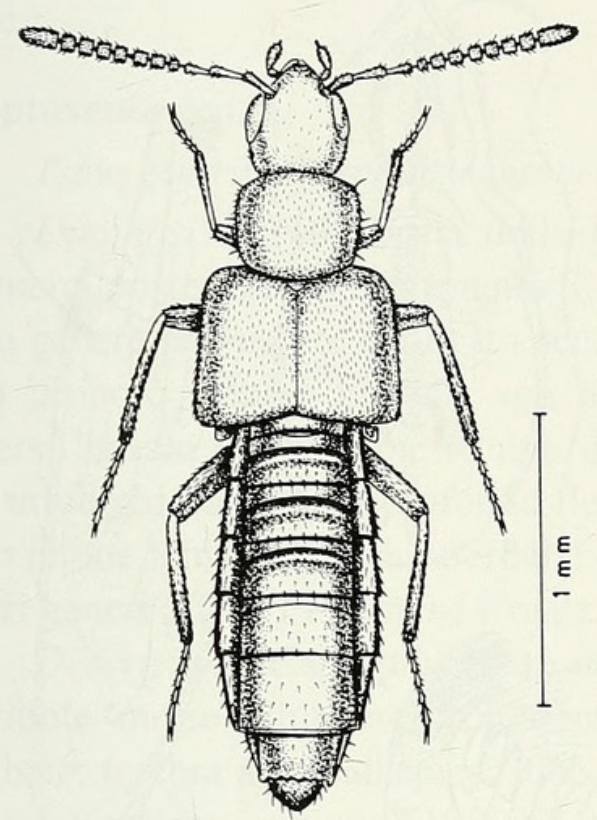

30
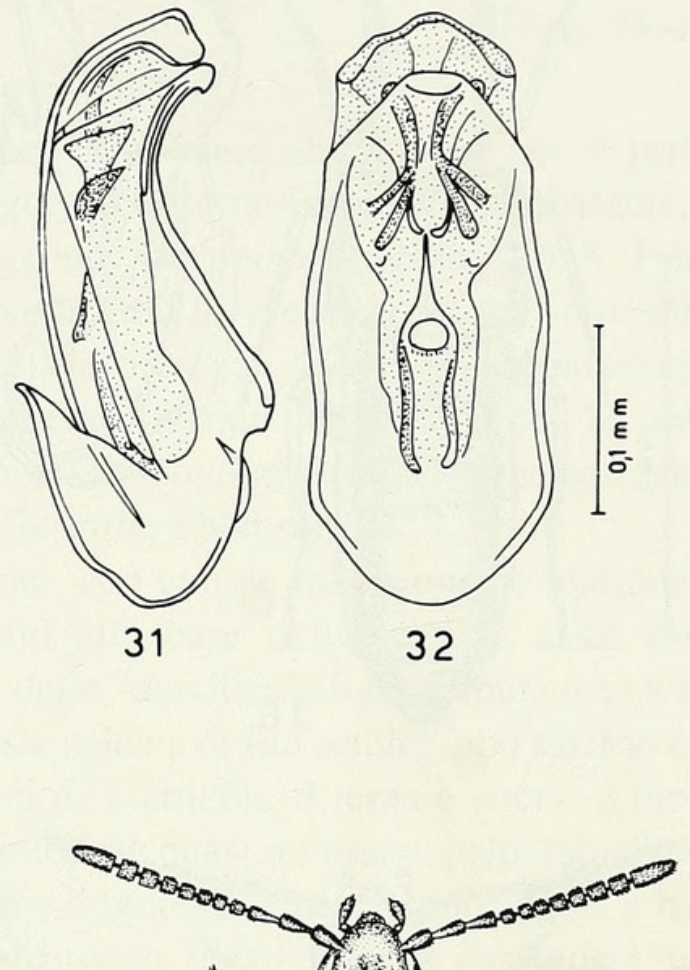

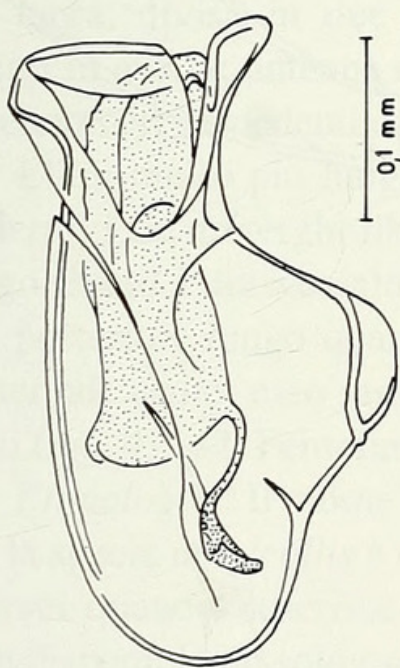

33

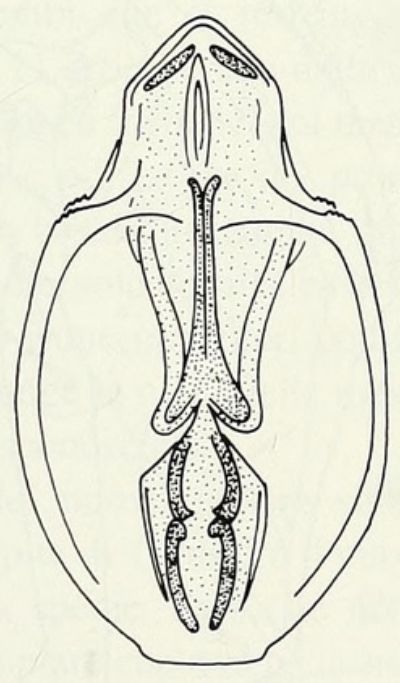

34

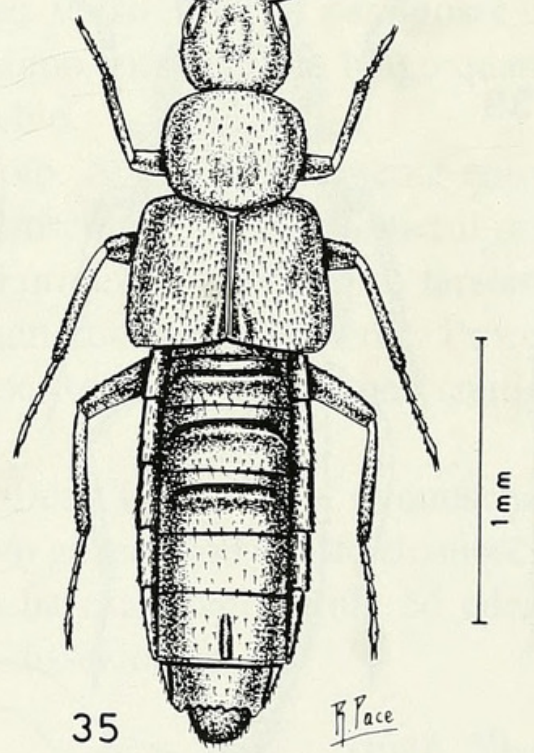

FIGG. 30-35

Habitus ed edeago in visione laterale e ventrale. 30-32: Pelioptera aberdarensis sp. n.; 33-35: Pelioptera ruandensis sp. $\mathrm{n}$. 


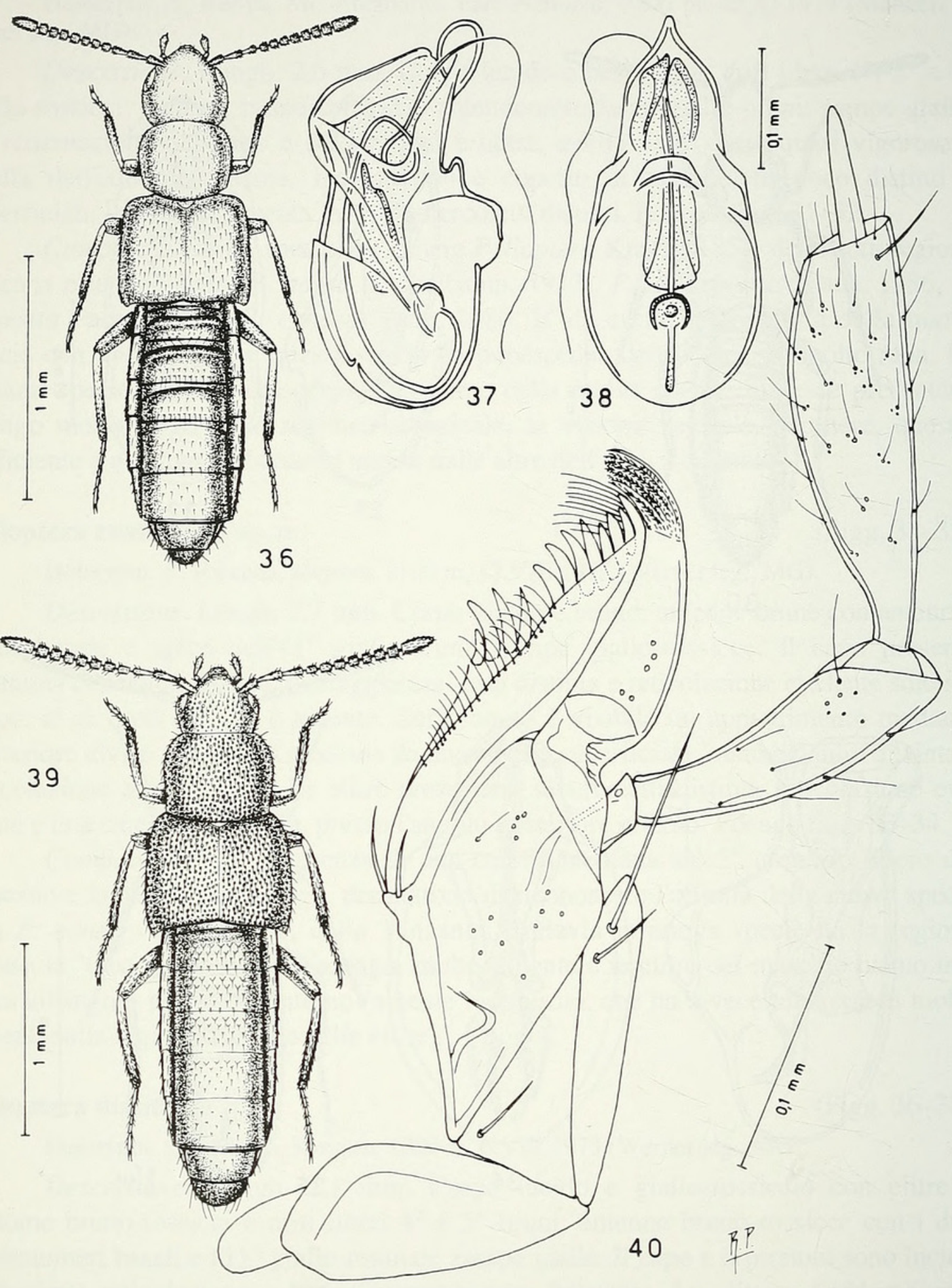

FIGG. 36-40

Habitus, edeago in visione laterale e ventrale e maxilla con palpo mascellare. 36-38: Pelioptera dimidiata sp. n.; 39-40: Askeptoxenia acuticollis (Fauvel), gen. n., holotypus ô. 
sporgente dall'orifizio apicale dell'edeago della nuova specie, mentre in abyssinorum non è presente e l'edeago di abyssinorum è molto più sviluppato di quello della nuova specie.

\section{Askeptoxenia gen. n.}

(Figg. 39-44)

Typus generis: Askeptoxenia acuticollis (Fauvel, 1907).

Diagnosi. Per la forma della ligula, per le antenne allungate e per il primo tarsomero posteriore lungo quanto i due seguenti tarsomeri considerati insieme, il nuovo genere può essere collocato accanto al genere Aloconota Thomson, 1858. Tuttavia il pronoto sinuato davanti agli angoli posteriori, la presenza di un solo solco trasverso basale dell'addome (e non due o tre), la presenza di scultura squamiforme sugli uroterghi basali e la profonda flessione al lato ventrale dell'edeago, che ha apice diviso in due lembi, sono caratteri che distinguono il nuovo genere da Aloconota, come da altri generi affini: Pelioptera Kraatz, 1857, Geostiba Thomson, 1859, ecc.

Descrizione. Capo più stretto del pronoto, con tempie robustamente marginate; mandibole molto allungate, con dente interno alla base della terebra, assai poco sporgente; terebra acuta all'apice; lobo interno delle "maxillae" (fig. 40) più corto e più stretto dell'esterno, con una fila interna di robuste spine e di fini setole; lobo esterno con estremità pubescente; palpi mascellari composti di 4 articoli: il terzo è stretto e molto lungo; mento (fig. 44) trasverso, con margine anteriore quasi rettilineo; palpi labiali di 3 articoli (fig. 43): il primo articolo è assai lungo e il secondo è brevissimo; ligula a base molto larga, divisa in due lembi che si restringono verso l'apice; paraglosse non sporgenti in avanti; antenne di 11 articoli; con undicesimo antennomero lungo quanto i tre antennomeri precedenti compresi insieme, nel maschio.

Elitre molto più lunghe e più larghe del pronoto. Addome lievemente ristretto all'indietro; i tre uroterghi liberi basali presentano microscultura squamiforme; il primo urotergo libero è trasversalmente solcato alla base. Formula tarsale 4-5-5; tarsomero basale posteriore lungo quanto i due tarsomeri contigui considerati insieme. Processo mesosternale acuto: esso raggiunge la metà delle mesocoxe, che tra loro sono contigue. Edeago figg. 41-42. Femmina sconosciuta.

Etimologia. Il nome del nuovo genere significa "Ospite non riconosciuto". Infatti la specie acuticollis è ospite di Termiti e il nuovo genere non è stato riconosciuto da Fauvel quando descrisse la specie, dato che non ha esaminato ligula ed edeago, avendo disponible un solo esemplare che non ha osato dissezionare.

Askeptoxenia acuticollis (Fauvel, 1907), comb. n.

(Figg. 39-44)

Atheta (Dimetrota) acuticollis FAUvEL, 1907: 52.

Atheta (Dimetrota) fauveli FENYES, 1920: 205 ("nomen novum" non necessario); BERNHAUER \& SCHEERPELTZ, 1926: 663.

Materiale esaminato: Holotypus ô, Kilimanjaro, Kibonoto, 12, Termites, acuticollis FVL, Atheta, (Mus. Bruxelles).

Geopora aequinoctialis (Fauvel, 1900)

(Figg. 45-48)

Atheta aequinoctialis, Fauvel, 1900: 73.

Atheta (s. str.) aequinoctialis, BernHAUER \& SCHEERPELTZ, 1926: 638. 


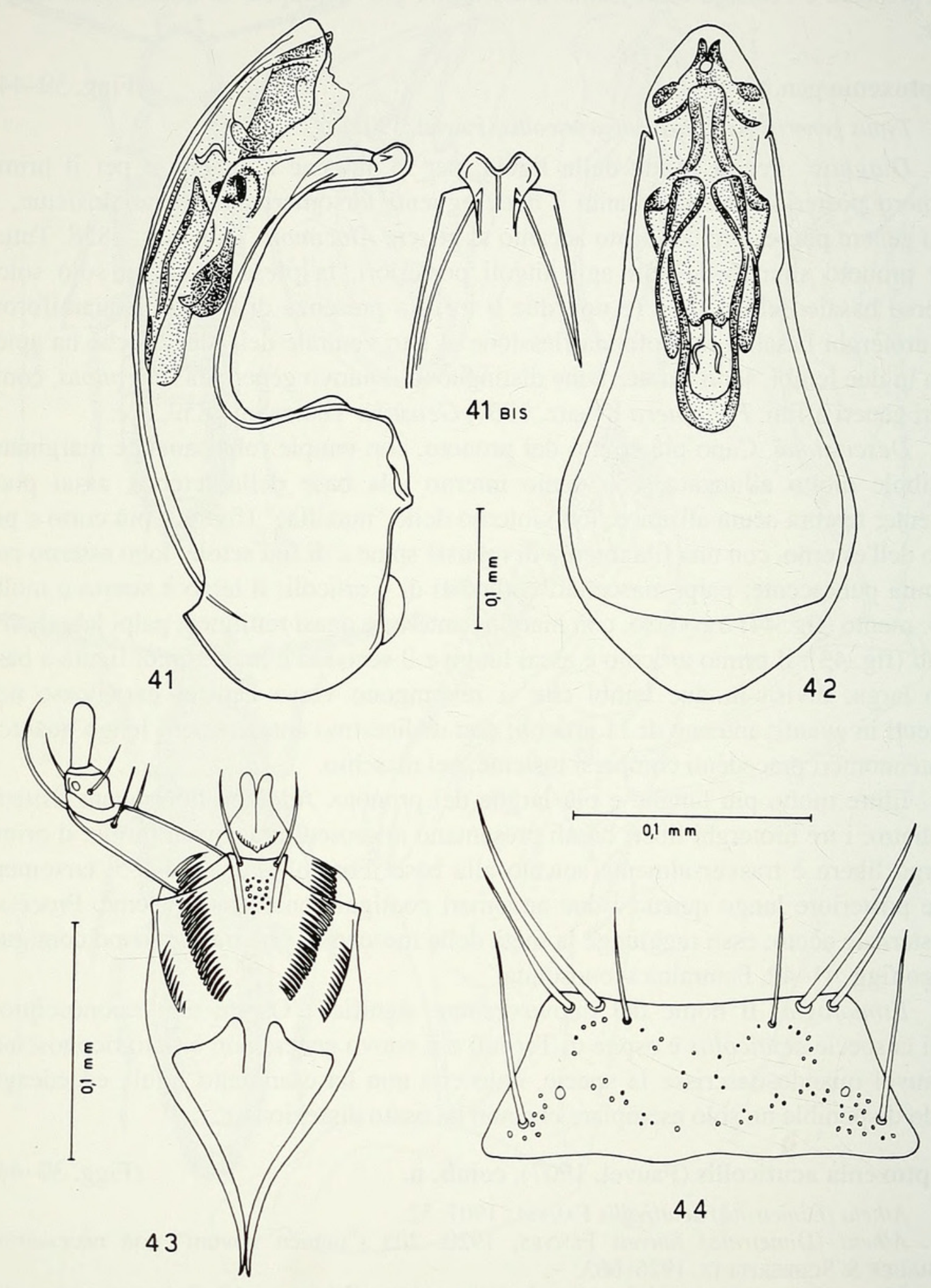

FIGG. $41-44$

Edeago in visione laterale, ventrale (solo l'apice) e dorsale, labio con palpo labiale e mento. 41-44: Askeptoxenia acuticollis (Fauvel), gen. n., holotypus ô. 
Geopora aequinoctialis, PACE, 1986: 109.

Materiale esaminato: Lectotypus $\hat{\sigma}$, Congo, Kinchassa, 11, Atheta aequinoctialis FVL, type, presente designazione (Mus. Bruxelles); paralectotypi: 1 o e $2+q$, stessa provenienza (Mus. Bruxelles).

La specie è qui illustrata per la prima volta.

\section{Geopora umtaliensis sp. $\mathrm{n}$.}

(Figg. 49-50)

Holotypus +, Rhodésie, Umtali, II.1969 (R. Mussard leg., MG).

Descrizione. Lungh. 2,0 mm. Corpo lucido e giallo con $4^{\circ}$ urite libero giallorossiccio; antenne giallo-rossicce; zampe gialle. Il capo e il pronoto hanno punteggiatura confusa nell'evidente reticolazione. Le elitre presentano punteggiatura poco evidente e reticolazione svanita. Reticolazione netta e tubercoletti fini coprono l'addome. Spermateca fig. 50.

Comparazioni. Il corpo molto stretto della nuova specie e la forma inconsueta della spermateca (con gibbosità preapicale), non permettono di avvicinare sistematicamente la nuova specie ad altre specie note.

\section{Leptoporodota tambachensis sp. $\mathrm{n}$.}

(Figg. 51-52) MG).

Holotypus \&, Kenya, Tambach, E Eldoret, 2000 m, 17.XI.1974 (Mahnert \& Perret leg.,

Descrizione. Lungh. 2,1 mm. Corpo lucido e giallo rossiccio con elitre e uriti liberi $4^{\circ}$ e base del $5^{\circ}$ rossicci; antenne giallo-rossicce con i due antennomeri basali gialli; zampe gialle. La reticolazione del capo e del pronoto è distinta, quella delle elitre e dell'addome è netta. La punteggiatura del capo è estremanente svanita. Tubercoletti molto svaniti coprono le elitre. Spermateca fig. 51.

Comparazioni. Per la forma della spermateca (a $\mathrm{S}$ rovesciata), la nuova specie può essere avvicinata sistematicamente a L. kiboensis Pace, 1985, del Kilimangiaro, ma questa specie non presenta una profonda introflessione apicale del bulbo distale della spermateca, nè il bulbo prossimale dilatato come nella nuova specie. Esternamente la nuova specie ha elitre più lunghe del pronoto e occhi poco ridotti, mentre in kiboensis le elitre sono più corte del pronoto e gli occhi sono ridottissimi.

\section{Atheta (Microdota) tapina sp. $n$.}

Holotypus ơ, Kenya, Narok, Loita Hills, sous Morijo, 2050 m, 5.XI.1977 (Mahnert \& Perret leg., MG).

Paratypus: $1 \delta$, stessa provenienza.

Descrizione. Lungh. 1,9 mm. Corpo lucido e bruno, comprese le antenne; zampe gialle. La reticolazione del capo e del pronoto è distinta, quella delle elitre è netta e quella dell'addome superficiale. Il capo presenta punteggiatura svanita. Il pronoto e le elitre sono coperti di tubercoletti distinti. Edeago figg. 54-55, maxille e palpo mascellare fig. 56, labio con palpo labiale fig. 57.

Comparazioni. L'edeago della nuova specie è simile a quello di A. eichelbaumi Bernhauer, 1915, della Tanzania, per i suoi lati paralleli nella regione subapicale, in visione ventrale, ma l'edeago della nuova specie è più sviluppato di quello di 


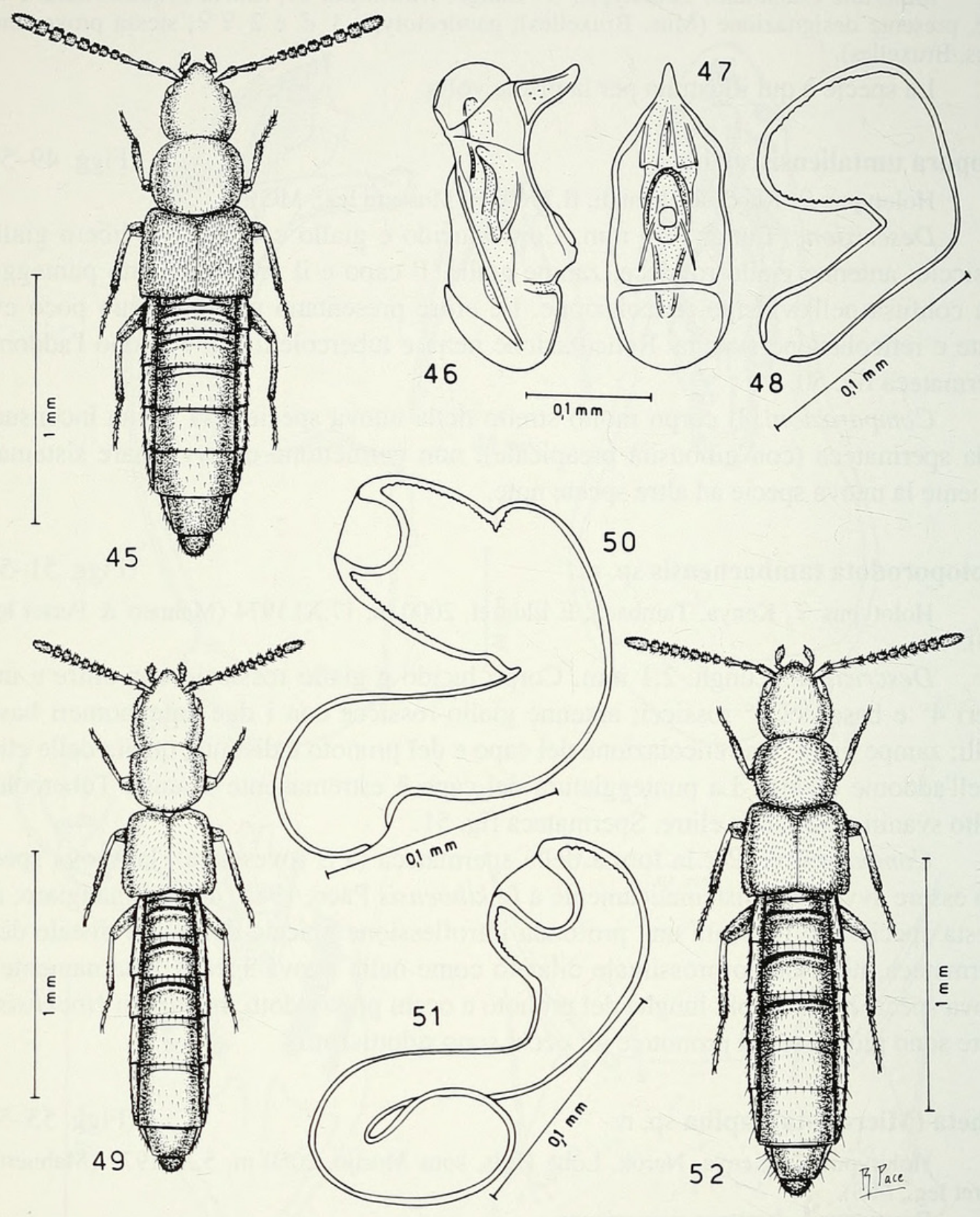

FIGG. 45-52

Habitus, edeago in visione laterale e ventrale e spermateca. 45-48: Geopora aequinoctialis (Fauvel), lectotypus ô e paralectotypus + ; 49-50: Geopora umtaliensis sp. n.; 51-52: Leptoporodota tambachensis sp. $\mathrm{n}$. 
eichelbaumi e ha un distinto pezzo copulatore arcuato del sacco interno, assente in eichelbaumi.

Atheta (Microdota) kisumuensis sp. n.

(Figg. 58-62)

Holotypus ô, Kenya, Miss. Kaimosi, NE Kisumu, 1650 m, 11.XI.1974 (Mahnert \& Perret leg., MG).

Paratypi: 5 es., stessa provenienza.

Descrizione. Lungh. 1,7 mm. Corpo debolmente lucido e nero, comprese le antenne; zampe giallo-rossicce. Solo il capo e l'addome mostrano reticolazione estremamente svanita: il resto del corpo è privo di reticolazione. I tubercoletti che coprono la superficie del capo sono superficiali, quelli sul resto del corpo sono distinti. Edeago figg. 59-60, spermateca fig. 61 e $6^{\circ}$ urite libero del maschio fig. 62.

Comparazioni. Per la forma simile dell'habitus e della spermateca, la nuova specie si colloca sistematicamente vicina ad A. kiboshoana Bernhauer, 1915, della Tanzania (nota solo sull'holotypus femmina). Le due specie sono separate dai seguenti più evidenti caratteri: introflessione apicale del bulbo distale della spermateca molto profonda nella nuova specie e poco profonda in kiboshoana; pronoto meno trasverso nella nuova specie e più trasverso in kiboshoana.

\section{Atheta (Microdota) mussardi sp. n.}

(Figg. 63-66)

Holotypus ô, Rhodésie, Umtali, II.1969 (R. Mussard leg., MG).

Paratypi: $4 \delta \hat{\sigma}$, stessa provenienza.

Descrizione. Lungh. 1,7 mm. Corpo lucido e bruno, comprese le antenne; zampe giallo-rossicce. La reticolazione del capo e dell'addome è distinta, quella del pronoto e delle elitre è svanita. Tutto il corpo è coperto di tubercoletti salienti. Edeago figg. 64-65, $6^{\circ}$ urotergo libero del maschio fig. 66.

Comparazioni. La nuova specie è differente da A. eichelbaumi Bernhauer, 1915, della Tanzania, per l'edeago più sviluppato e per i lati dell'edeago (in visione ventrale) convergenti verso l'apice e non paralleli come in eichelbaumi.

\section{Atheta (Microdota) acusifera sp. n.}

(Figg. 67-70)

Holotypus đ̊, Rhodésie, Umtali, II.1969 (R. Mussard leg., MG).

Descrizione. Lungh. 2,1 mm. Corpo lucido e bruno con uriti liberi $3^{\circ}, 4^{\circ}$ e $5^{\circ}$ nero-bruni; antenne brune; zampe giallo-rossicce. Il capo e il pronoto presentano punteggiatura superficiale e reticolazione distinta. Il capo ha una larga concavità discale. La reticolazione delle elitre è superficiale, quella degli uroterghi svanita e a maglie trasverse. Tubercoletti svaniti coprono le elitre. Edeago figg. $68-69,6^{\circ}$ urotergo libero del maschio fig. 70 .

Comparazioni. L'edeago della nuova specie presenta alcuni caratteri riscontrabili nell'edeago di A. dilaticollis Pace, 1986, della Tanzania. Tuttavia l'appendice aghiforme ventrale dell'edeago, rende la specie finora unica.

Etimologia. Il nome della nuova specie significa "Portatrice d'ago"; infatti l'edeago porta un'appendice aghiforme ventrale. 


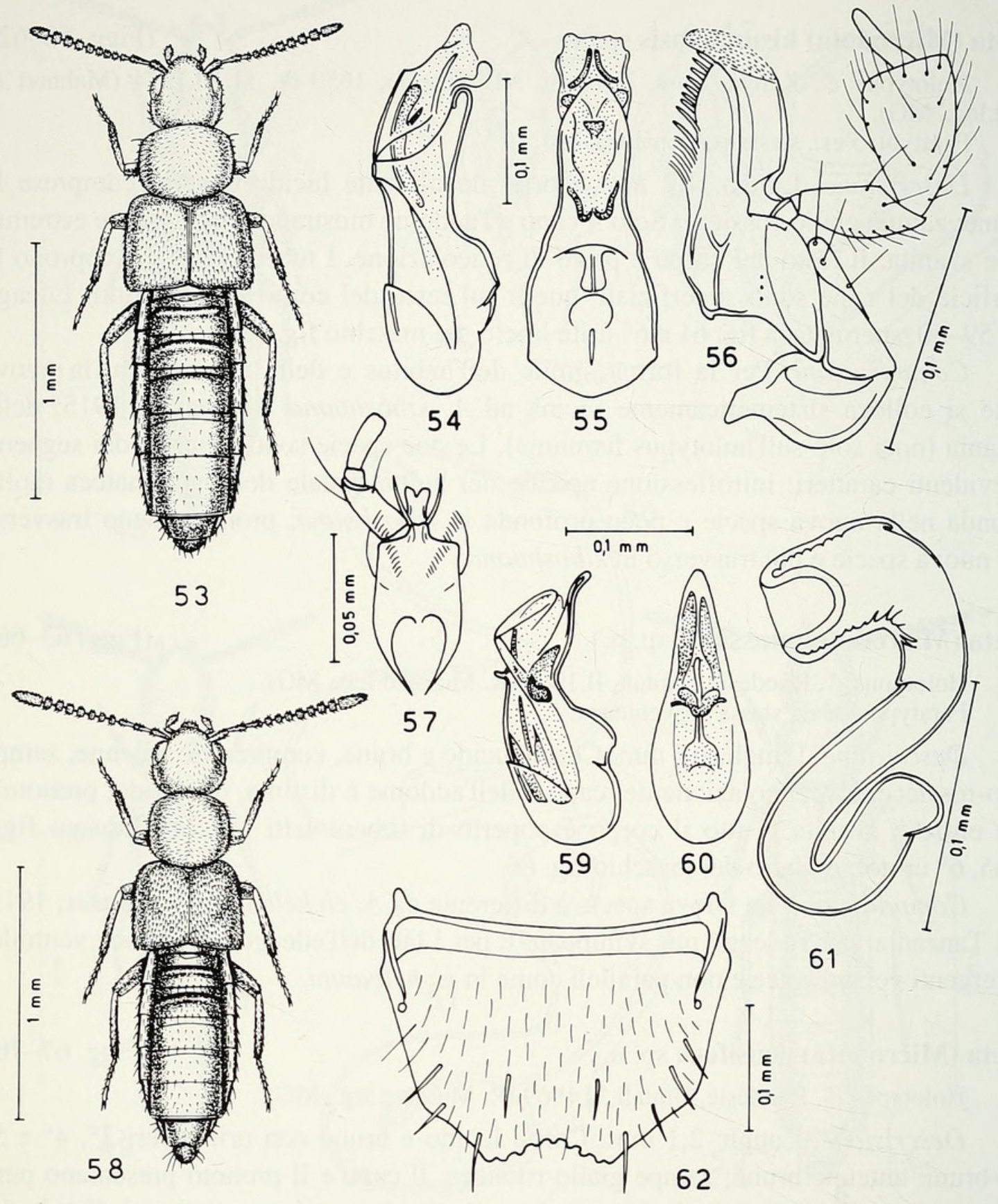

FIGG. 53-62

Habitus, edeago in visione laterale e ventrale, maxilla con palpo mascellare, labio con palpo labiale, spermateca e $6^{\circ}$ urotergo libero del maschio. 53-57: Atheta (Microdota) tapina sp. n.; 58-62: Atheta (Microdota) kisumuensis sp. n. 


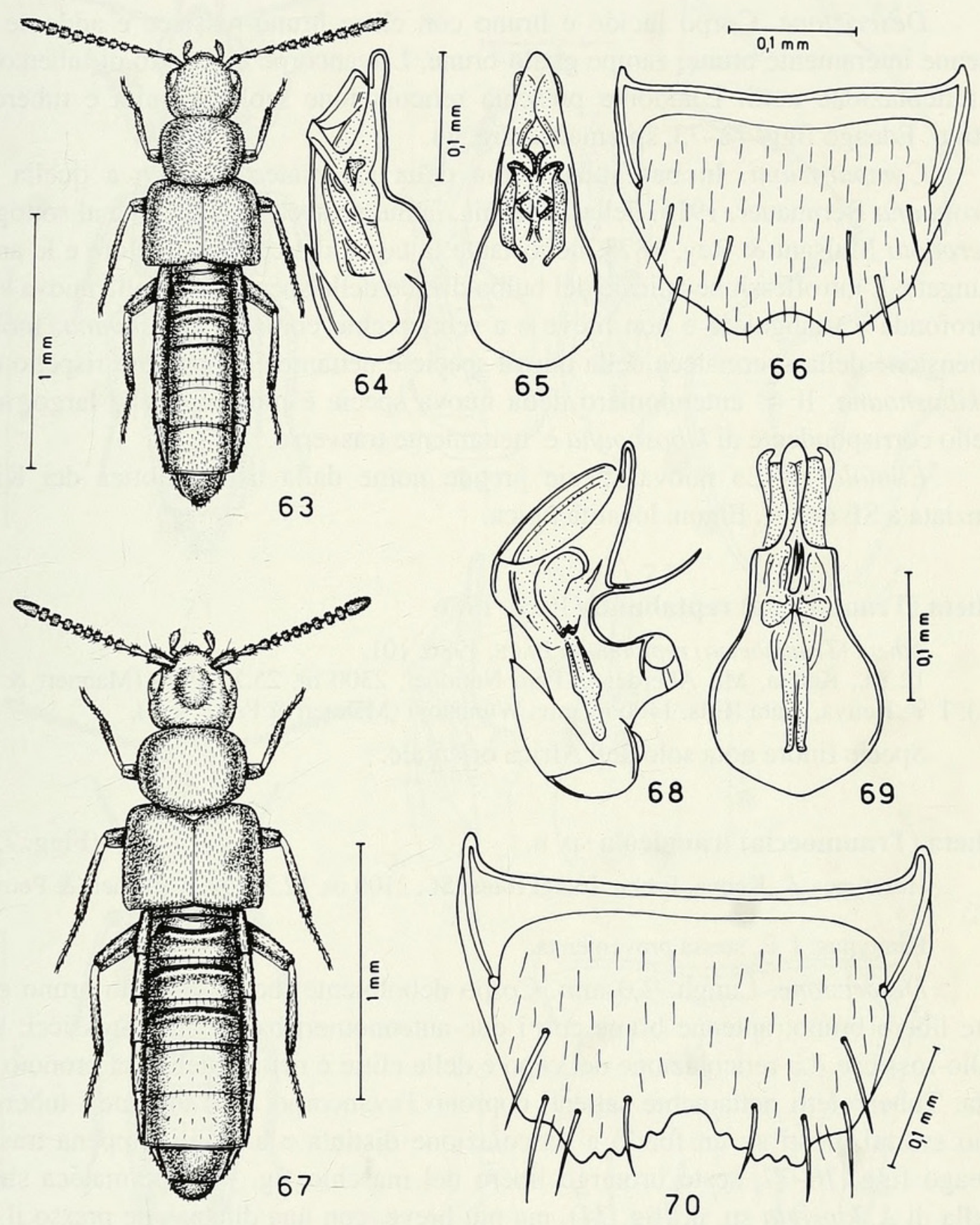

FIGG. 63-70

Habitus, edeago in visione laterale e ventrale, $6^{\circ}$ urotergo libero del maschio. 63-66: Atheta (Microdota) mussardi sp. n.; 67-70: Atheta (Microdota) acusifera sp. n. 
Atheta (Microdota) kipsigia sp. n.

(Figg. 71-74)

Holotypus ơ, Kenya, Mt. Elgon, env. 2650 m, 24.XI.1974 (Mahnert \& Perret leg., MG).

Paratypi: 5 es., stessa provenienza, ma 2700 m e 15.XI.1974.

Descrizione. Corpo lucido e bruno con elitre bruno-rossicce e addome nero; antenne interamente brune; zampe giallo-brune. L'avancorpo è coperto di tubercoletti e di reticolazione netti. L'addome presenta reticolazione molto svanita e tubercoletti distinti. Edeago figg. 72-73, spermateca fig. 74.

Comparazioni. In base alla forma della spermateca, simile a quella di $A$. kiboshoana Bernhauer, 1915, della Tanzania, la nuova specie è attribuita al sottogenere Microdota Mulsant \& Rey, 1873, nonostante la taglia del corpo maggiore e le antenne allungate. L'introflessione apicale del bulbo distale della spermateca della nuova specie, è profonda e triangolare e non breve e a semicerchio come in kiboshoana. Inoltre la dimensione della spermateca della nuova specie è nettamente maggiore rispetto quella di kiboshoana. Il $4^{\circ}$ antennomero della nuova specie è più lungo che largo, mentre quello corrispondente di kiboshoana è nettamente trasverso.

Etimologia. La nuova specie prende nome dalla tribù nilotica dei Kipsigi, stanziata a SE del M. Elgon, località tipica.

\section{Atheta (Traumoecia) reptabunda Pace, 1986}

Atheta (Traumoecia) reptabunda PACE, 1986: 101.

12 es., Kenya, Mt. Aberdares, Parc National, 2300 m, 25.XI.1974 (Mahnert \& Perret leg.); 1 \& , Kenya, Taita Hills, 1400 m, env. Wundanyi (Mahnert \& Perret leg.).

Specie finora nota solo dell'Africa orientale.

\section{Atheta (Traumoecia) irangicola sp. n.}

(Figg. 75-78) MG).

Holotypus ơ, Kenya, Embu, Irangi forest St., 2100 m, 12.X.1977 (Mahnert \& Perret leg.,

Paratypus: 1 , stessa provenienza.

Descrizione. Lungh. 2,0 mm. Corpo debolmente lucido e giallo-bruno con $4^{\circ}$ urite libero bruno; antenne brune con i due antennomeri basali giallo-rossicci; zampe giallo-rossicce. La reticolazione del capo e delle elitre è netta, quella del pronoto è distinta. Tubercoletti nettamente salienti coprono l'avancorpo. Sull'addome i tubercoletti sono svaniti, posti su un fondo a reticolazione distinta e a maglie appena trasverse. Edeago figg. 76-77, sesto urotergo libero del maschio fig. 78. Spermateca simile a quella di A. kipsigia sp. n. (fig. 74), ma più breve, con una dilatazione presso il bulbo prossimale.

Comparazioni. L'edeago della nuova specie è simile per grandezza e per aspetto generale a quello di A. reptabunda Pace, 1986, della Tanzania, tuttavia nel sacco interno dell'edeago della nuova specie è assente una larga spina ricurva, presente invece in reptabunda e le "bretelle" dell'edeago sono strettissime nella nuova specie e larghissime in reptabunda. Inoltre la nuova specie ha elitre nettamente più lunghe del pronoto e occhi ben sviluppati, mentre in reptabunda le elitre sono lunghe quanto il pronoto e gli occhi sono molto ridotti. 

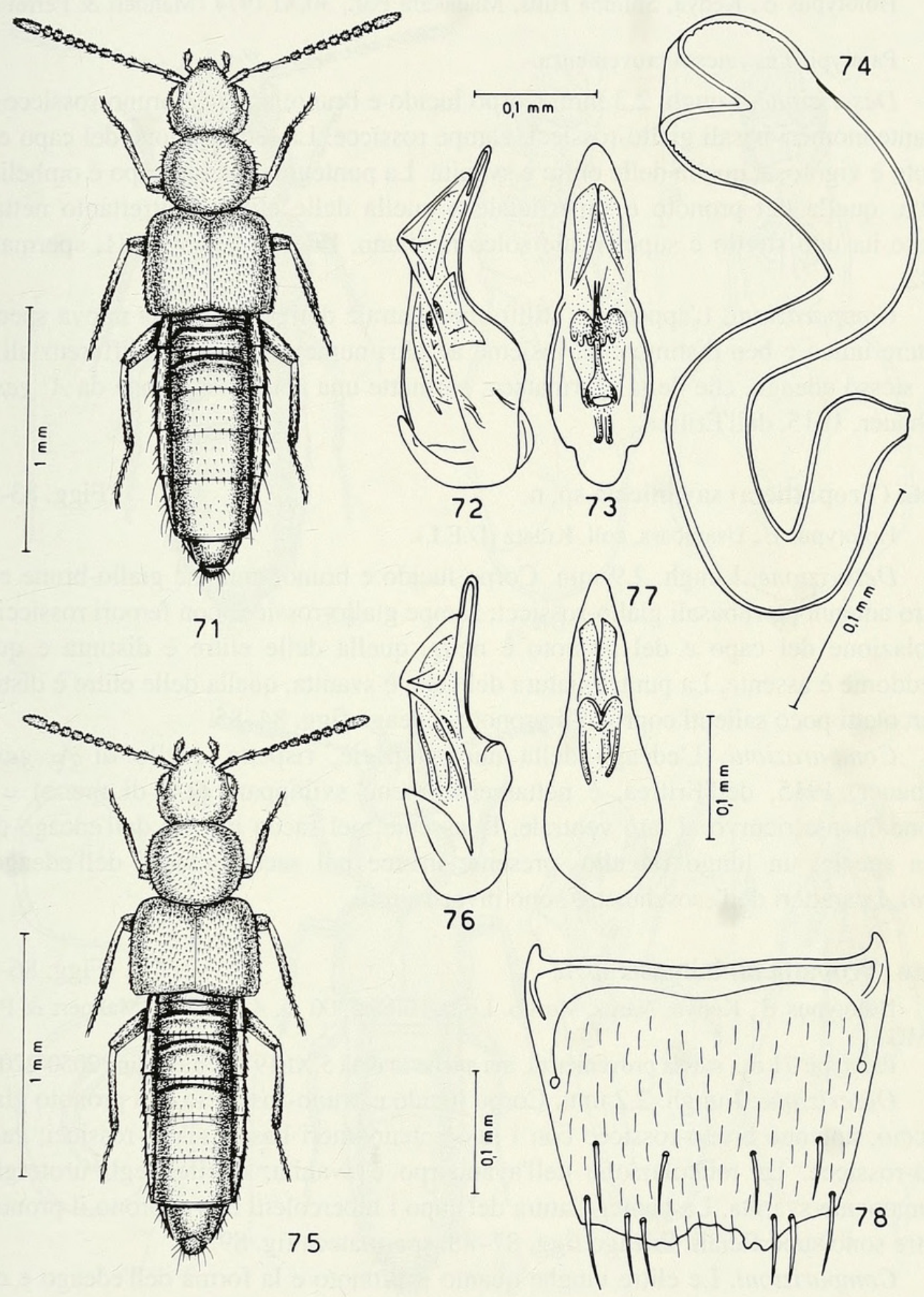

FIGG. 71-78

Habitus, edeago in visione laterale e ventrale, spermateca e $6^{\circ}$ urotergo libero del maschio. 71-74: Atheta (Microdota) kipsigia sp. n.; 75-78: Atheta (Traumoecia) irangicola sp. $\mathrm{n}$. 

MG).

Holotypus đ̊, Kenya, Shimba Hills, Madakara For., 30.XI.1974 (Mahnert \& Perret leg.,

Paratypi: 7 es., stessa provenienza.

Descrizione. Lungh. 2,3 mm. Corpo lucido e bruno; antenne bruno-rossicce con i tre antennomeri basali giallo-rossicci; zampe rossicce. La reticolazione del capo e del pronoto è vigorosa, quella delle elitre è svanita. La punteggiatura del capo è ombelicata e netta, quella del pronoto è superficiale e quella delle elitre è altrettanto netta. Il pronoto ha uno stretto e superficiale solco mediano. Edeago figg. 80-81, spermateca fig. 82 .

Comparazioni. L'appendice stiliforme ventrale dell'edeago della nuova specie è carattere unico e ben distinto che, insieme ad altri numerosi caratteri differenziali, sia dello stesso edeago, che della spermateca, permette una netta distinzione da A. gestroi Bernhauer, 1915, dell'Eritrea.

\section{Atheta (Tropatheta) savanicola sp. n.}

(Figg. 83-85)

Holotypus ơ, Usambara, coll. Kraatz (D.E.I.).

Descrizione. Lungh. 2,9 mm. Corpo lucido e bruno; antenne giallo-brune con i quattro antennomeri basali giallo-rossicci; zampe giallo-rossicce con femori rossicci. La reticolazione del capo e del pronoto è netta, quella delle elitre è distinta e quella dell'addome è assente. La punteggiatura del capo è svanita, quella delle elitre è distinta. Tubercoletti poco salienti coprono il pronoto. Edeago figg. 84-85.

Comparazioni. L'edeago della nuova specie, rispetto quello di A. gestroi Bernhauer, 1915, dell'Eritrea, è nettamente meno sviluppato (1/3 di meno) e più profondamente ricurvo al lato ventrale. $E^{\prime}$ assente, nel sacco interno dell'edeago della nuova specie, un lungo flagello, presente invece nel sacco interno dell'edeago di gestroi. I caratteri dell'esoscheletro sono invece simili.

Atheta (Tropatheta) loitensis sp. n.

(Figg. 86-89) leg., MG).

Holotypus ơ, Kenya, Narok Morijo, Loita Hills, 2300 m, 4.XI.1977 (Mahnert \& Perret

Paratypi: 71 es., stessa provenienza, ma anche in data 5.XI.1977 e altitudine 2050-2200 m.

Descrizione. Lungh. 2,2 mm. Corpo lucido e bruno-rossiccio con pronoto giallorossiccio; antenne bruno-rossicce con i due antennomeri basali giallo-rossicci; zampe giallo-rossicce. La reticolazione dell'avancorpo è svanita, quella degli uroterghi è estremamente svanita. La punteggiatura del capo i tubercoletti che coprono il pronoto e le elitre sono superficiali. Edeago figg. 87-88, spermateca fig. 89.

Comparizioni. Le elitre lunghe quanto il pronoto e la forma dell'edeago e della spermateca, sono caratteri sufficienti a distinguere la nuova specie da A. gestroi Bernhauer, dell'Eritrea.

\section{Atheta (Tropatheta) embuicola sp. n.}

(Figg. 90-91)

Holotypus q, Kenya, Embu, Kirimiri Forest, O de Runyenje, 1550 m, 13.X.1977 (Mahnert \& Perret leg., MG). 

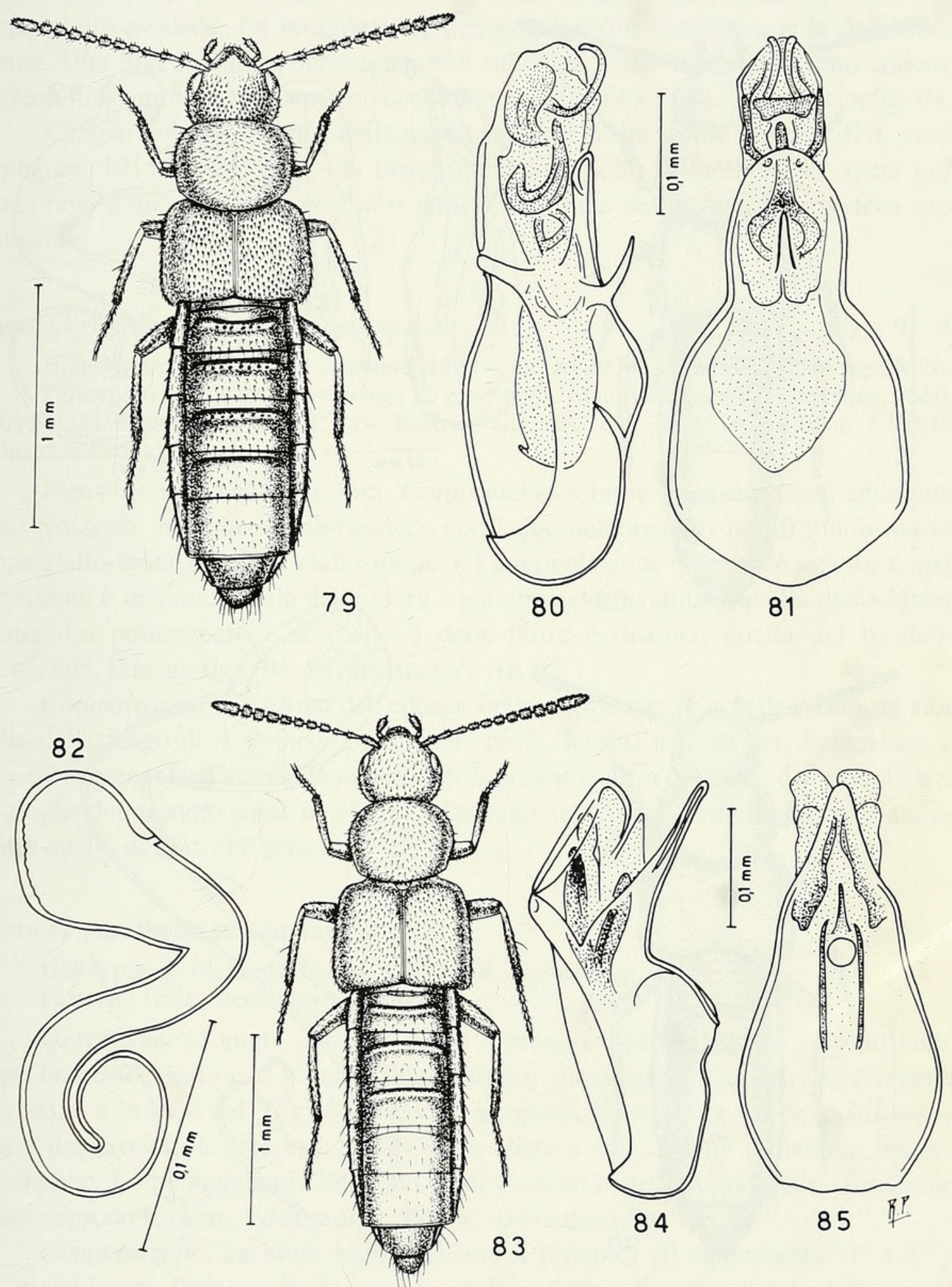

FIGG. 79-85

Habitus, edeago in visione laterale e ventrale e spermateca. 79-82: Atheta (Tropatheta) shimbaensis sp. n.; 83-85: Atheta (Tropatheta) savanicola sp. $\mathrm{n}$. 

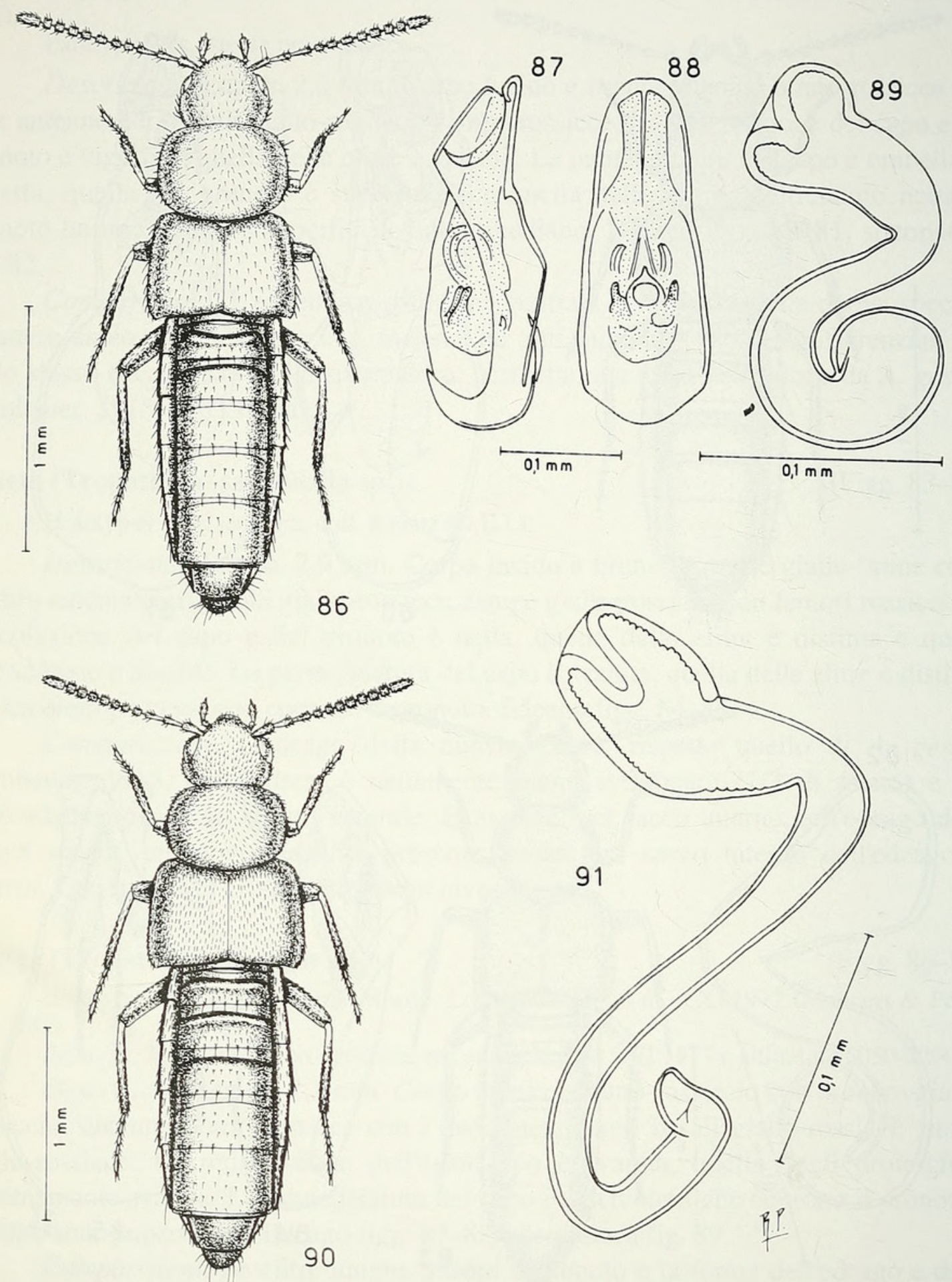

FIGG. 86-91

Habitus, edeago in visione laterale e ventrale e spermateca. 86-89: Atheta (Tropatheta) loitensis sp. n.; 90-91: Atheta (Tropatheta) embuicola sp. n. 
Descrizione. Lungh. 2,9 mm. Corpo lucido e bruno-rossiccio con uriti liberi $3^{\circ}$, $4^{\circ}$ e $5^{\circ}$ bruni; antenne bruno-rossicce con i due antennomeri basali giallo-rossicci; zampe giallo-rossicce. La reticolazione dell'avancorpo è distinta, quella dell'addome assente. Una fina e distinta punteggiatura è sul capo. Pronoto ed elitre sono coperti di tubercoletti svaniti. Distinti sono invece i tubercoletti addominali. Spermateca fig. 91.

Comparazioni. L'habitus della nuova specie è molto simile a quello di A. gestroi Bernhauer, 1915, dell'Eritrea, ma la spermateca è molto differente, per avere bulbo distale non sferico come in gestroi e parte prossimale della stessa spermateca molto allungata.

Atheta (Tropatheta) nanyukensis sp. n.

Figg. 92-95)

Holotypus ô, Kenya, env. Nanyuki, 1900 m, 22.XI.1974 (Mahnert \& Perret leg., MG).

Paratypi: 6 es., stessa provenienza; 25 es., Kenya, Mau Escarpment, S-East Mau, 2850 m; 6.XI.1977 (Mahnert \& Perret leg.); 7 es., Kenya, Taita Hills, env. Wundanyi, 1400 m, 2.XII.1974 (Mahnert \& Perret leg.).

Descrizione. Lungh. 2,6 mm. Corpo lucido e bruno, con estremità addominale bruno-rossiccia; antenne bruno-rossicce con i due antennomeri basali giallo-rossicci; zampe giallo-brune con tarsi giallo-rossicci. La reticolazione del capo è vigorosa, quella del pronoto è distinta, quella delle elitre è estremanente svanita e quella dell'addome è assente. La punteggiatura del capo e delle elitre è distinta, quella del pronoto è superficiale. Edeago figg. 93-94, spermateca fig. 95.

Comparazioni. La forma dell'edeago della nuova specie ricorda molto da vicino quella dell'edeago di A. gestroi Bernhauer, 1915, dell'Eritrea, sia per dimensione che per aspetto generale. Tuttavia la nuova specie presenta elitre più corte del pronoto e non più lunghe del pronoto come in gestroi e l'edeago, in visione ventrale, ha apice arcuato, mentre quello di gestroi è acuto.

\section{Atheta (Tropatheta) mashonarum sp. n.}

(Figg. 96-99)

Holotypus ô, Rhodésie, Umtali, II.1969 (R. Mussard leg., MG).

Paratypi: 12 es., stessa provenienza.

Descrizione: Lungh. 2,4 mm. Capo e pronoto opachi, resto del corpo lucido. Corpo bruno-rossiccio con $4^{\circ}$ urite libero bruno; antenne rossicce con i due antennomeri basali e la base del $3^{\circ}$ giallo-rossicci; zampe giallo-rossicce. La reticolazione del capo e del pronoto è vigorosa, quella delle elitre e dell'addome è distinta, trasversa sull'addome. La punteggiatura del capo e del pronoto è assai superficiale. Tubercoletti svaniti coprono le elitre. Edeago figg. 97-98, spermateca fig. 99.

Comparazioni. Le elitre lunghe quanto il pronoto, gli antennomeri $4^{\circ}$ a $8^{\circ}$ più lunghi che larghi, l'edeago di dimensione molto ridotta e il bulbo distale della spermateca di ridotta grandezza, distinguono la nuova specie da A. gestroi Bernhauer, 1915, dell'Eritrea, che presenta elitre più lunghe del pronoto, antennomeri $7^{\circ}$ e $8^{\circ}$ trasversi, l'edeago molto sviluppato e il bulbo distale della spermateca ipertrofico.

Etimologia. La nuova specie prende nome dai Mashona, popolazione stanziata ad oriente dello Zimbabwe. 


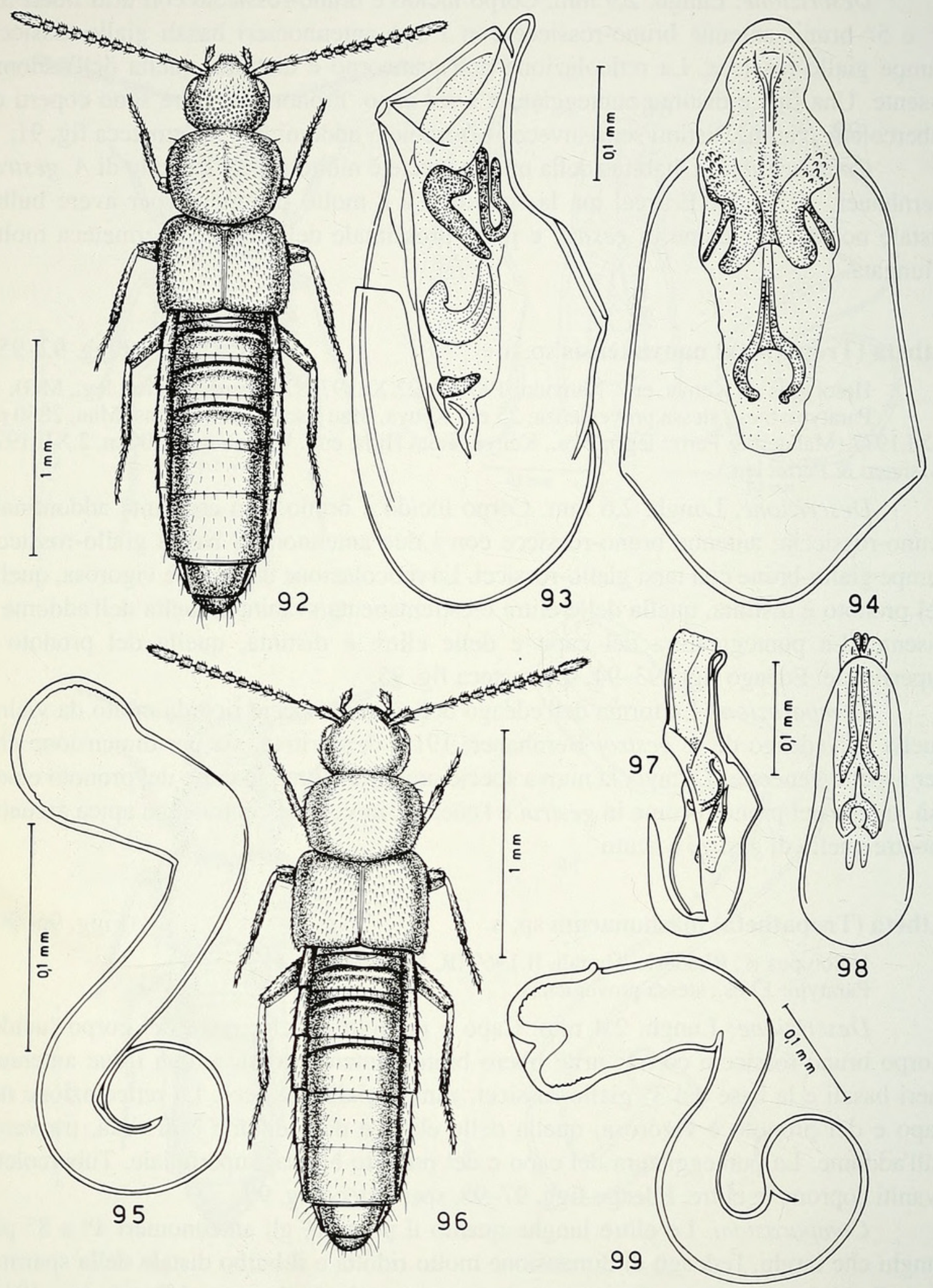

FIGG. 92-99

Habitus, edeago in visione laterale e ventrale e spermateca. 92-95: Atheta (Tropatheta) nanyukensis sp. n.; 96-99: Atheta (Tropatheta) mashonarum sp. $\mathrm{n}$. 
Atheta (Taxicera) suprema Bernhauer, 1934

(Figg. 100-103 bis)

Atheta (Plataraea) suprema BERNHAUER, 1934: 244.

Materiale esaminato: Lectotypes ơ, Ruwenzori, 4200 m, VII.1932, Burgeon, Atheta (Bessobia) suprema BRNH, typus, suprema BRNH, typus (Plataraea (Mus. Chicago), presente designazione; paralectotypi: 5 es., stessa provenienza (Mus. Chicago).

1 ठิ e 1 q, Ruwenzori, Bujuko Hut, 1350 ft., I.1984 (L. Lengeler leg.).

Nota. La presenza di una lunga setola su ciascun lembo della ligula (fig. 103 bis), permette di attribuire la specie preferibilmente a Taxicera Mulsant \& Rey, 1873, sottogenere che include specie presentanti due lunghe setole sulla ligula, mentre nel sottogenere Plataraea Thomson, 1858, le specie sono prive di dette setole sulla ligula.

Specie già nota del Ruwenzori (località tipica) e della "Nyamgazani Valley" (inedito del "Field Museum" di Chicago).

Rinvenuta su Senecio erioneuron (annotazione inedita del "Field Museum" di Chicago).

Atheta (Taxicera) lacrymalis Fauvel, 1907

Atheta lacrymalis FAUvel, 1907: 54.

Atheta (Acrotona) lacrymalis, BERNHAUER \& SCHEERPELTZ, 1926: 675.

1 \&, Mt. Kenya, 3050 m, St. Lodge, 25.XI.1974 (Mahnert \& Perret leg.).

Specie finora nota solo sull'holotypus $q$ dell'Escarpment (Wa-Kikouyou), raccolto nell'agosto del 1904.

Esemplare comparato con l'holotypus. Grazie all'esame della ligula la specie va attribuita al sottogenere Taxicera Mulsant \& Rey, 1973. Infatti su ciascum lembo della ligula è presente una lunga setola, carattere questo tipico del sottogenere Taxicera.

\section{Atheta (Dimetrota) malevestita sp. n.}

(Figg. 104-107)

Holotypus $\delta$, Rwanda, Kayove, 2100 m, 29.IV.1973 (Werner leg., MG).

Paratypi: 6 es., stessa provenienza.

Descrizione. Lungh. 2,1 mm. Corpo lucido e bruno-rossiccio con pronoto ed estremità addominale rossicci; antenne brune con i due antennomeri basali giallorossicci; zampe giallo-rossicce. La reticolazione è distinta, tranne sul pronoto dove è svanita. La punteggiatura del capo è distinta. I tubercoletti che coprono il pronoto sono superficiali, quelli delle elitre sono ben salienti. Edeago figg. 105-1067, spermateca fig. 107.

Comparazioni. Per la forma della spermateca e dell'edeago, la nuova specie è ben distinta da A. convexula Eichelbaum, 1913, della Tanzania (figg. 118-121).

Atheta (Dimetrota) mandibularis sp. $\mathrm{n}$.

(Figg. 108-111)

Holotypus ơ, Rwanda, Kayove, 2100 m, 29.IV.1973 (Werner leg., MG).

Descrizione. Lungh. 2,0 mm. Corpo lucido e bruno con estremità addominale bruno-rossiccia; antenne bruno-rossicce; zampe gialle. La reticolazione del capo è assente, quella del pronoto è molto svanita, quella delle elitre e dell'addome è netta. Il capo presenta punteggiatura svanita. Il pronoto e le elitre non mostrano distinti tubercoletti. Edeago figg. 109-110, mandibola fig. 111. 

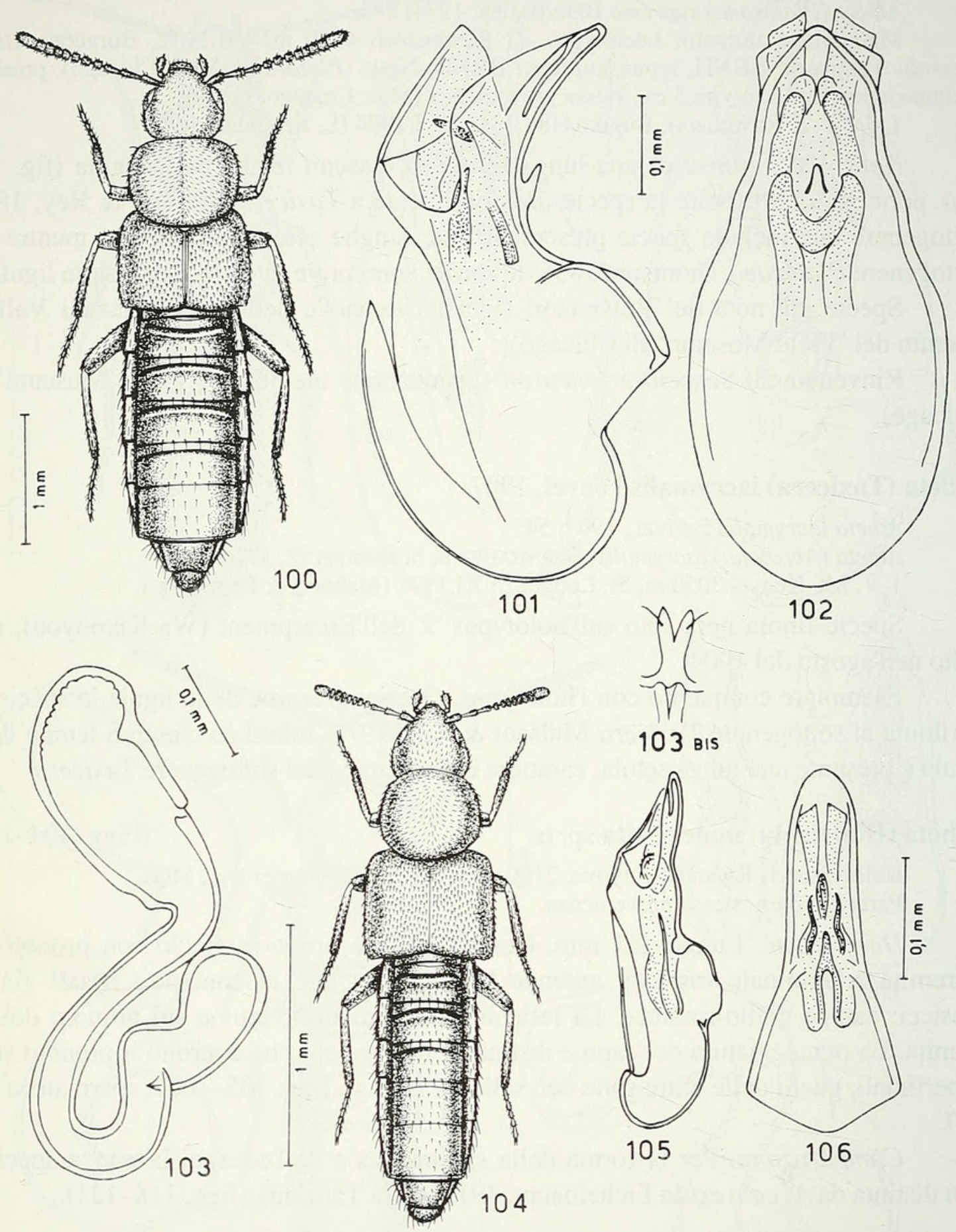

FIGG. 100-106

Habitus, edeago in visione laterale e ventrale, ligula e spermateca. 100-103: Atheta (Taxicera) suprema Bernhauer, lectotypus of e paralectotypus + ; 104-106: Atheta (Dimetrota) malevestita sp. $n$. 
Comparazioni. Specie che per la forma dell'edeago appare simile ad A. malevestita sp. n. sopra descritta. Si distingue per avere mandibole molto lunghe (fig. 111) e acute (tozze in malevestita), per la netta reticolazione delle elitre, per $1^{\prime} 11^{\circ}$ antennomero più lungo e per l'edeago più sviluppato.

Atheta (Datomicra) rudicollis (Bernhauer, 1915)

(Figg. 112-115)

Oxypoda rudicollis BERNHAUER, 1915: 188.

Atheta (Datomicra) rudicollis, PACE, 1986: 109.

Materiale esaminato: Holotypus + , Arusha, Ju, 1905.XII, Africa or., Katona, Oxypoda rudicollis BRNH, typus (Mus. Budapest).

22 es., Kenya, Narok, Loita Hills, sous Morija, 5.XI.1977 (Mahnert \& Perret leg.).

L'holotypus è qui illustrato per la prima volta.

Specie già nota della Tanzania e Zaire. Nuova per il Kenya.

Atheta (Datomicra) kiboensis Pace, 1985

Atheta (Datomicra) kiboensis Pace, 1985: 140.

1 \&, Kenya, Narok, Loita Hills, sous Morijo, 5.XI.1977 (Mahnert \& Perret leg.).

Specie finora nota solo del Kilimangiaro.

Atheta (Datomicra) ferrugata Fauvel, 1907

(Figg. 116-117)

Atheta ferrugata FAUVEL, 1907: 53.

Atheta (Acrotona) ferrugata, BERNHAUER \& SCHEERPELTZ, 1926: 673.

Atheta (Datomicra) ferrugata, PACE, 1986: 86.

Materiale esaminato: Holotypus $q$, Afrique allemande, ferrugata FVL (Mus. Bruxelles).

La specie è qui illustrata per la prima volta.

Atheta (Dimetrota) convexula Eichelbaum, 1913

(Figg. 118-121)

Atheta (Coprothassa) convexula EichelBaum, 1913: 146.

Atheta (Acrotona) convexula, PACE, 1986: 109.

Materiale esaminato: Lectotypus oे, Amani, Atheta convexula Eichelbaum, type, presente designazione (D.E.I.).

Atheta (Datomicra) ferrugatoides sp. n.

(Figg. 122-123) MG).

Holotypus \&, Kenya, Mau For., Mau Saumit Kedowa, 7.XI.1974 (Mahnert \& Perret leg.,

Paratypus: 1 \& , Kenya, env. Endebess pr. Kitale, 14.XI.1974 (Mahnert \& Perret leg.).

Descrizione. Lungh. 2,7 mm. Corpo lucido e bruno-rossiccio; antenne brune con i due antennomeri basali gialli; zampe giallo-rossicce. I tubercoletti della superficie del capo e delle elitre sono poco salienti, quelli del pronoto e dell'addome sono molto salienti. Non vi è traccia di reticolazione sulla superficie del corpo. Spermateca fig. 123.

Comparazioni. Specie simile ad A. ferrugata Fauvel, 1907, della Tanzania (figg. 116-117). Se ne distingue soprattutto per i caratteri della spermateca. L'introflessione apicale del bulbo distale della spermateca della nuova specie è corta, mentre in ferrugata è profonda e il bulbo prossimale della spermateca della nuova specie è nettamente più largo di quello di ferrugata. 

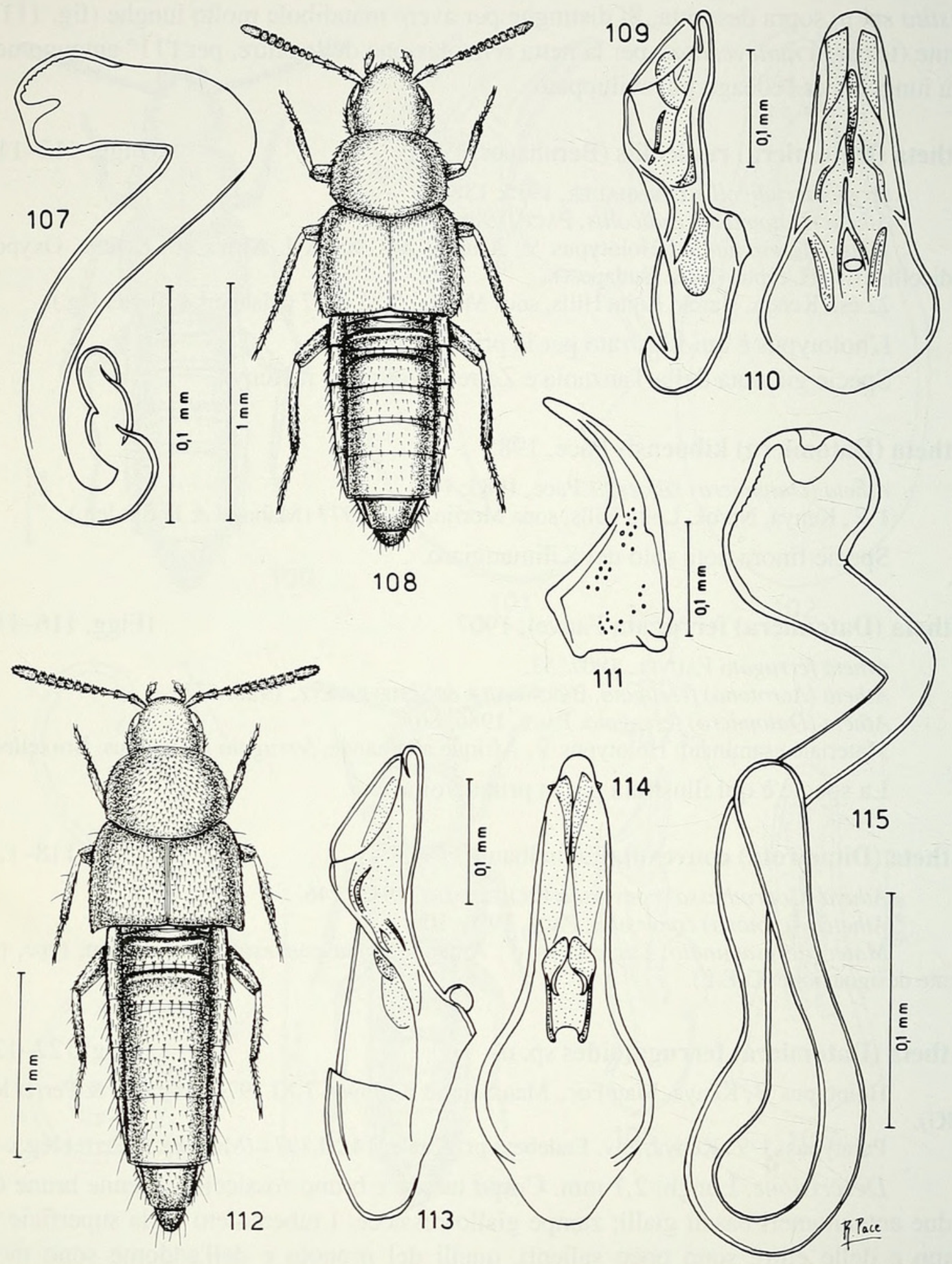

FIGG. 107-115

Spermateca, habitus, edeago in visione laterale e ventrale e mandibola. 107: Atheta (Dimetrota) malevestita sp. n.; 108-111: Atheta (Dimetrota) mandibularis sp. n.; 112-115: Atheta (Datomicra) rudicollis (Bernhauer), holotypus $q$. 

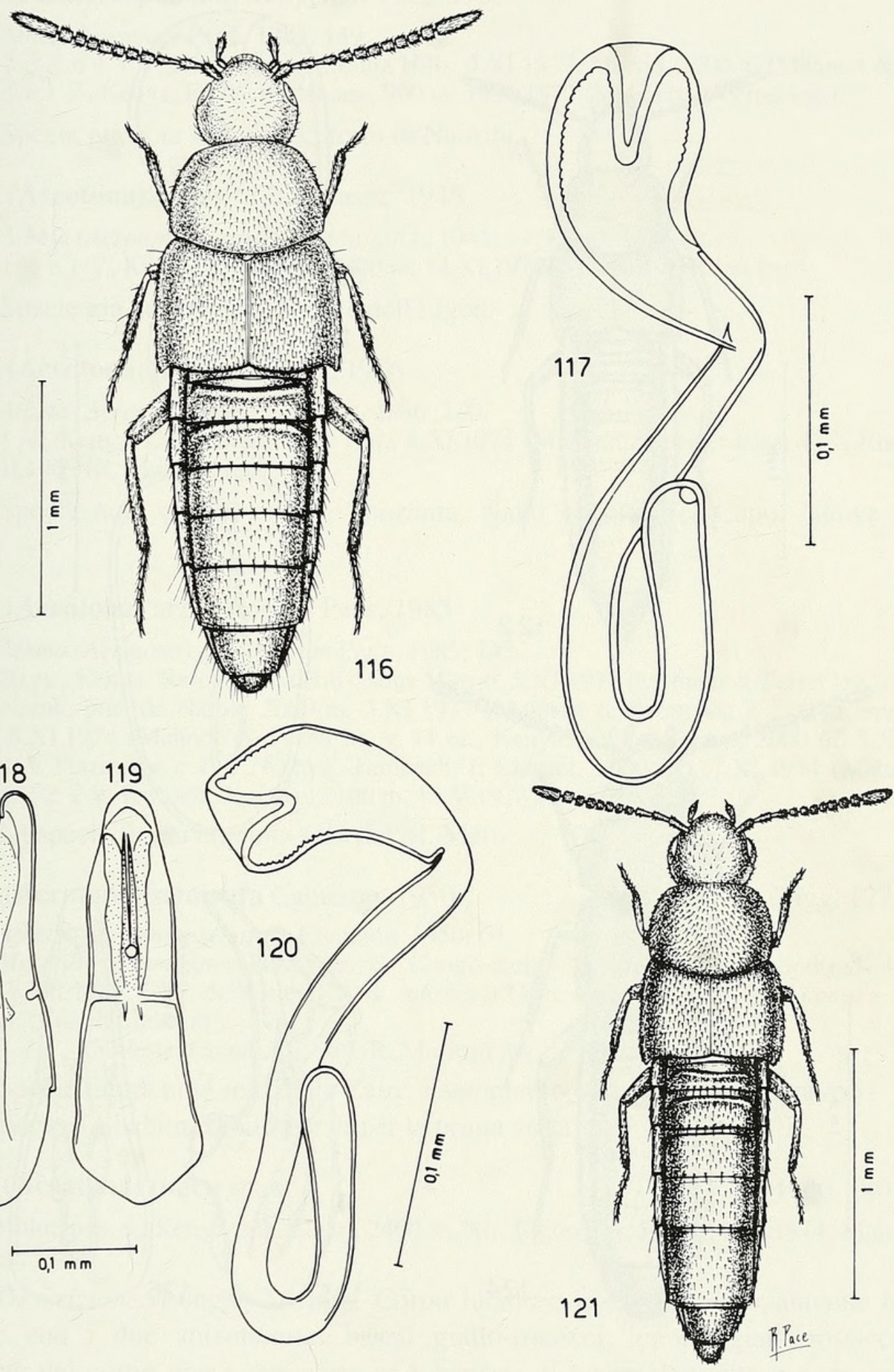

FIGG. 116-121

Habitus, spermateca ed edeago in visione laterale e ventrale. 116-117: Atheta (Datomicra) ferrugata Fauvel, holotypus + ; 118-121: Atheta (Dimetrota) convexula Eichelbaum, lectotypus ô. 

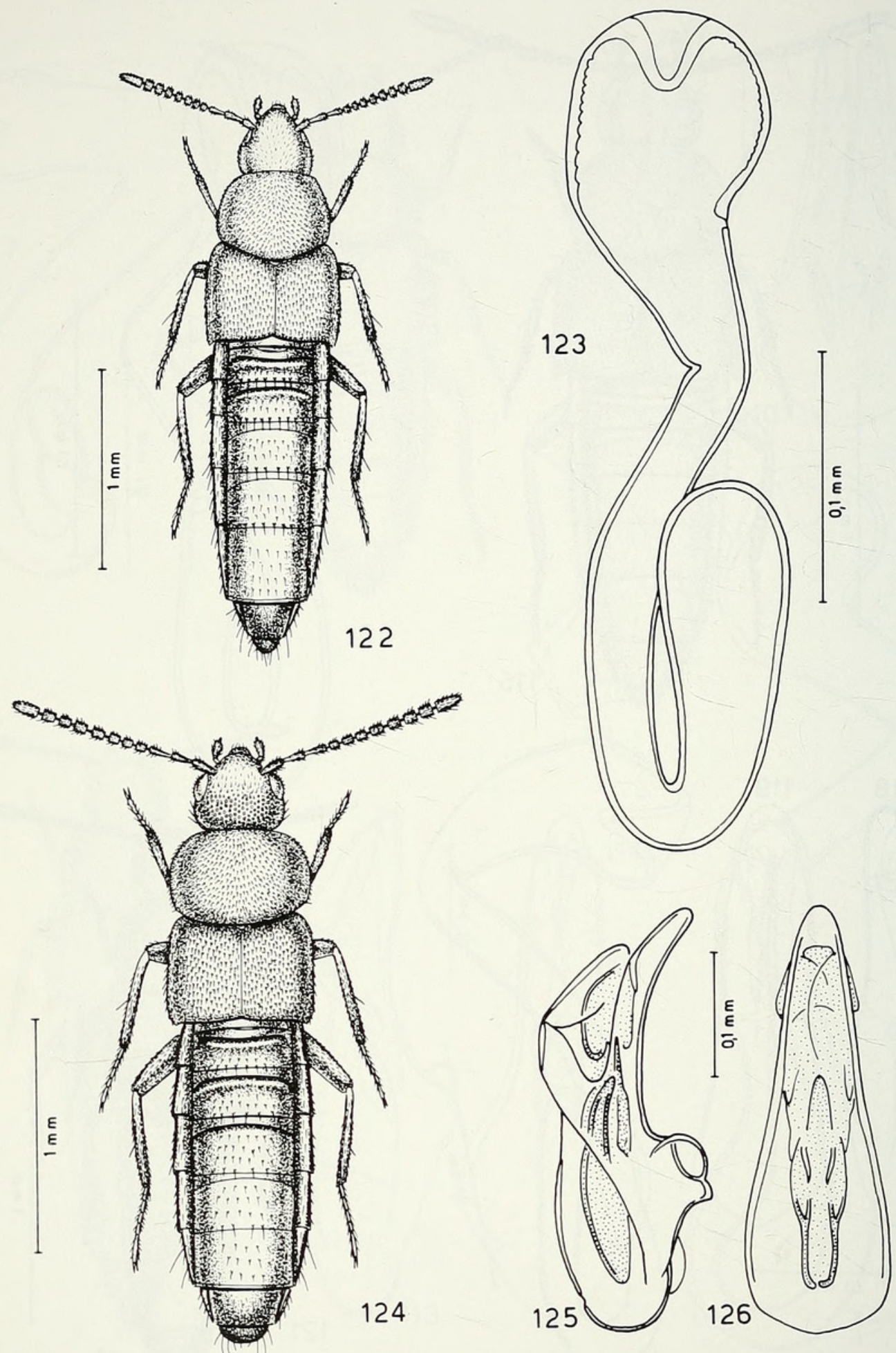

FIGG. $122-126$

Habitus, spermateca ed edeago in visione laterale e ventrale. 122-123: Atheta (Datomicra) ferrugatoides sp. n.; 124-126: Atheta (Acrotona) semifura Cameron, esemplare della Rodesia. 


\section{Atheta (Phanerosphaena) kenyensis Pace, 1985}

Atheta kenyensis PACE, 1985: 149.

2 oे of e 4 q $q$, Kenya, Narok, Loita Hills, 4.XI.1977, Morijo, 2200 m (Mahnert \& Perret leg.); 1 ô e 1 q, Kenya, Embu, pr. Ishiara, 900 m, 14.X.1977 (Mahnert \& Perret leg.).

Specie già nota solo dei dintorni di Nairobi.

Atheta (Acrotona) parasita Bernhauer, 1945

Atheta (Acrotona) parasita Bernhauer, 1945: 19; Pace, 1986: 86.

1 ô e 1 q , Kenya, Mt. Elgon, 2800 m, 14.XI.1974 (Mahnert \& Perret leg.).

Specie già nota del M. Meru e dell'Elgon.

Atheta (Acrotona) nigricola Pace, 1986

Atheta (Acrotona) nigricola PACE, 1986: 100.

1 ơ, Kenya, Lac Nakuru, Parc Nat., 6.XI.1974 (Mahnert \& Perret leg.); 1 o, Rhodésie, Umtali, II.1969 (R. Mussard leg.). Kenya.

Specie nota dell'Abissinia, Tanzania, Natal e Città del Capo. Nuova per il

\section{Atheta (Acrotona) armentorum Pace, 1985}

Atheta (Acrotona) armentorum PACE, 1985: 142.

20 es., Kenya, Narok, Loita Hills, sous Morijo, 5.XI.1977 (Mahnert \& Perret leg.); 12 es., Kenya, Narok, près de Narok, 2000 m, 3.XI.1977 (Mahnert \& Perret leg.); 1 \&, Kenya, Lac Nakuru, 6.XI.1974 (Mahnert \& Perret leg.); 14 es., Kenya, Kikuyu Escar., 2000 m, 3.XI.1977 (Mahnert \& Perret leg.); 1 \&, Kenya, Tambach, E Eldoret, 2000 m, 17.XI.1974 (Mahnert \& Perret leg.); 2 $q$, Rwanda, Kayove, 2100 m, 15.V.1973 (Werner leg.).

La specie finora era nota solo del M. Meru.

Atheta (Acrotona) semirufa Cameron, 1950

(Figg. 127-129)

Atheta (Acrotona) semirufa Cameron, 1950: 64.

Materiale esaminato: Paratypus ơ, Congo Belge, P.N.A., Kanyabayondo (Kabasha), 1760 m, 7.XII.1934, G. F. de Witte: 878, A. rufonigra Cam. (cancellato), A. (Acrotona) semirufa n. n. Cam. (British Museum).

3 ơ ठे., Rhodésie, Umtali, II.1969 (R. Mussard leg.)

Specie finora nota solo dello Zaire. Esemplari comparati con un syntypo.

Edeago e habitus qui illustrati per la prima volta.

Atheta (Acrotona) tugen sp. n.

(Figg. 130-132)

Holotypus ơ, Kenya, Mt. Elgon, 2400 m, Mt. Elgon For. Res., 14.XI.1974, Mahnert \& Perret leg., MG).

Descrizione. Lungh. 2,4 mm. Corpo lucido e rossiccio scuro; antenne brunorossicce con i due antennomeri basali giallo-rossicci; zampe giallo-rossicce. La superficie del corpo non è reticolata ed è coperta di tubercoletti fitti e poco salienti. Edeago figg. 131-132.

Comparazioni. Specie simile ad A. basipennis Fauvel, 1907, della Tanzania, a motivo della forma dell'edeago e dell'habitus. Se ne distingue tra l'altro per avere l'apice dell'edeago diviso (in basipennis apice intero).

Etimologia. La nuuova specie prende nome dai Tugen, gruppo etnico del Kenya. 

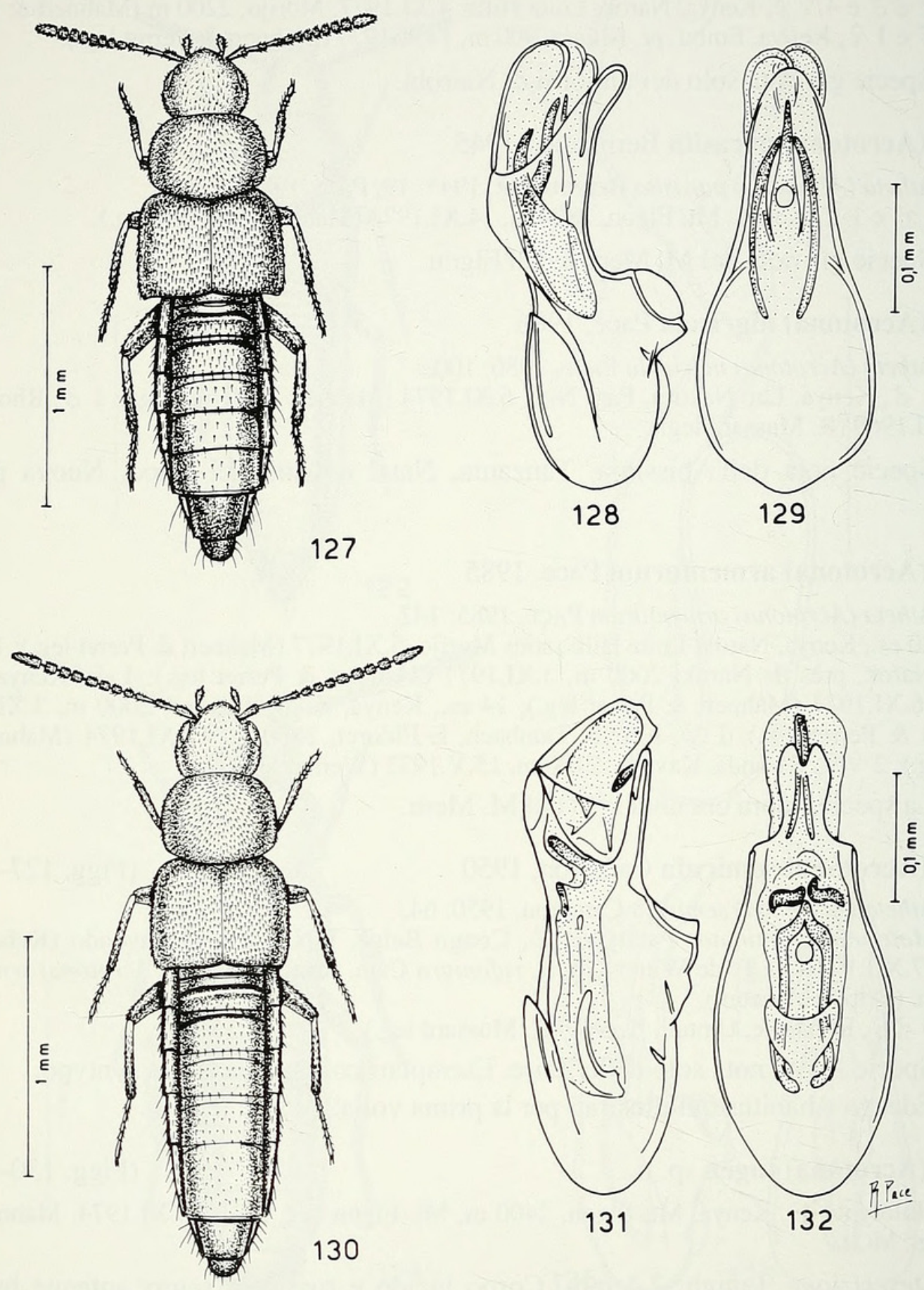

FIGG. $127-132$

Habitus ed edeago in visione laterale e ventrale. 127-129: Atheta (Acrotona) semirufa Cameron, paratypus o; 130-132: Atheta (Acrotona) tugen sp. n. 
Atheta (Acrotona) creticornis sp. n.

Holotypus ô, Rwanda, Kayove, 2100 m, 15.V.1973, (Werner leg., MG). (Werner leg.).

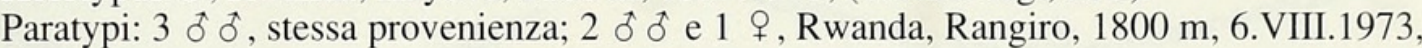

Descrizione. Lungh. 2,5 mm. Corpo lucido e bruno-rossiccio; antenne brunorossicce con base del primo antennomero gialla; zampe gialle. La reticolazione del capo e del pronoto è distinta, quella delle elitre e dell'addome è assente. I tubercoletti che coprono la superficie del capo e delle elitre sono poco distinti, quelli del pronoto sono salienti. Edeago figg. 134-135, spermateca fig. 136.

Comparazioni. In base alla forma della spermateca, la nuova specie sembra affine ad A. kibatiana Cameron, 1950, dello Zaire, ma la nuova specie ha la spermateca nettamente più sviluppata e l'edeago ha apice a foggia di spatola, in visione ventrale (stretto in kibatiana).

Etimologia. Il nome della nuova specie significa «Antenne cresciute».

\section{Atheta (Acrotona) promissionum sp. n.}

(Figg. 137-138)

Holotypus + , Kenya, env. Nanyuki, 1900 m, 22.XI.1974, (Mahnert \& Perret leg., MG).

Descrizione. Lungh. 2,5 m. Corpo lucido e bruno, comprese le antenne; zampe giallo-rossicce. La reticolazione del capo è svanita, quella del pronoto assente e quella delle elitre è distinta. Tubercoletti nettamente salienti coprono l'avancorpo. Spermateca fig. 138.

Comparazioni. Specie affine alla precedente A. creticornis sp. n. in base alla forma della spermateca. Ne differisce perché la parte prossimale delle spermateca descrive una sola spira (una spira e mezza in creticornis), le elitre sono coperte di reticolazone distinta nella nuova specie, mentre in creticornis le elitre sono prive di reticolazione e il $4^{\circ}$ antennomero della nuova specie è più lungo che largo, mentre quello corrispondente di creticornis è trasverso.

\section{Atheta (Acrotona) zimbabwensis sp. n.}

(Figg. 139-142)

Holotypus đ̊, Rhodésie, Umtali, II.1969, (R. Mussard leg. MG).

Paratypi: 13 es., stessa provenienza.

Descrizione. Lungh. 2,4 mm. Corpo lucido e giallo-rossiccio con capo, elitre e uroterghi rossicci; margine posteriore degli uroterghi giallo-rossiccio; antenne brunorossicce con i due antennomeri basali giallo-rossicci; zampe giallo-rossicce. La reticolazione del capo è distinta, ma assente sul disco; assente pure sul pronoto e sulle elitre; la punteggiatura del capo è distinta e fitta, ma assente sul disco. Il pronoto e le elitre sono coperti di tubercoletti salienti. Edeago figg. 140-141, spermateca fig. 142.

Comparazioni. Per la forma dell'edeago e per l'habitus, la nuova specie può essere sistematicamente avvicinata ad A. parasita Bernhauer, 1845, del Kenya, ma l'ultimo antennomero del maschio della nuova specie è chiaramente più corto del corrispondente di parasita; l'edeago è più largo e ha lati convergenti verso l'apice nella nuova specie, mentre in parasita i lati sono tra loro paralleli e la spermateca è priva di introflessione apicale del bulbo distale (robusta e profonda in parasita). 

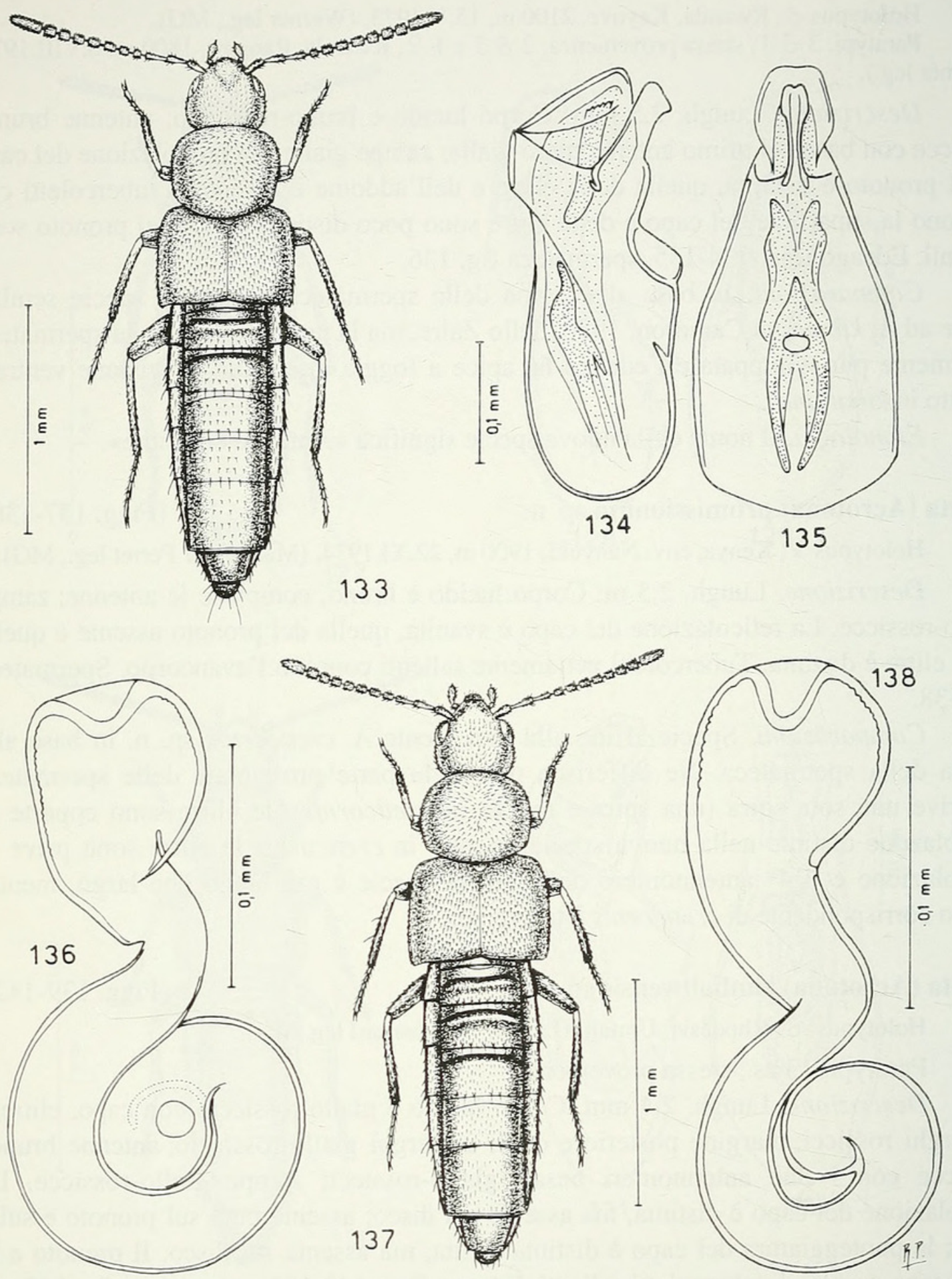

FIGG. 133-138

Habitus, edeago in visione laterale e ventrale e spermateca. 133-136: Atheta (Acrotona) creticornis sp. n.; 137-138: Atheta (Acrotona) promissionum sp. $\mathrm{n}$. 

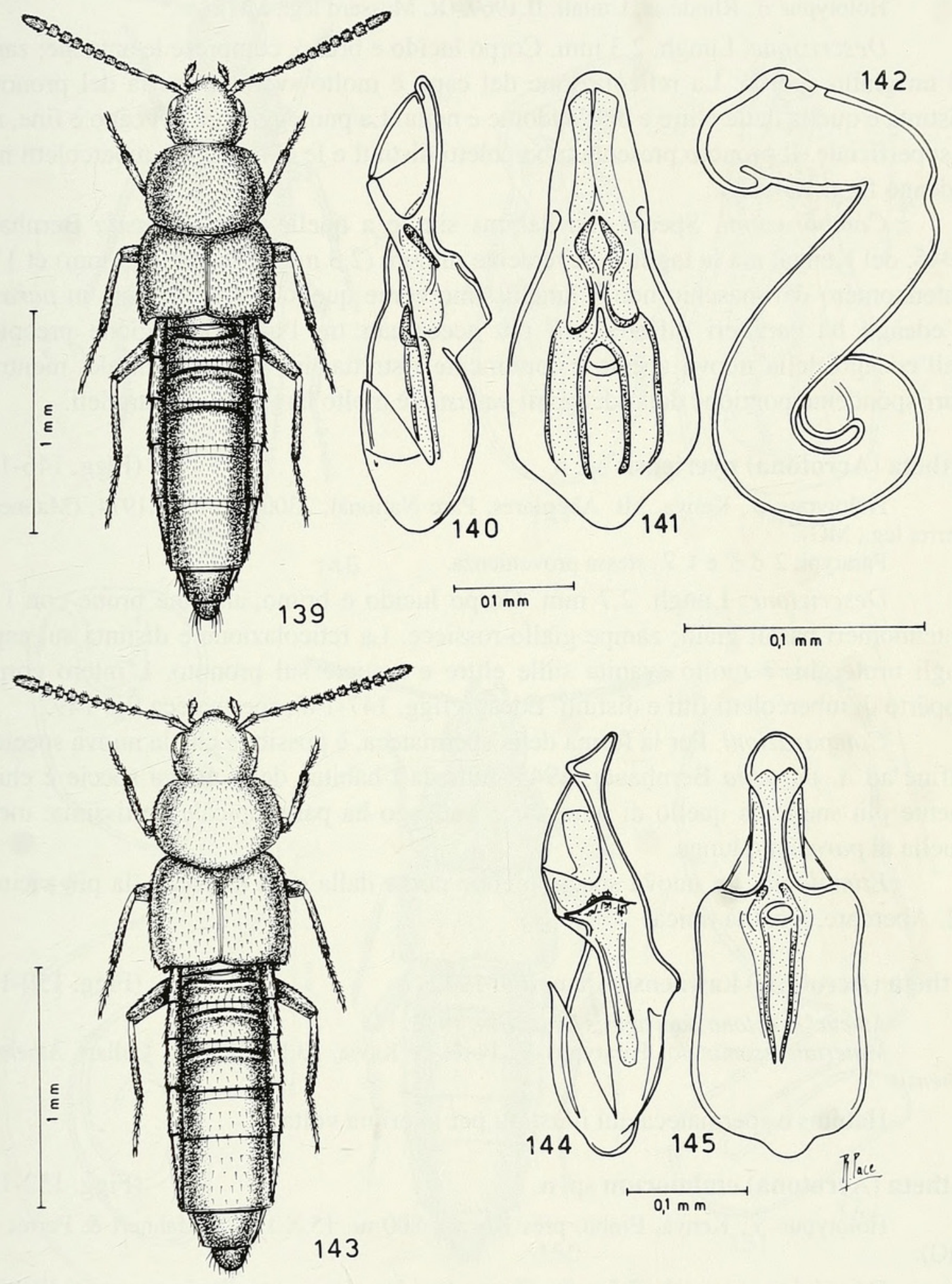

FIGG. 139-145

Habitus, edeago in visione laterale e ventrale e spermateca. 139-142: Atheta (Acrotona) zimbabwensis sp. n.; 143-145: Atheta (Acrotona) umtaliensis sp. n. 
Atheta (Acrotona) umtaliensis sp. n.

(Figg. 143-145)

Holotypus ơ, Rhodésie, Umtali, II.1969, (R. Mussard leg., MG).

Descrizione. Lungh. 2,3 mm. Corpo lucido e bruno, comprese le antenne; zampe di un giallo sporco. La reticolazione del capo è molto svanita, quella del pronoto è distinta e quella delle elitre e dell'addome è netta. La punteggiatura del capo è fine, rada e superficiale. Il pronoto presenta tubercoletti distinti e le elitre hanno tubercoletti netti. Edeago figg. 144-145.

Comparazioni. Specie con habitus simile a quelle di A. parasita Bernhauer, 1945 , del Kenya, ma la taglia è lievemente minore $(2,3 \mathrm{~mm}$ invece di $2,5 \mathrm{~mm})$ et 1 ' $11^{\circ}$ antennomero del maschio non è lunghissimo come quello corrispondente in parasita. L'edeago ha caratteri differenziali più accentuati: tra l'altro la regione preapicale dell'edeago della nuova specie è fortemente ristretta, in visione ventrale, mentre la corrispondente porzione dell'edeago di parasita è molto larga e a lati paralleli.

Atheta (Acrotona) nyeriensis sp. $\mathrm{n}$.

(Figg. 146-149)

Holotypus ơ, Kenya, Mt. Aberdares, Parc National, 2300 m, 25.XI.1974, (Mahnert \& Perret leg., MG).

Paratypi: 2 oे $\delta$ e $1 \%$, stessa provenienza.

Descrizione. Lungh. 2,7 mm. Corpo lucido e bruno; antenne brune con i due antennomeri basali gialli; zampe giallo-rossicce. La reticolazione è distinta sul capo e sugli uroterghi, è molto svanita sulle elitre e assente sul pronoto. L'intero corpo è coperto di tubercoletti fitti e distinti. Edeago figg. 147-148, spermateca fig. 149.

Comparazioni. Per la forma della spermateca, è possibile che la nuova specie sia affine ad $A$. parasita Bernhauer, 1945, tuttavia l'habitus della nuova specie è chiaramente più snello di quello di parasita e l'edeago ha parte apicale cortissima, mentre quella di parasita è lunga.

Etimologia. La nuova specie prende nome dalla città di Nyeri, la più vicina al M. Aberdare, località tipica.

Atheta (Acrotona) kawaensis Cameron, 1932

(Figg. 150-151)

Atheta (Acrotona) kawaensis CAMERON, 1932: 144.

Materiale esaminato: Paratypus + , Forêt de Kawa, 23.IV.1929, A. Collart, Atheta kawaensis.

Habitus e spermateca qui illustrati per la prima volta.

Atheta (Acrotona) embuorum sp. n.

(Figg. 152-153)

Holotypus f, Kenya, Embu, près Kogari, 800 m, 15.X.1977. (Mahnert \& Perret leg., MG).

Descrizione. Lungh. $2,5 \mathrm{~mm}$. Corpo lucido e bruno-rossiccio con uriti liberi $3^{\circ}$, $4^{\circ}$ e $5^{\circ}$ bruni; antenne bruno-rossicce con i due antennomeri basali giallo-rossicci; zampe giallo-rossicce con femori bruno-rossicci. La reticolazione del capo e del pronoto è netta e fine, quella delle elitre è distinta, quella dell'addome assente. La punteggiatura del capo è superficiale e assente sul disco, quella del pronoto è svanita e quella delle elitre è distinta. Spermateca fig. 153. 


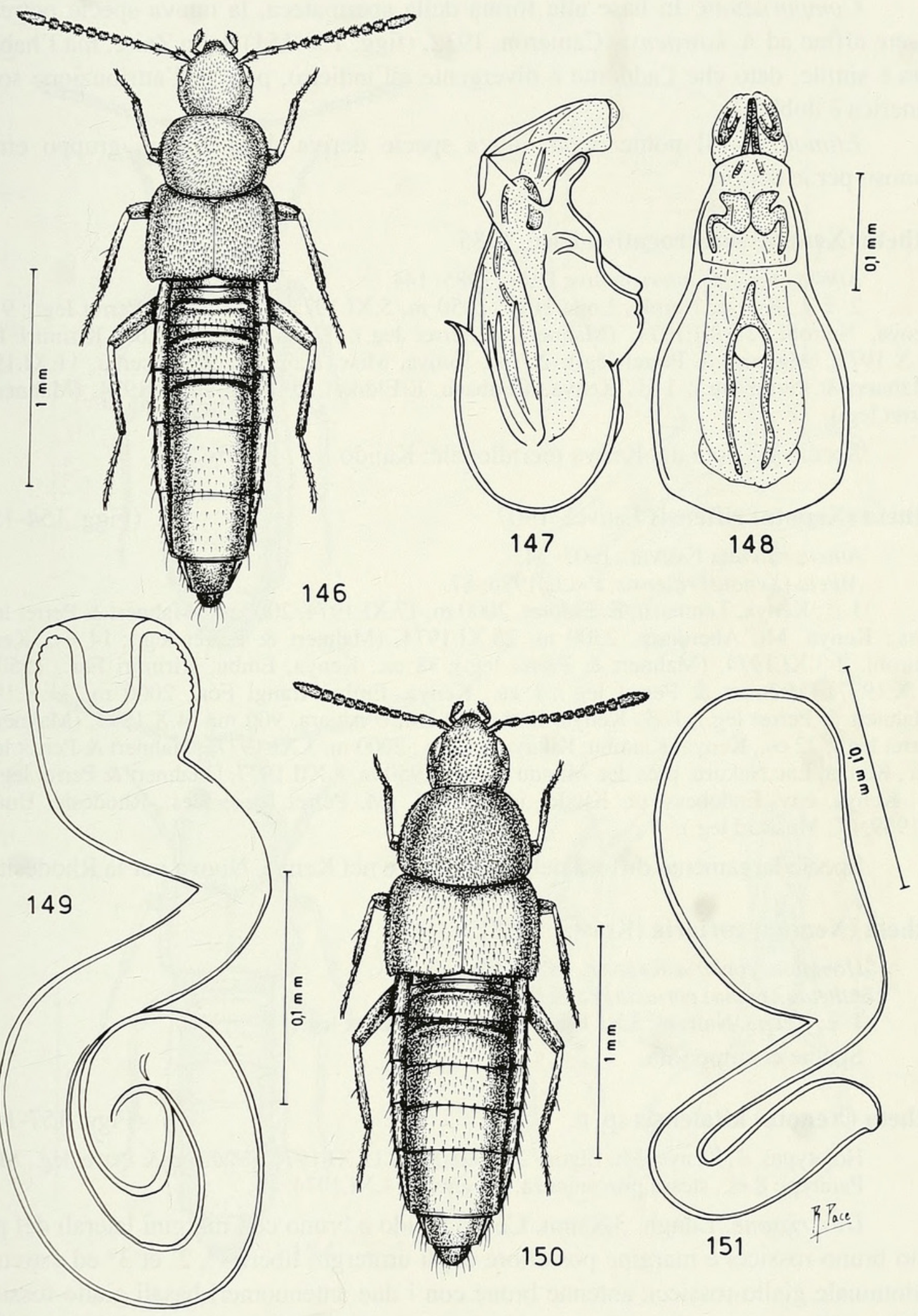

FIGG. 146-151

Habitus, edeago in visione laterale e ventrale e spermateca. 146-149: Atheta (Acrotona) nyeriensis sp. n.; 150-151: Atheta (Acrotona) kawaensis Cameron, paratypus + . 
Comparazioni. In base alla forma della spermateca, la nuova specie potrebbe essere affine ad A. kawaensis Cameron, 1932, (figg. 150-151) dello Zaire, ma l'habitus non è simile, dato che l'addome è divergente all'indietro, per cui l'attribuzione sottogenerica è dubbia.

Etimologia. Il nome della nuova specie deriva dagli Embu, gruppo etnico famoso per le danze.

\section{Atheta (Xenota) interrogativa Pace, 1985}

Atheta (Xenota) interrogativa PACE, 1985: 144.

2 ㅇ , Kenya, Narok,, Loita Hills, 2050 m, 5.XI.1977, (Mahnert \& Perret leg.); 9 es., Kenya, Nairobi, 2-3.XI.1974, (Mahnert \& Perret leg.); 1 q, Kenya, Embu, Kirimiri For., 13.X.1977, (Mahnert \& Perret leg.); 25 es., Nenya, Miss. Kaimosi, NE Kisumu, 11.XI.1974, (Mahnert \& Perret leg.); 1 ơ, Kenya, Tambach, E Eldoret, 2000 m, 17.XI.1974, (Mahnert \& Perret leg.).

Specie già nota del Kenya meridionale: Kajido.

Atheta (Xenota) riftensis Fauvel, 1907

(Figg. 154-156)

Atheta riftensis FAUVEL, 1907: 54.

Atheta (Xenota) riftensis, PACE, 1986: 87.

1 ơ, Kenya, Tambach, E. Eldoret, 2000 m, 17.XI.1974, 2000 m, (Mahnert \& Perret leg.); 3 es.; Kenya, Mt. Aberdares, 2300 m, 25.XI.1974, (Mahnert \& Perret leg.); 14 es., Kenya, Nairobi, 2-3.XI.1974, (Mahnert \& Perret leg.); 38 es., Kenya, Embu, Kirimiri For., 1550 m, 13.X.1977, (Mahnert \& Perret leg.); 1 es., Kenya, Embu, Irangi For., 2000 m, 11.X.1977, (Mahnert \& Perret leg.); 1 ơ, Kenya, Embu, 20 Km 0 Ishiara, 900 m, 14.X.1977, (Mahnert \& Perret leg.); 22 es., Kenya, Kiambu, Kikuyu Escarp., 2000 m, 3.XI.1977, (Mahnert \& Perret leg.); 1 f, Kenya, Lac Nakuru, près dee Mundu Estate, 1950 m, 8.XII.1977, (Mahnert \& Perret leg.); 6 es., Kenya, env. Endebess, pr. Kitale, 14.XI.1974, (M. Perret leg.); 3 es., Rhodésie, Umtali, II.1969, (R. Mussard leg.).

Specie largamente diffusa nella Tanzania e nel Kenya. Nuova per la Rhodesia.

\section{Atheta (Xenota) coriaria (Kraatz, 1858)}

Homalota coriaria KRAATZ, 1858: 282.

Atheta (Xenota) coriaria, PACE, 1984: 263.

1 , Kenya, Nairobi, 3.XI.1974, (Mahnert \& Perret leg.).

Specie cosmopolita.

Atheta (Xenota) kitalensis sp. n.

(Figg. 157-160)

Holotypus ð̊, Kenya, Mt. Elgon, 2700-2800 m, 15.XI.1974, (Mahnert \& Perret leg., MG). Paratypi: 8 es., stessa provenienza, ma anche 14.XI.1974.

Descrizione. Lungh. $3,8 \mathrm{~mm}$. Corpo lucido e bruno con margini laterali del pronoto bruno-rossicci e margine posteriore degli uroterghi liberi $1^{\circ}, 2$. et $3^{\circ}$ ed estremità addominale giallo-rossicci; antenne brune con i due antennomeri basali giallo-rossicci; zampe giallo-rossicce. Tutto il corpo è coperto di reticolazione netta. I tubercoletti della superficie del capo e del pronoto sono distinti, quelli delle elitre sono svaniti. Edeago figg. 158-159, spermateca fig. 160.

Comparazioni. Per la forma dell'edeago, la nuova specie sembra più affine ad $A$. scotti Bernhauer, 1931 che ad A. euphorbiae Bernhauer, 1931, entrambe dell'Abissinia. 

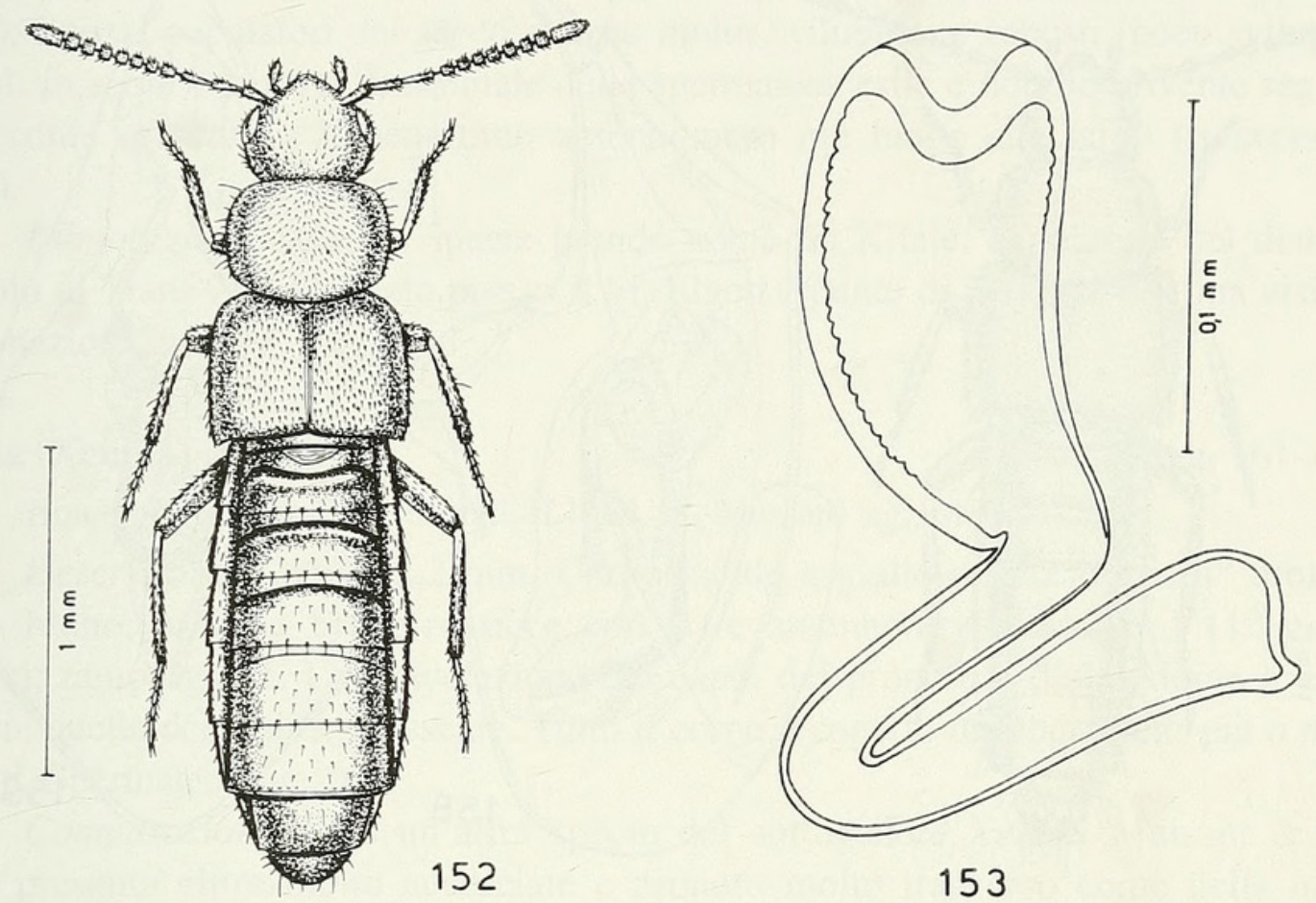

153
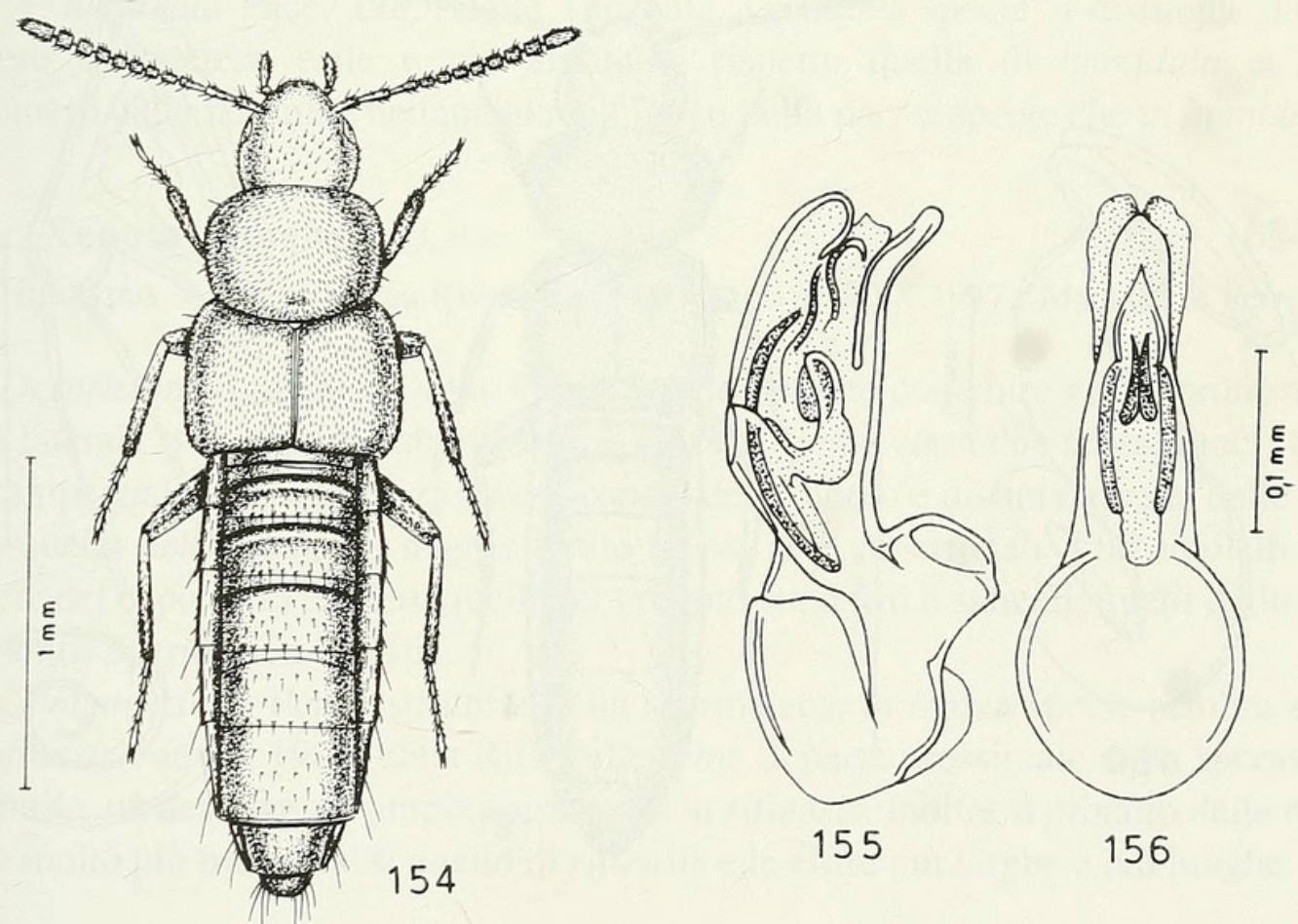

FIGG. 152-156

Habitus, spermateca ed edeago in visione laterale e ventrale. 152-153: Atheta (Acrotona) embuorum sp. n.; 154-156: Atheta (Xenota) riftensis Fauvel. 

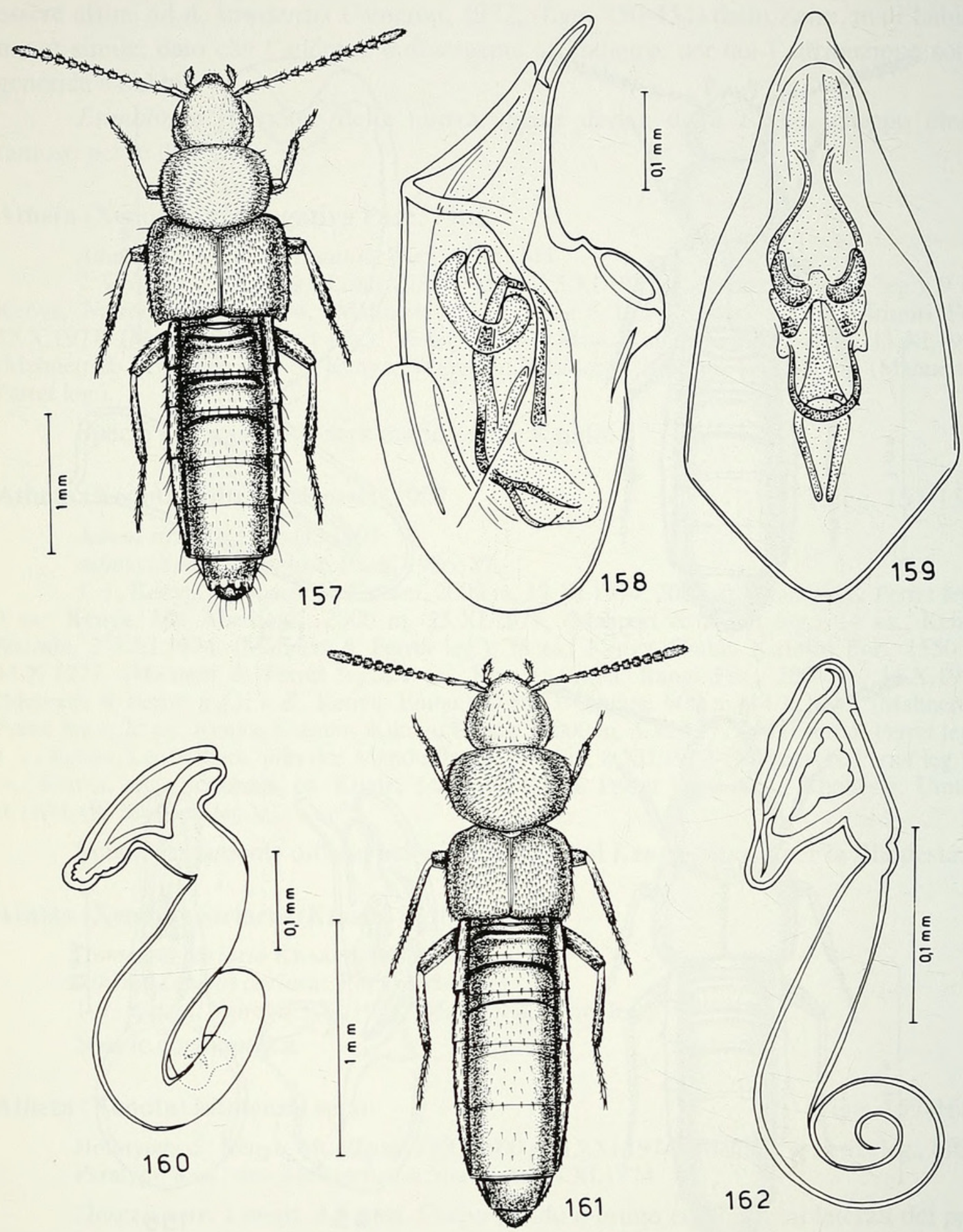

FIGG. 157-162

Habitus, edeago in visione laterale e ventrale e spermateca. 157-160: Atheta (Xenota) kitalensis sp. n.; 161-162: Atheta (Xenota) cincta sp. n. 
La nuova specie differisce da $A$. scotti perché ha l'apice dell'edeago smussato e più largo (apice acuto in scotti), la «crista apicalis» poco sviluppata (molto sviluppata in scotti), i pezzi copulatori del sacco interno molto sviluppati e robusti (poco sviluppati ed esili in scotti), la parte prossimale della spermateca esile e non descrivente regolari spire come in scotti e il penultimo antennomero più lungo che largo (trasverso in scotti).

Etimologia. La nuova specie prende nome da Kitale, capoluogo del distretto agricolo di Trans-Nzoie situato presso il M. Elgon e punto di partenza per una visita al parco nazionale del M. Elgon.

Atheta (Xenota) cincta sp. $\mathrm{n}$.

(Figg. 161-162)

Holotypus + , Rhodésie, Umtali, II.1969, (R. Mussard leg., MG).

Descrizione. Lungh. 2,2 mm. Corpo lucido e giallo-rossiccio con $4^{\circ}$ urotergo libero bruno; antenne bruno-rossicce con i tre antennomeri basali e $1^{\prime} 11^{\circ}$ giallorossicci; zampe gialle. La reticolazione del capo, del pronoto e dell'addome è molto svanita, quella delle elitre è assente. Tutto il corpo è coperto di tubercoletti più o meno salienti. Spermateca fig. 162.

Comparazioni. Solo un'altra specie del sottogenere Xenota Mulsant \& Rey, 1874, presenta elitre molto accorciate e pronoto molto trasverso come nella nuova specie: A. humidula Pace, 1985, delle Tanzania. La nuova specie si distingue da essa per avere spermateca esile e più allungata rispetto quella di humidula e $1^{\prime} 11^{\circ}$ antennomero della femmina nettamente piú lungo nella nuova specie che in humidula.

Atheta (Xenota) tanensis sp. n.

(Figg. 163-164) MG).

Holotypus + , Kenya, Tana River, Galole Hola, 60 m, 20.X.1977, (Mahnert \& Perret leg.,

Descrizione. Lungh. 2,1 mm. Corpo lucido e bruno con elitre giallo-brune aventi margini laterali, posteriore e suturale bruni; antenne brune con i due antennomeri basali gialli; zampe gialle. La reticolazione del capo e del pronoto è distinta, quella delle elitre è netta, quella dell'addome a maglie molto trasverse e superficiali. I tubercoletti della superficie del capo sono distinti, quelli del pronoto sono fini e salienti, quelli delle elitre sono svaniti. Spermateca fig. 164.

Comparazioni. Per la struttura della spermateca, la nuova specie sembra affine ad A. riftensis Fauvel, 1907, della Rift-Valley, ma la parte prossimale della spermateca non è sottile, nè descrive un'ampia spira come in riftensis. Inoltre il pronoto della nuova specie è molto più trasverso di quello di riftensis e le elitre più larghe e più lunghe.

Atheta (Oxypodera) densiventris Fauvel, 1907

(Figg. 165-168)

Atheta densiventris FAUVEL, 1907: 54.

Atheta (s. str.) densiventris, BERNHAUER \& SCHEERPELTZ, 1926: 64. Bruxelles).

Materiale esaminato: Holotypus ôे, Afrique or. allemande, densiventris FVL, type (Mus.

1 ठे, Kenya, Nairobi, 3.XI.1974, Mahnert \& Perret leg.). 


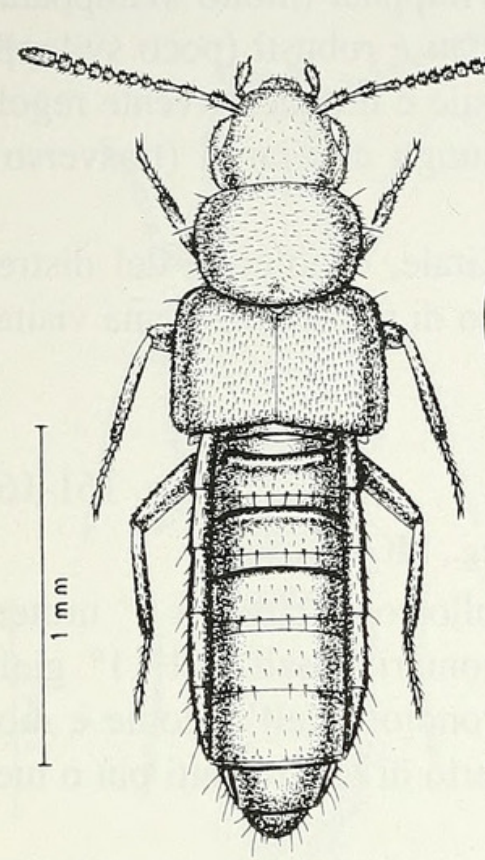

163

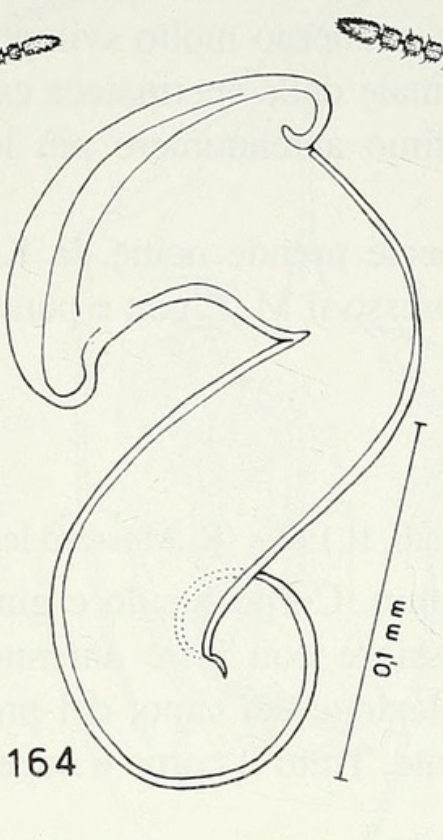

- 0000000

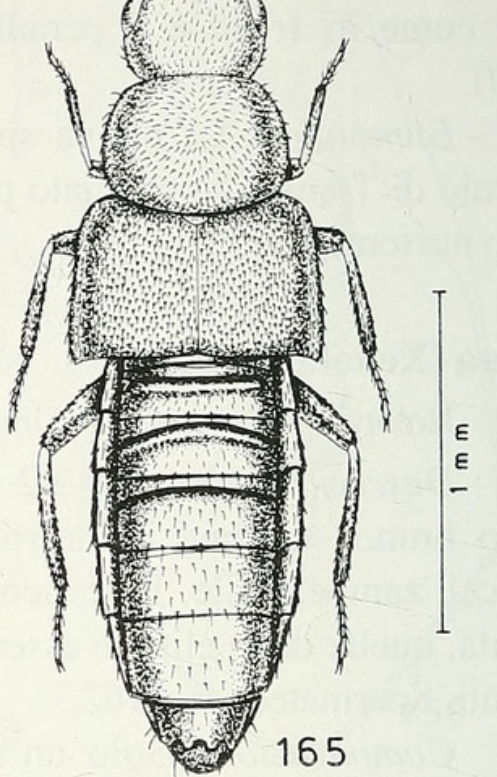

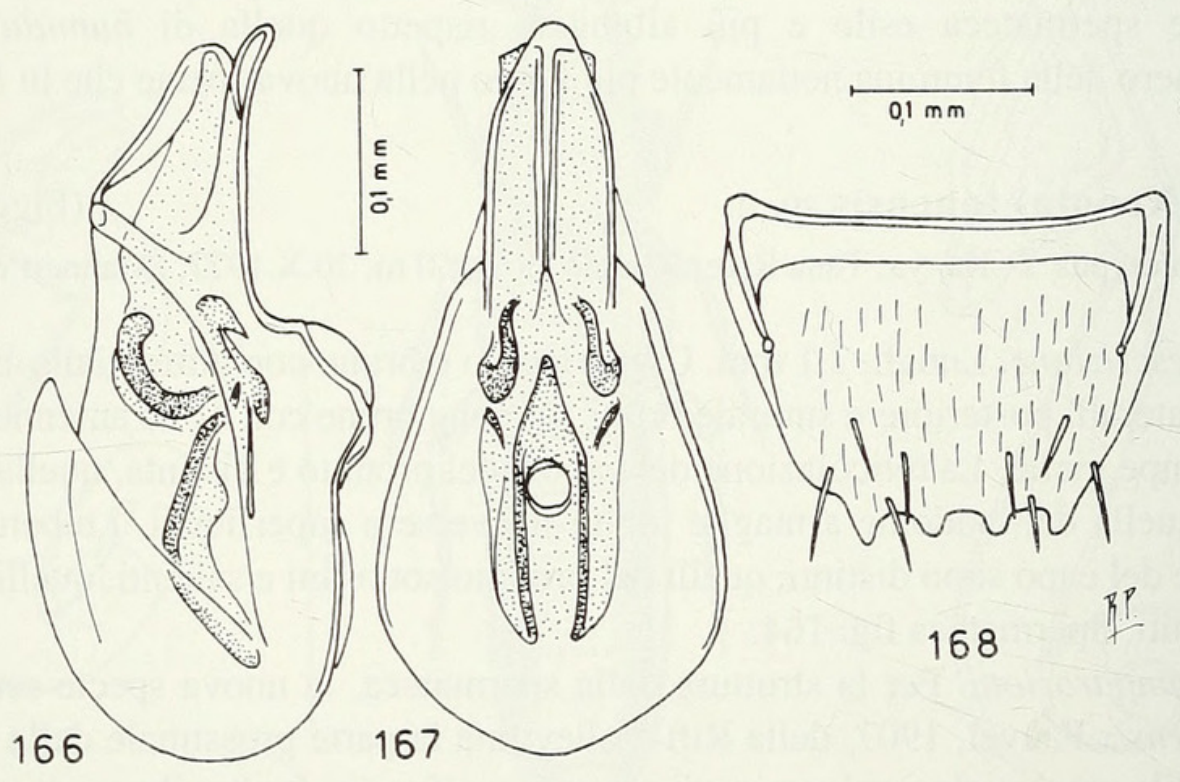

FIGG. 163-168

Habitus, spermateca, edeago in visione laterale e ventrale e $6^{\circ}$ urotergo libero del maschio. 163-164: Atheta (Xenota) tanensis sp. n.; 165-168: Atheta (Oxypodera) densiventris Fauvel, holotypus. 

illustrati.

Habitus, edeago e quinto urotergo libero del maschio qui per la prima volta

Specie finora nota su un maschio di località imprecisata dell'Africa orientale.

Atheta (Oxypodera) andreinii Bernhauer, 1927

(Figg. 169-172)

Atheta (Acrotona) andreinii Bernhauer, 1927: 80.

Materiale esaminato: Lectotypus ô, Eritrea, Adi-Caie, 10.IV.1902, Dr. Andreini, 243, Atheta andreinii BRNH, Typ., presente designazione, (Mus. La Specola, Firenze, $\mathrm{N}^{\circ} 7789$ ); paralectotypi: 35 es., stessa provenienza e Museo.

Nota. La spermateca e l'edeago di A. andreinii indicano senza dubbio l'appartenenza della specie al sottogenere Oxypodera Bernhauer, 1915 e non al sottogenere Acrotona Thomson, 1859.

La specie è qui illustrata per la prima volta. Essa è estremamente affine ad $A$. densiventris Fauvel, 1907, sopra illustrata. I caratteri differenziali sono esposti nella seguente chiave:

1 Occhi sporgenti; $11^{\circ}$ antennomero del maschio lungo come i due precedenti antennomeri considerati insieme; reticolazione del pronoto svanita; elitre piú larghe; $6^{\circ}$ urotergo libero del maschio dentellato al margine posteriore (fig. 168); apice dell'edeago piú stretto, in visione ventrale. Lungh. $2,2 \mathrm{~mm}$. Africa orientale. . . . . . . . densiventris Fauvel

Occhi meno sporgenti; $11^{\circ}$ antennomero del maschio lungo come i tre precedenti antennomeri considerati insieme; reticolazione del pronoto estremamente svanita; elitre piuttosto strette; $6^{\circ}$ urotergo libero del maschio con margine posteriore non dentellato; apice dell'edeago più largo, in visione ventrale. Lungh. $2,7 \mathrm{~mm}$. Eritrea. . . . . . . andreinii Bernhauer

Atheta (Oxypodera) chyuluensis Cameron, 1942

(Figg. 173-176)

Atheta (Acrotona) chyuluensis CAMERON, 1942: 331.

Atheta (Xenota) chyuluensis, PACE, 1986: 87.

Materiale esaminato: Lectotypus § , Coryndon Museum Expedit., Chyulu Hills, june 38, alt. 5660, Atheta chyuluensis Cam., presente dseignazione (Brit. Mus.); paralectotypi: 2 ठे e 2 $q$, stessa provenienza, (Brit. Mus.).

1 q, Kenya, Nairobi, 3.XI.1974, (Mahnert \& Perret leg.); 1 ơ, Kenya, Narok, Loita Hills, 4.XI.1977, (Mahnert \& Perret leg.); 3 ơ ơ, Kenya, Tambach, E Eldoret, 2000 m, 17.XI.1974 (Mahnert \& Perret leg.).

Specie diffusa dal Kenya alla Tanzania, la specie é qui illustrata per la prima volta.

\section{Atheta (Oxypodera) nairobianorum Pace, 1985}

Atheta (Oxypodera) nairobianorum Pace, 1985: 144.

1 q, Kenya, Embu, Kirimiri Forest, 1550 m, 13.X.1977, (Mahnert \& Perret leg.); 1 q, Kenya, Nakuru, Mau Escarpment, 2700 m, 6.XI.1977, (Mahnert \& Perret leg.).

Specie già nota del Kenya. 


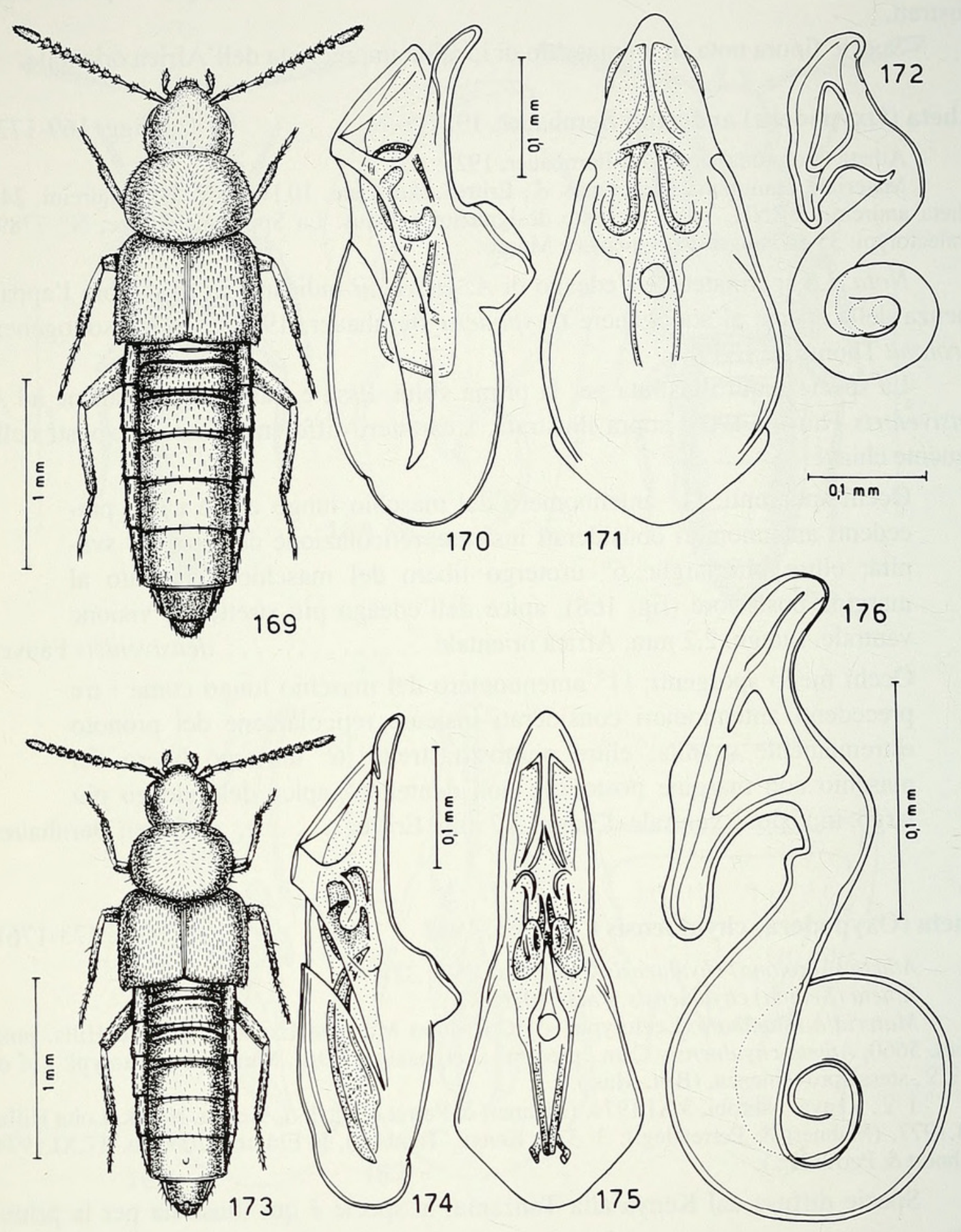

FIGG. 169-176

Habitus, edeago in visione laterale e ventrale e spermateca. 169-172: Atheta (Oxypodera) andreinii Bernhauer, lectotypus ô e paralectotypus + ; 173-176: Atheta (Oxypodera) chyuluensis Cameron, lectotypus of e paralectotypus $q$. 


\section{Atheta (Oxypodera) fugata Pace, 1985}

Atheta (Oxypodera) fugata PACE, 1985: 146.

10 es., Mt. Kenya, 3250 m, S Met St. Lodge, 23.XI.1974, (Mahnert \& Perret leg.).

Specie finora nota solo del M. Meru.

\section{Atheta (Oxypodera) mombasana Bernhauer, 1934}

(Figg. 177-179)

Atheta (Oxypodera) mombasana BERNHAUER, 1934: 246.

Atheta (Oxypodera) mombasana, PACE, 1986: 109, sp. bona.

Materiale esaminato: Lectotypus ơ, Mombasa, $36 \mathrm{Km}$ Sud Lubero, fin VIII.1932, L. Burgeon, mombasana BRNH, Type, mombasana BRNH, Type, presente designazione (Mus. Chicago).

Specie qui illustrata per la prima volta.

Nota. Per un mio errore di trascrizione, nel 1986 ho posto in sinonimia di Atheta paludosa Bernhauer, 1931, A. mombasana Bernhauer, 1934, in luogo di A. mombassana Bernhauer, 1932. Pertanto stabilisco la corretta sinonima come segue:

\section{Atheta (Oxypodera) paludosa Bernhauer, 1931}

Atheta (Coprothassa) paludosa Bernhauer, 1931: 602.

Atheta (Coprothassa) mombassana BernHAUER, 1934: 214, syn. n. (nec Atheta mombasana BERNHAUER, 1934: 246).

\section{Atheta (Oxypodera) pseudomombasana sp. n.}

(Figg. 180-182 e 198-194)

Holotypus ơ, Kenya, Nairobi, 3.XI.1974, (Mahnert \& Perret leg., MG).

Paratypus: $1 \uparrow$, stessa provenienza.

Descrizione. Lungh. 3,0 mm. Corpo lucido e bruno-rossiccio; antenne brune con i due antennomeri basali giallo-rossicci; zampe giallo-rossicce. La reticolazione del capo, delle elitre e dell'addome è distinta, quella del pronoto è assente. I tubercoletti sono distinti o salienti su tutto il corpo. Edeago figg. 181-182.

Comparazioni. Specie affine ad A. mombasana Bernhauer, 1934, per la forma dell'edeago, ma quello della nuova specie ha taglia minore (figg. 178-179 e 181-182), non è profondamente arcuato al lato ventrale come quello di mombasana. Inoltre gli occhi della nuova specie sono più sporgenti e i denti del margine posteriore del $6^{\circ}$ urotergo libero del maschio sono più distanziati tra loro nella nuova specie che in mombasana.

\section{Atheta (Oxypodera) kayovensis sp. n.}

(Figg. 183-186)

Holotypus ơ, Rwanda, Kayove, 2100 m, 15.V.1973, (Werner leg., MG). (Werner leg.).

Paratypi: 2 $q$, stessa provenienza; 1 o e 1 \% , Rwanda, Rangiro, 1800 m, 20.VIII.1976,

Descrizione. Lungh. 3,0 mm. Corpo lucido e giallo rossiccio con capo e uriti liberi $3^{\circ}, 4^{\circ}$ e $5^{\circ}$ bruni ed elitre rossicce; antenne bruno-rossicce, con i due antennomeri basali giallo-rossicci; zampe gialle. La reticolazione del corpo è distinta, tranne sulle elitre dove è molto svanita. La punteggiatura del capo è distinta. I tubercoletti sul pronoto sono netti, quelli sulle elitre sono superficiali. Edeago figg. 184-185, spermateca fig. 186. 

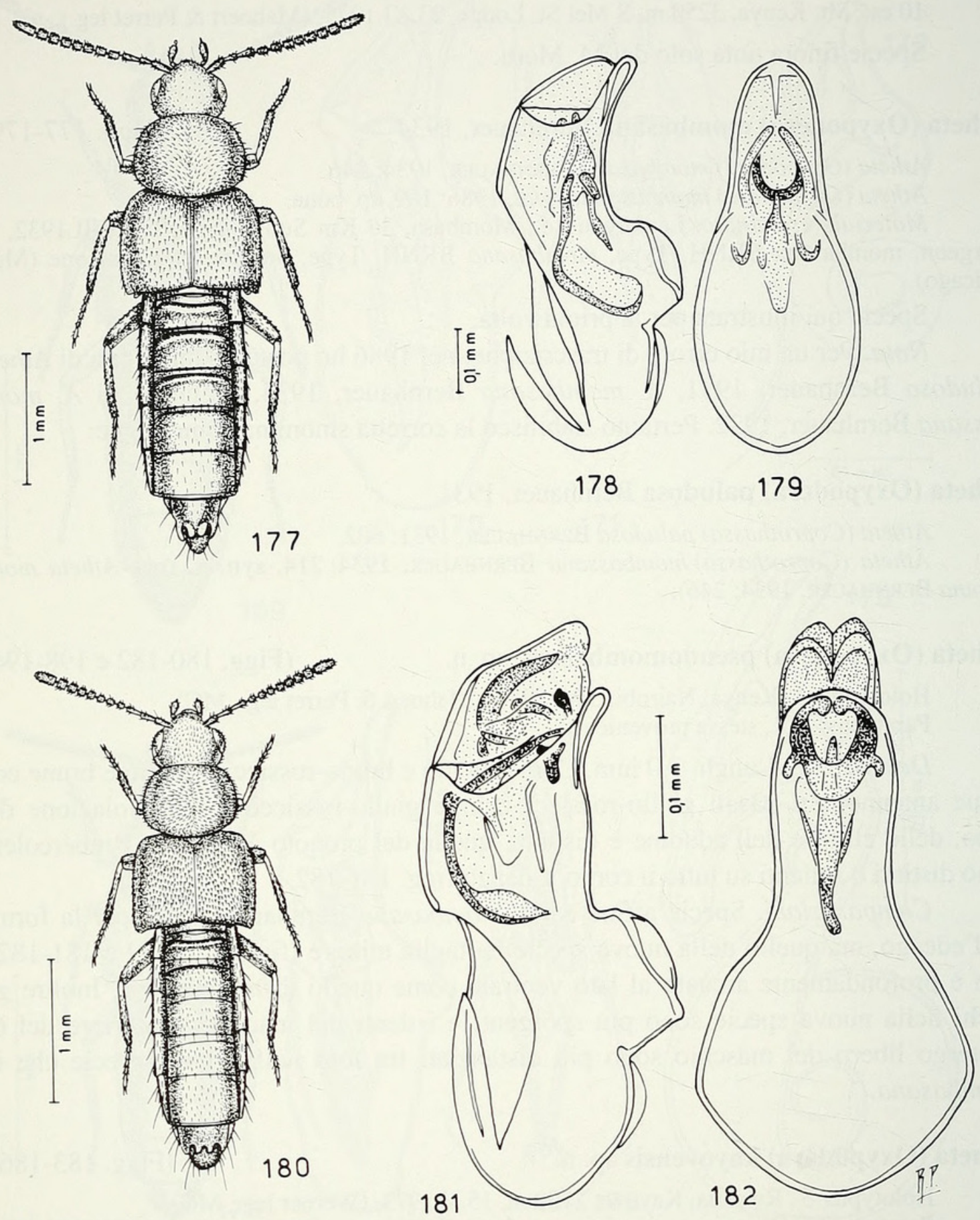

FIGG. 177-182

Habitus ed edeago in visione laterale e ventrale. 177-179: Atheta (Oxypodera) mombasana Bernhauer, lectotypus ơ; 180-182: Atheta (Oxypodera) pseudomombasana sp. n. 
Comparazioni. Alla grande taglia del corpo di questa specie non corrisponde un edeago proporzionalmente grande, come è osservabile in tutte le specie del sottogenere Oxypodera Bernhauer, 1915. Una sola specie possiede edeago di taglia uguale a quello della nuova specie: A. haramayana Bernhauer, 1931, dell'Abissinia, ma haramayana ha corpo di lunghezza minore $(2,1 \mathrm{~mm})$. Inoltre nella nuova specie è assente la "crista apicalis", mentre in haramayana è presente e il sacco interno dell'edeago presenta una formazione chitinosa rivestita di setole nella nuova specie, mai osservata in altre specie del sottogener Oxypodera.

Atheta (Oxypodera) nakuruensis sp. $\mathrm{n}$.

(Figg. 187-189)

Holotypus ơ, Kenya, lac Nakuru, Parc Nat., (Mahnert \& Perret leg., MG).

Descrizione. Lungh. 2,7 mm. Corpo lucido e rossiccio con capo, elitre e uriti liberi $1^{\circ}, 2^{\circ}, 3^{\circ}$ e $4^{\circ}$ bruno-rossicci; antenne rossicce con i due antennomeri basali e $1^{\prime} 11^{\circ}$ giallo-rossicci; zampe giallo-rossicce. La reticolazione del capo è superficiale, quella del pronoto e dell'addome è assente, quella delle elitre è netta. Tutto il corpo è coperto di tubercoletti distinti. Edeago figg. 188-189.

Comparazioni. La nuova specie presenta elitre più corte del pronoto. Specie del sottogenere Oxypodera Bernhauer, 1915, con questo stesso carattere, sono da citare $A$. kenyamontis Pace, 1986, A. montanella Bernhauer, 1934, del Kivu, A. burgeoniana Bernhauer, 1934, del Ruwenzori e A. complicans Pace, 1985, del Kilimangiaro. Nessuna di esse ha edeago identico a quello della nuova specie. Prendendo in esame il solo apice dell'edeago, in visione ventrale, A. kenyamontis lo ha tronco, A. burgeoniana e A. complicans lo hanno acuto. La sola specie che presenta l'apice dell'edeago smussato come quello della nuova specie, è A. montanella, ma questa specie ha edeago molto più sviluppato, con pezzi copulatori del sacco interno che sembrano molto differenti (purtroppo l'edeago dell'holotypus di montanella ha il sacco interno evaginato). Inoltre l'habitus di montanella è stretto, le antenne sono proporzionalmente più lunghe e gli occhi sono sporgenti.

\section{Atheta (Oxypodera) kaimosensis sp. $\mathrm{n}$.}

(Figg. 190-193)

Holotypus đ̊, Kenya, Miss. Kaimosi, NE Kisumu, 1650 m, 11.XI.1974, (Mahnert \& Perret leg., MG).

Paratypi: 5 es., stessa provenienza.

Descrizione. Lungh. 2,3 mm. Corpo lucido e rossiccio con pronoto giallorossiccio e uriti liberi $2^{\circ}, 3^{\circ}, 4^{\circ}$ e $5^{\circ}$ bruni; Antenne brune con i due antennomeri basali giallo-rossicci; zampe giallo-rossicce. La reticolazione del capo è distinta, quella del pronoto e dell'addome assente, quella delle elitre è svanita. La punteggiatura del capo è distinta. Tubercoletti fini e distinti coprono il resto del corpo. Edeago figg. 191-192, spermateca fig. 193.

Comparazioni. La nuova specie per molti caratteri dell'edeago e della spermateca si presenta sistematicamente vicina ad. A. chyuluensis Cameron, 1942 (figg. 173-176), del Kenya e della Tanzania. Infatti il sacco interno dell'edeago delle due specie mostra due lame chitinose ricurve e a punta acuta, ma mentre in chyuluensis una 


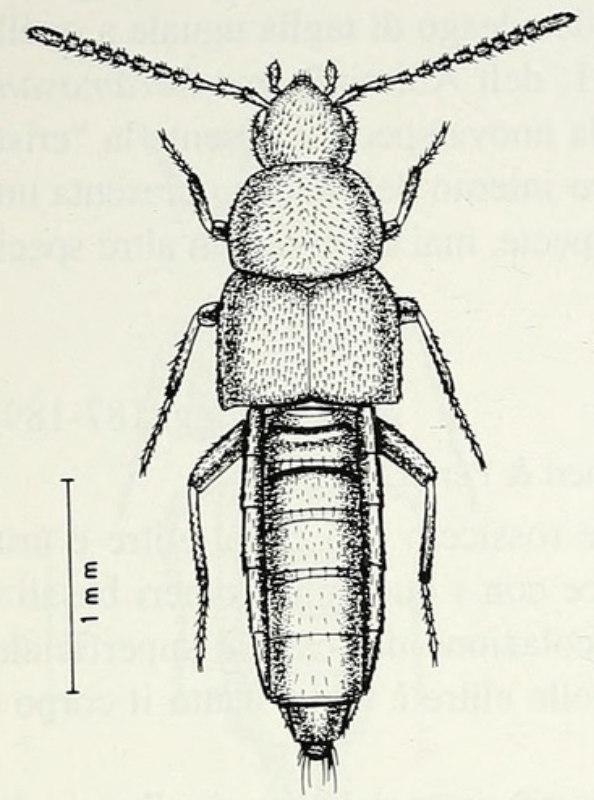

183
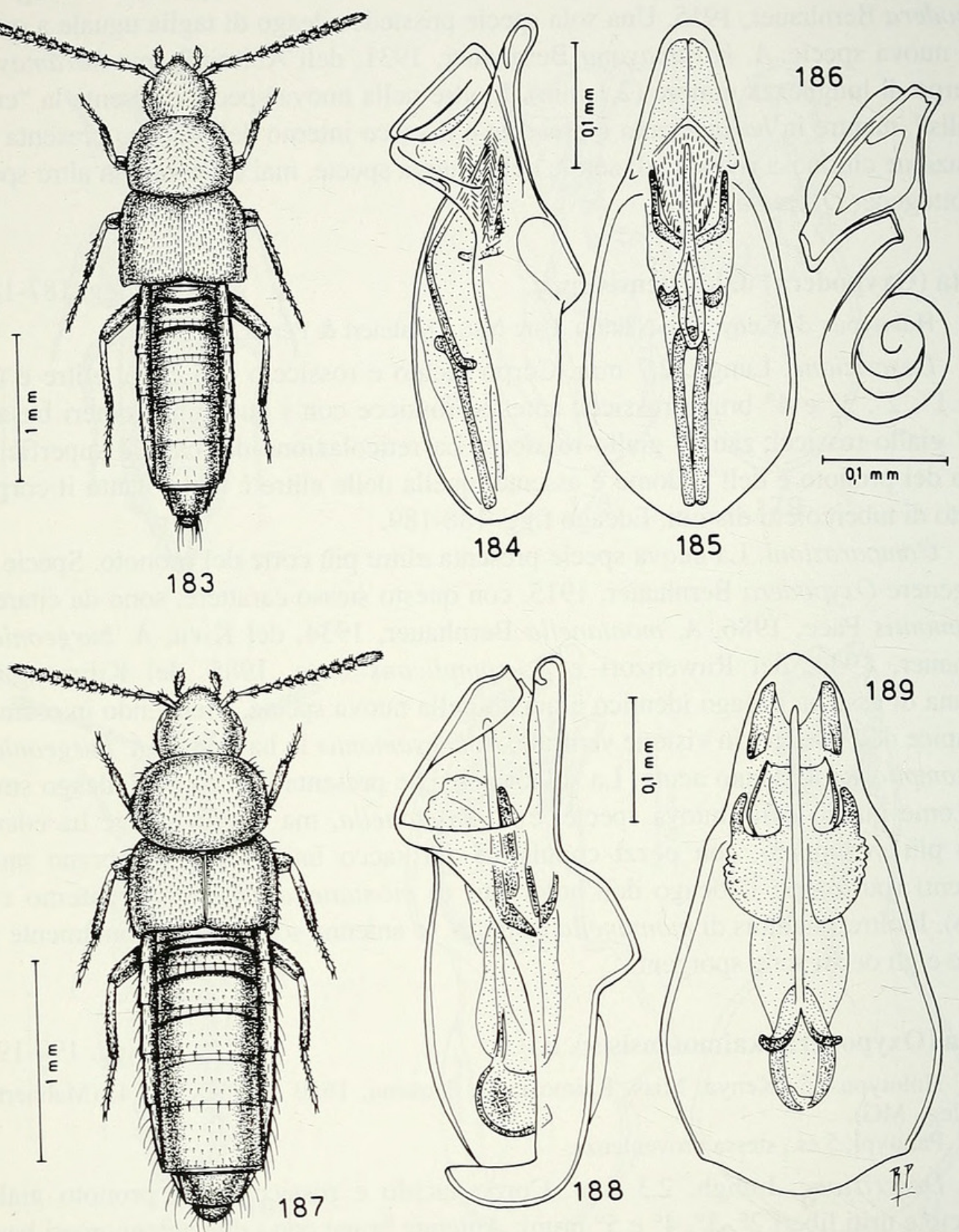

FIGG. 183-189

Habitus, edeago in visione laterale e ventrale e spermateca. 183-186: Atheta (Oxypodera) kayovensis sp. n.; 187-189: Atheta (Oxypodera) nakuruensis sp. $\mathrm{n}$. 
è lunghissima e l'altra cortissima e tozza, nella nuova specie dette lame chitinose sono simmetriche, con base molto larga. La spermateca ha bulbo distale molto stretto in chyuluensis, largo nella nuova specie.

\section{Atheta (Oxypodera) rangirensis sp. $\mathrm{n}$.}

(Figg. 194-197)

Holotypus đ̊, Rwanda, Rangiro, 1800 m, 6.VIII.1973, (Werner leg., MG).

Descrizione. Lungh. $2,7 \mathrm{~mm}$. Corpo lucido e bruno con elitre giallo-brune; antenne bruno-rossicce con i due antennomeri basali giallo-rossicci; zampe giallorossicce. Su tutto il corpo la reticolazione è distinta. La punteggiatura del capo è evidente. I tubercoletti che coprono pronoto ed elitre sono svaniti. Edeago figg. 196197, $6^{\circ}$ urotergo libero del maschio fig. 194.

Comparazioni. L'edeago delle specie del sottogenere Oxypodera Bernhauer, 1915, ha la regione della "crista apicalis" per lo più poco sporgente al lato ventrale. Fa eccezione l'edeago della nuova specie che ha la regione della "crista apicalis" vistosamente sporgente. Per questo carattere e per altri, come l'apice dell'edeago in visione ventrale con lati preapicali paralleli e il $3^{\circ}$ e il $4^{\circ}$ degli antennomeri compressi lateralmente, la nuova specie è chiaramente distinta dalle altre note del sottogenere.

\section{Atheta (Oxypodera) implicatoides sp. $\mathrm{n}$.}

(Figg. 200-201)

Holotypus \&, Rhodésie, Umtali, II. 1969, (R. Mussard leg., MG).

Descrizione. Lungh. 2,9 mm. Corpo lucido e bruno-rossiccio con uriti liberi $4^{\circ} \mathrm{e}$ $5^{\circ}$ bruni; antenne brune con i tre antennomeri basali giallo-rossicci; zampe giallorossicce. La reticolazione del capo è distinta, quella del pronoto e dell'addome è svanita, quella delle elitre è vigorosa. La punteggiatura del capo è distinta, quella del pronoto è svanita e quella delle elitre è netta. Spermateca fig. 201.

Comparazioni. Specie simile ad A. implicata Pace, 1985, del Kilimangiaro, ma la spermateca ha parte prossimale molto sottile (parte prossimale larga in implicata). La nuova specie è pure distinta da A. pseudomombasana sp. n. sopra descritta perché la parte prossimale della spermateca non è foggiata a spirale.

\section{Atheta (Oxypodera) mahnerti sp. $\mathrm{n}$.}

(Figg. 202-205)

Holotypus ơ, Kenya, Narok, Loita Hills, SO Morijo, 2050 m, 4-5.XI.1977, (Mahnert \& Perret leg., MG).

Paratypi: 14 es., stessa provenienza; 3 es., Kenya, Thomson's Falls, 2350 m, 20.XI.1974, (Mahnert \& Perret leg.); 1 o e 2 ㅇ + , Kenya, Nakuru, Mau Escarp. près Enangiperi, 2700 m, 6.XI.1977, (Mahnert \& Perret leg.).

Descrizione. Lungh. 2,9 mm. Corpo lucido e bruno-rossiccio con capo e uriti liberi $3^{\circ}, 4^{\circ}$ e $5^{\circ}$ bruni; antenne bruno-rossicce con antennomero basale giallo-rossiccio; zampe giallo-rossicce. La reticolazione del capo è svanita, quella del pronoto molto superficiale e quella delle elitre e dell'addome è netta. La punteggiatura del capo è svanita. I tubercoletti che coprono il pronoto sono distinti e quelli delle elitre poco salienti. Edeago figg. 204-205, spermateca fig. 203.

Comparazioni. La nuova specie, per la forma dell'edeago e della spermateca, è sistematicamente vicina ad A. paludosa Bernhauer, 1931, dell'Abissinia, ma un robus- 

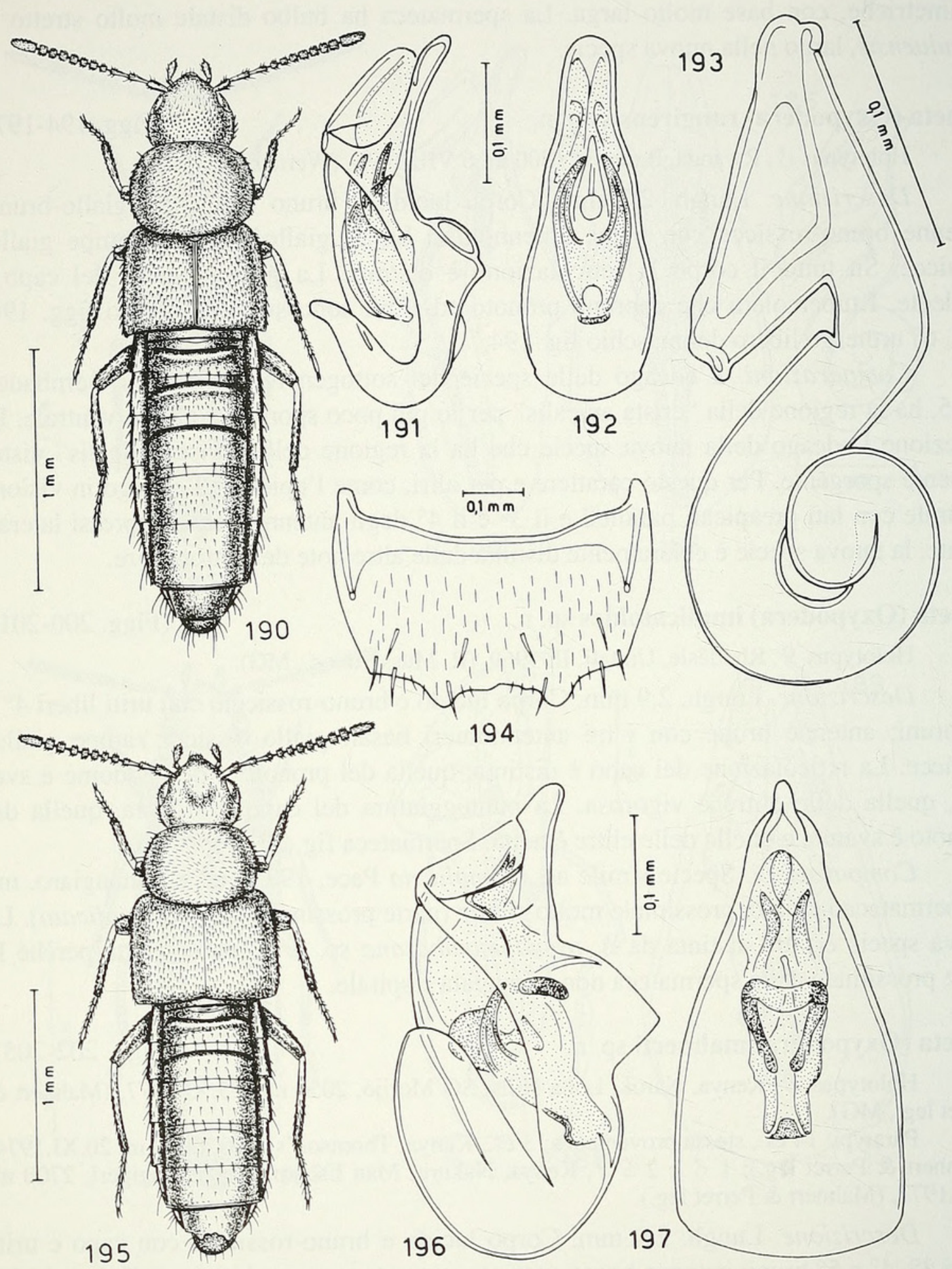

194

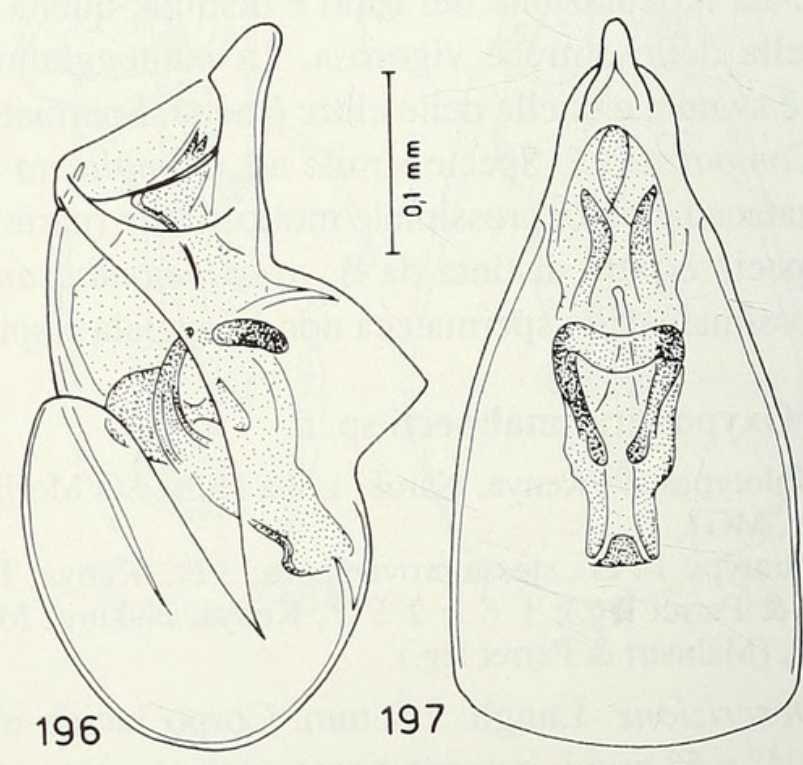

FIGG. 190-197

Habitus, edeago in visione laterale e ventrale, spermateca e $6^{\circ}$ urotergo libero del maschio. 190-193: Atheta (Oxypodera) kaimosensis sp. n.; 194-197: Atheta (Oxypodera) rangirensis sp. n. 


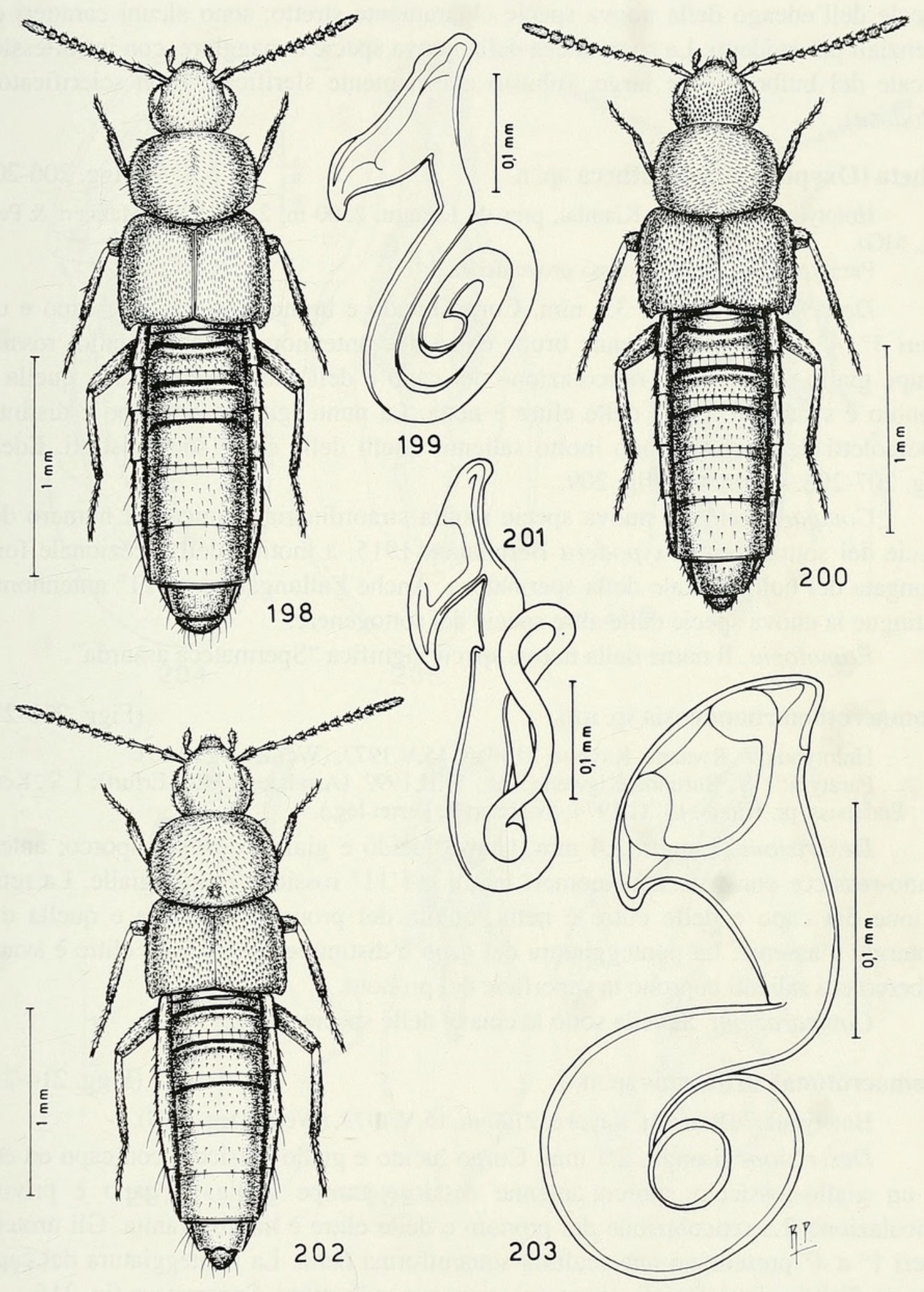

FIGG. 198-203

Habitus e spermateca. 198-199: Atheta (Oxypodera) pseudomombasana sp. n.; 200-201: Atheta (Oxypodera) implicatoides sp. n.; 202-203: Atheta (Oxypodera) mahnerti sp. n. 
tissimo pezzo copulatore del sacco interno dell'edeago della nuova specie e la parte apicale dell'edeago della nuova specie chiaramente stretto, sono alcuni caratteri differenziali più evidenti. La spermateca della nuova specie è maggiore, con introflessione apicale del bulbo distale largo, robusto e fortemente slerificato (non sclerificato in paludosa).

Atheta (Oxypodera) atopotheca sp. n.

(Figg. 206-209) leg., MG).

Holotypus đo, Kenya, Kiambu, près de Limuru, 2300 m, 2.XI.1977, (Mahnert \& Perret

Paratypi: 2 oे के e $1 \%$, stessa provenienza.

Descrizione. Lungh. 3,2 mm. Corpo lucido e bruno-rossiccio con capo e uriti liberi $3^{\circ}, 4^{\circ}$ e $5^{\circ}$ bruni; antenne brune con i due antennomeri basali giallo- rossicci; zampe giallo-rossicce. La reticolazione del capo e dell'addome è distinta, quella del pronoto è svanita e quella delle elitre è netta. La punteggiatura del capo è distinta. I tubercoletti del pronoto sono molto salienti, quelli delle elitre sono distinti. Edeago figg. 207-208, spermateca fig. 209.

Comparazioni. La nuova specie risulta straordinaria e unica nel numero delle specie del sottogenere Oxypodera Bernhauer, 1915, a motivo dell'eccezionale forma allungata del bulbo distale della spermateca. Anche l'allungatissimo $11^{\circ}$ antennomero distingue la nuova specie dalle altre specie del sottogenere.

Etimologia. Il nome della nuova specie significa "Spermateca assurda".

\section{Alomacrotona ruandensis sp. n.}

(Figg. 210-213)

Holotypus + , Rwanda, Kayove, 2100 m, 15.V.1973, (Werner leg., MG).

Paratypi: 1 \& , Burundi, Kigwena Res., 11.II.1992, (Arndt leg., Mus. Erfurt); 1 q, Kenya, env. Endebess, pr. Kitale, 14.XI.1974, (Mahnert \& Perret leg.).

Descrizione. Lungh. 3,4 mm. Corpo lucido e giallo-rossiccio sporco; antenne bruno-rossicce con i tre antennomeri basali e $1^{\prime} 11^{\circ}$ rossicci; zampe gialle. La reticolazione del capo e delle elitre è netta, quella del pronoto è svanita e quella degli uroterghi è assente. La punteggiatura del capo è distinta e quella delle elitre è svanita. Tubercoletti salienti coprono la superficie del pronoto.

Comparazioni. Si veda sotto la chiave delle specie.

\section{Alomacrotona curticornis sp. $\mathrm{n}$.}

(Figg. 214-215)

Holotypus \&, Rwanda, Kayove, 2100 m, 15.V.1973, (Werner leg., MG).

Descrizione. Lungh. 2,2 mm. Corpo lucido e giallo rossiccio con capo ed elitre di un giallo-rossiccio sporco; antenne rossicce; zampe gialle. Il capo è privo di reticolazione. La reticolazione del pronoto e delle elitre è molto svanita. Gli uroterghi liberi $1^{\circ}$ a $4^{\circ}$ presentano una scultura squamiforma netta. La punteggiatura del capo è svanita. Tubercoletti distinti stanno sul pronoto e sulle elitre. Spermateca fig. 215.

Comparazioni. Si veda sotto la chiave delle specie.

\section{Alomacrotona kenyensis sp. n.}

(Figg. 216-217)

Holotypus \&, Kenya, Miss. Kaimosi, NE Kisumu, 1650 m, 10.XI.1974, (Mahnert \& Perret leg., MG). 

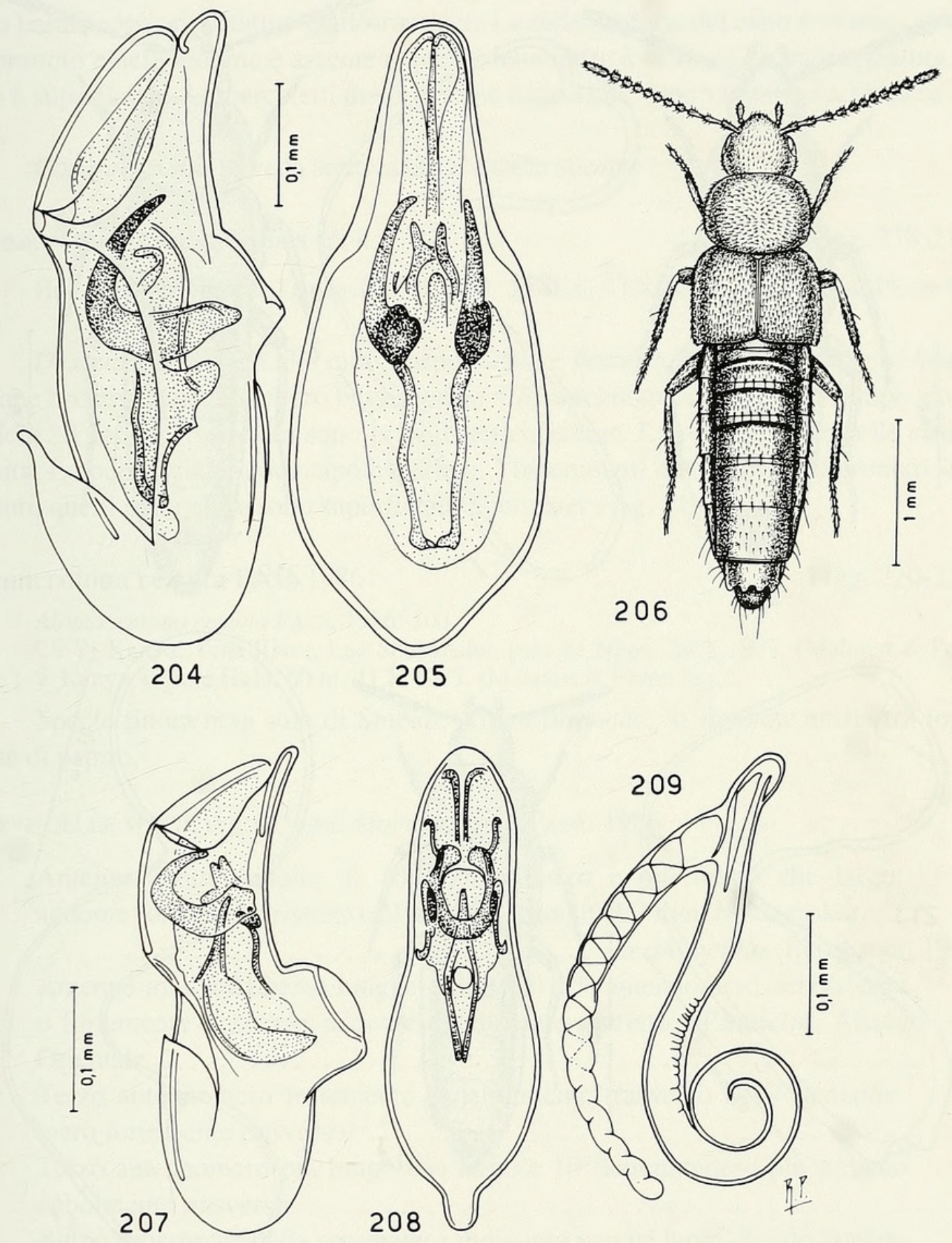

FIGG. 204-209

Edeago in visione laterale e ventrale, habitus e spermateca. 204-205: Atheta (Oxypodera) mahnerti sp. n.; 206-209: Atheta (Oxypodera) atopotheca sp. n. 

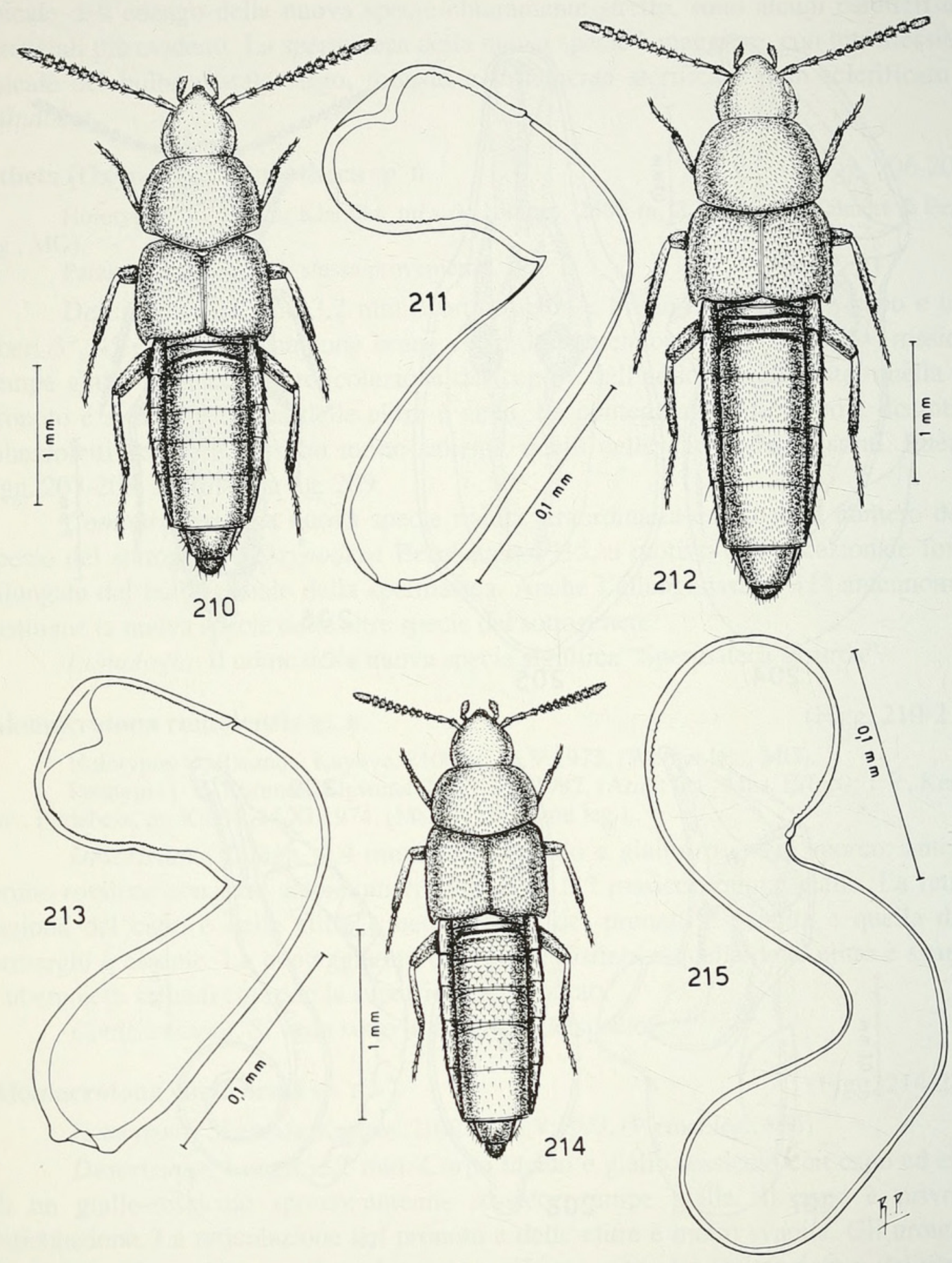

FIGG. $210-215$

Habitus e spermateca. 210-211: Alomacrotona ruandensis sp. n. del Rwanda; 212-213: Alomacrotona ruandensis sp. n., esemplare del Kenya; 214-215: Alomacrotona curticornis sp. $\mathrm{n}$. 
Descrizione. Lungh. 3,2 mm. Corpo lucido e bruno con estremità addominale rossiccia; antenne brune con antennomero basale giallo rossiccio e secondo antennomero basale rossiccio; zampe giallo-rossicce. La reticolazione del capo è svanita, quella del pronoto e dell'addome è assente e quella delle elitre è distinta. La punteggiatura del capo è superficiale. I tubercoletti del pronoto e delle elitre sono salienti. Spermateca fig. 217.

Comparazioni. Si veda sotto la chiave delle specie.

Alomacrotona tambachensis sp. $\mathrm{n}$.

(Figg. 218-219)

Holotypus \&, Kenya, Tambach, E Eldoret, 2000 m, 17.XI.1974, (Mahnert \& Perret leg., MG).

Descrizione. Lungh. 3,8 mm. Corpo lucido e bruno-rossiccio con addome bruno; antenne brune con antennomero basale giallo e $2^{\circ}$ antennomero rossiccio; zampe giallorossicce. Il capo e il pronoto sono privi di reticolazione. La reticolazione delle elitre è svanita. La punteggiatura del capo è distinta. I tubercoletti che coprono il pronoto sono salienti, quelli delle elitre sono superficiali. Spermateca fig. 219.

Alomacrotona remota Pace, 1986

(Figg. 220-221)

Alomacrotona remota PACE, 1986: 103.

2 ㅇ f, Kenya, Tana River, Lac Shakababo, près de Ngao, 28.X.1977, (Mahnert \& Perret leg.); 1 \& Kenya, Galole Hola, 60 m, 21.X.1977, (Mahnert \& Perret leg.).

Specie finora nota solo di Shibati, Africa orientale. Si rinviene anche tra foglie morte di papiro.

Chiave delle SPeCIE DEl Genere Alomacrotona PaCe, 1986

1 Antenne molto lunghe: il $10^{\circ}$ antennomero è più lungo che largo; addome fortemente ristretto all'indietro. Lungh. 3,9 mm. Madagaskar.

. . . . . . . . . . . . . . . . . termitophila (Bernhauer, 1901)

Antenne moderatamente lunghe o corte; il $10^{\circ}$ antennomero debolmente

o fortemente trasverso; addome debolmente ristretto all'indietro. Africa

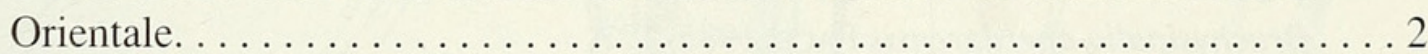

2 Terzo antennomero fortemente o debolmente trasverso e $10^{\circ}$ antenno-

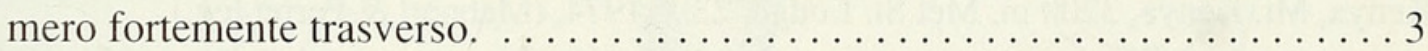

Terzo antennomero più lungo che largo e $10^{\circ}$ antennomero più $\mathrm{o}$ meno

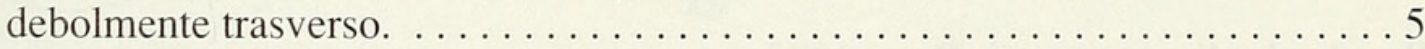

3 Bulbo prossimale della spermateca indistinto perché largo quanto la parte mediana della stessa spermateca. Lungh. 3,1 mm. Nairobi.

... . . invicta (Fauvel, 1907), comb. n. (olim Atheta invicta FAuvel, 1907: 54)

Bulbo prossimale della spermateca distinto, più largo della parte mediana della stessa spermateca. . . . . . . . . . . . . . . . . . 4

4 Addome coperto di microscultura squamiforme; spermateca grande quasi il doppio di quella di remota; bulbo distale della spermateca privo di introflessione apicale (fig. 215). Lungh. 2,2 mm. Rwanda. . . . curticornis sp. $\mathrm{n}$. 
- $\quad$ Addome coperto di tubercoletti salienti, così da dare un aspetto rugoso alla superficie; spermateca quasi della metà rispetto quella di curticornis; bulbo distale della spermateca con introflessione apicale (fig. 221). Lungh. 2,1-2,3 mm. Kenya, Tanzania, Namibia. . . . . . . . . remota Pace, 1986

$510^{\circ}$ antennomero debolmente trasverso; introflessione apicale del bulbo distale della spermateca, robustissima, cioè a parete spessa. . . . . . . . . 6

- $\quad 10^{\circ}$ antennomero appena trasverso; introflessione apicale del bulbo distale della spermateca, esile. . . . . . . . . . . . . . . . 7

6 Pronoto meno trasverso; spermateca esile, con introflessione apicale del bulbo disale, subconica. Lungh. 3,0 mm. Tanzania.

grandicollis (Bernhauer, 1915)

- $\quad$ Pronoto più trasverso; spermateca robustissima e tozza con introflessione apicale del bulbo distale emisferica (fig. 219). Lungh. 3,8 mm. Kenya. tambachensis sp. $\mathrm{n}$.

7 Occhi molto sviluppati, più lunghi delle tempie; parte prossimale della spermateca più corta della distale (fig. 217). Lungh. 3,2 mm. Kenya.

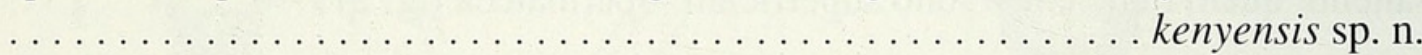

- Occhi ridotti, più brevi delle tempie; parte prossimale della spermateca più lunga della parte distale. Lungh. $3,4 \mathrm{~mm} \ldots \ldots \ldots \ldots$ ruandensis $\mathrm{sp} . \mathrm{n}$.

\section{Brachysipalia imbellis Pace, 1985}

Brachysipalia imbellis PACE, 1985: 130.

1 , Kenya, Embu, près de Kogari, 800 m, 6.XI.1974, (Mahnert \& Perret leg.).

Specie finora nota solo del M. Aberdare.

Brachysipalia crassa Pace, 1985

Brachysipalia crassa PACE, 1985: 125.

5 es., Kenya, Mt. Kenya, 3050 m, Met St. Lodge, 23.X.1974, (Mahnert \& Perret leg.).

Specie finora nota solo del M. Aberdare.

\section{Brachysipalia aberdarensis Pace, 1985}

Brachysipalia aberdarensis PACE, 1985: 127.

1 o, Kenya, Mt. Aberdares, Parc National, 25.XI.1975, (Mahnert \& Perret leg.); 8 es. Kenya, Mt. Kenya, 3200 m, Met St. Lodge, 23.X.1974, (Mahnert \& Perret leg.).

Specie finora nota solo del M. Aberdare.

\section{Brachysipalia meruensis Pace, 1985}

Brachysipalia meruensis PACE, 1985: 130.

42 es., Kenya, Mt. Kenya, 3050 m, Met St. Lodge, 23.X.1974, (Mahnert \& Perret leg.).

Specie finora nota solo del M. Meru.

\section{Brachysipalia irangensis sp. $\mathrm{n}$.}

(Figg. 222-225) leg., MG).

Holotypus ơ, Kenya, Embu, Irangi Forest St., 2000 m, 11.X.1977, (Mahnert \& Perret

Paratypi: 9 es., stessa provenienza. 

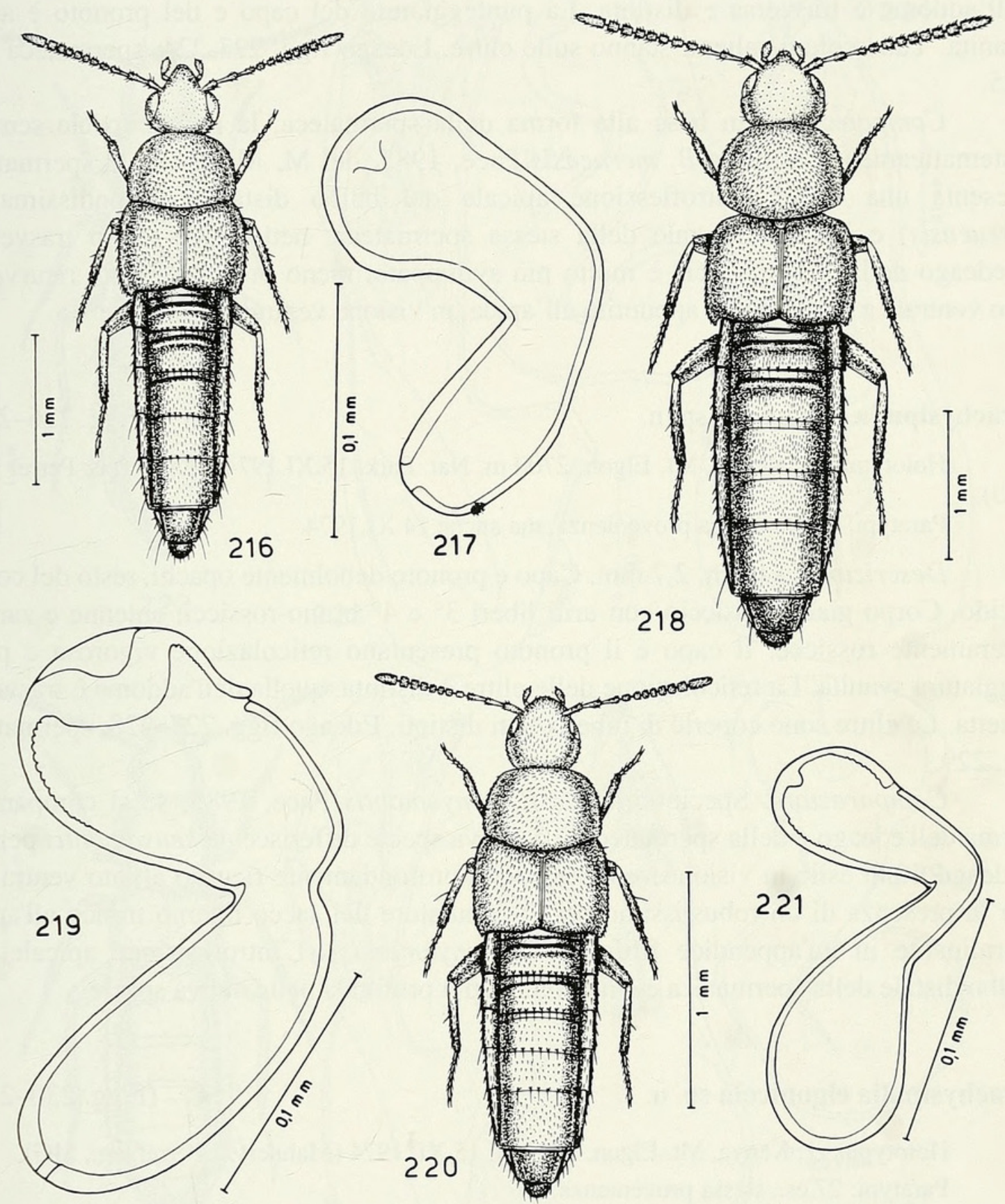

FIGG. 216-221

Habitus e spermateca. 216-217: Alomacrotona kenyensis sp. n.; 218-219: Alomacrotona tambachensis sp. n.; 220-221: Alomacrotona remota Pace. 
Descrizione. Lungh, 3,4 mm. Capo e pronoto opachi, resto del corpo lucido. Corpo rossiccio; antenne giallo-rossicce con i due antennomeri basali gialli; zampe giallo-rossicce. La reticolazione del capo e del pronoto è vigorosa, quella delle elitre e dell'addome è trasversa e distinta. La punteggiatura del capo e del pronoto è assai svanita. Tubercoletti salienti stanno sulle elitre. Edeago figg. 223-224, spermateca fig. 225.

Comparazioni. In base alla forma della spermateca, la nuova specie sembra sistematicamente vicina a $B$. meruensis Pace, 1985, del M. Meru, ma la spermateca presenta una debole introflessione apicale del bulbo distale (profondissima in meruensis) e il bulbo distale della stessa spermateca, nettamente meno trasverso. L'edeago della nuova specie è molto più sviluppato, meno profondamente ricurvo al lato ventrale e molto meno appuntito all'apice, in visione ventrale.

\section{Brachysipalia elgonensis sp. $n$.}

(Figg. 226-229) MG).

Holotypus ठ̊, Kenya, Mt. Elgon, 2700 m, Nat. Park, 15.XI.1974 (Mahnert \& Perret leg.,

Paratypi: 20 es., stessa provenienza, ma anche 14.XI.1974.

Descrizione. Lungh. 2,7 mm. Capo e pronoto debolmente opachi, resto del corpo lucido. Corpo giallo-rossiccio con uriti liberi $3^{\circ}$ e $4^{\circ}$ bruno-rossicci; antenne e zampe interamente rossicce. Il capo e il pronoto presentano reticolazione vigorosa e punteggiatura svanita. La reticolazione delle elitre è distinta, quella dell'addome è trasversa e netta. Le elitre sono coperte di tubercoletti distinti. Edeago figg. 227-228, spermateca fig. 229.

Comparazioni. Specie simile a B. kenyamontis Pace, 1985 , se si compara la forma dell'edeago e della spermateca. La nuova specie differisce da kenyamontis perché l'edeago è più esile in visione ventrale, meno profondamente ricurvo al lato ventrale e per la presenza di un robustissimo pezzo copulatore del sacco interno tronco all'apice (terminante in un'appendice filiforme in kenyamontis). L'introflessione apicale del bulbo distale della spermateca è chiaramente più profonda nella nuova specie.

\section{Brachysipalia elgonicola sp. $n$.}

(Figg. 230-233)

Holotypus đ̊, Kenya, Mt. Elgon, 2700 m, 15.XI. 1974 (Mahnert \& Perret leg., MG).

Paratypi: 27 es., stessa provenienza.

Descrizione. Lungh. 2,2 mm. Corpo lucido e giallo-rossiccio; antenne giallobrune con i due antennomeri basali gialli; zampe gialle. La reticolazione del capo e del pronoto è molto svanita, quella delle elitre e dell'addome netta. La punteggiatura del capo e del pronoto è molto superficiale. Tubercoletti svaniti coprono le elitre. Edeago figg. 231-232, spermateca fig. 233.

Comparazioni. L'edeago e la spermateca della nuova specie hanno forma cosi differente rispetto quella delle altre specie del genere, che non è possibile avvicinare sistematicamente la nuova specie ad altre simili. 


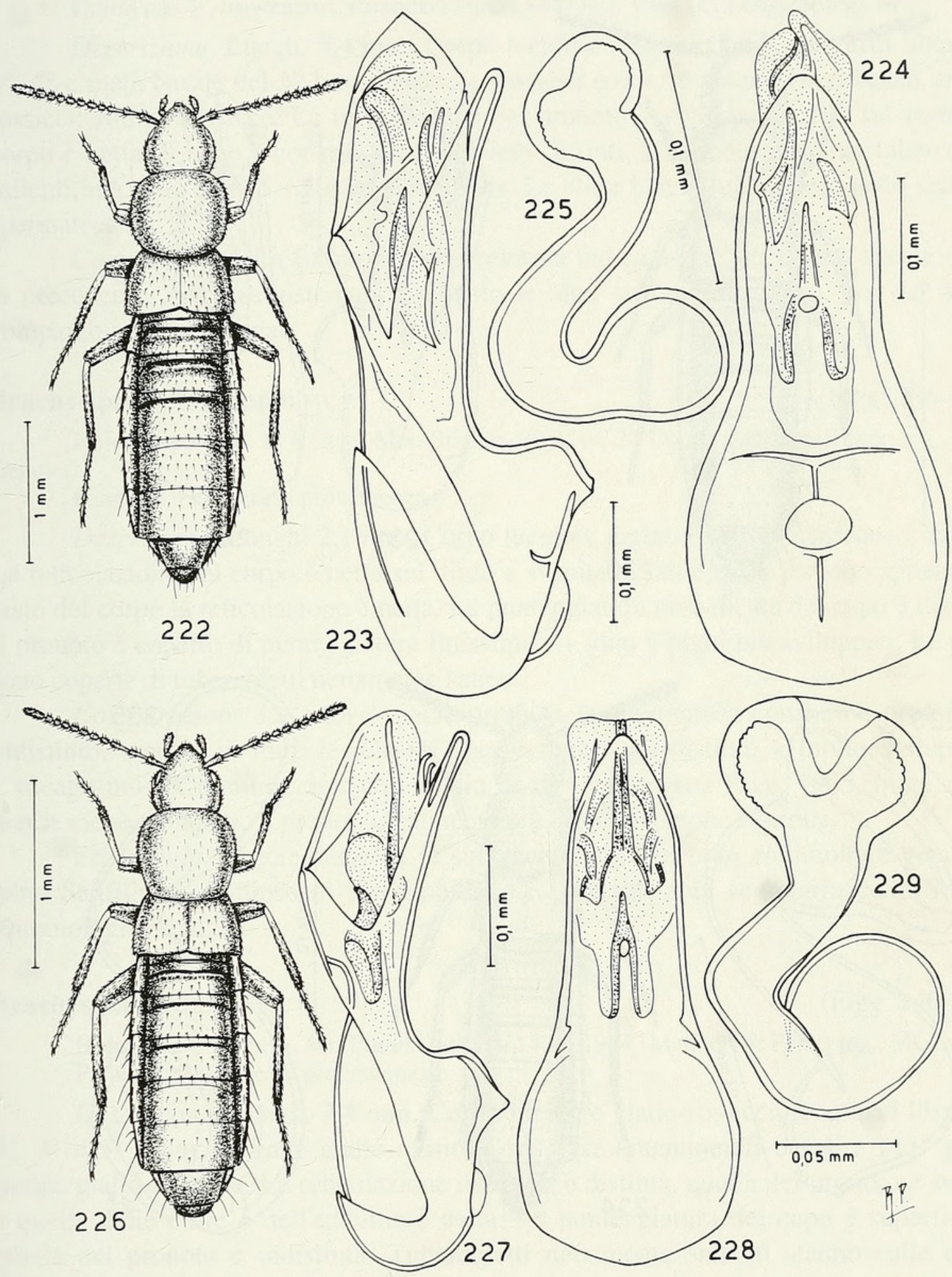

FIGG. 222-229

Habitus, edeago in visione laterale e ventrale e spermateca. 222-225: Brachysipalia irangensis sp. n.; 226-229: Brachysipalia elgonensis sp. n. 

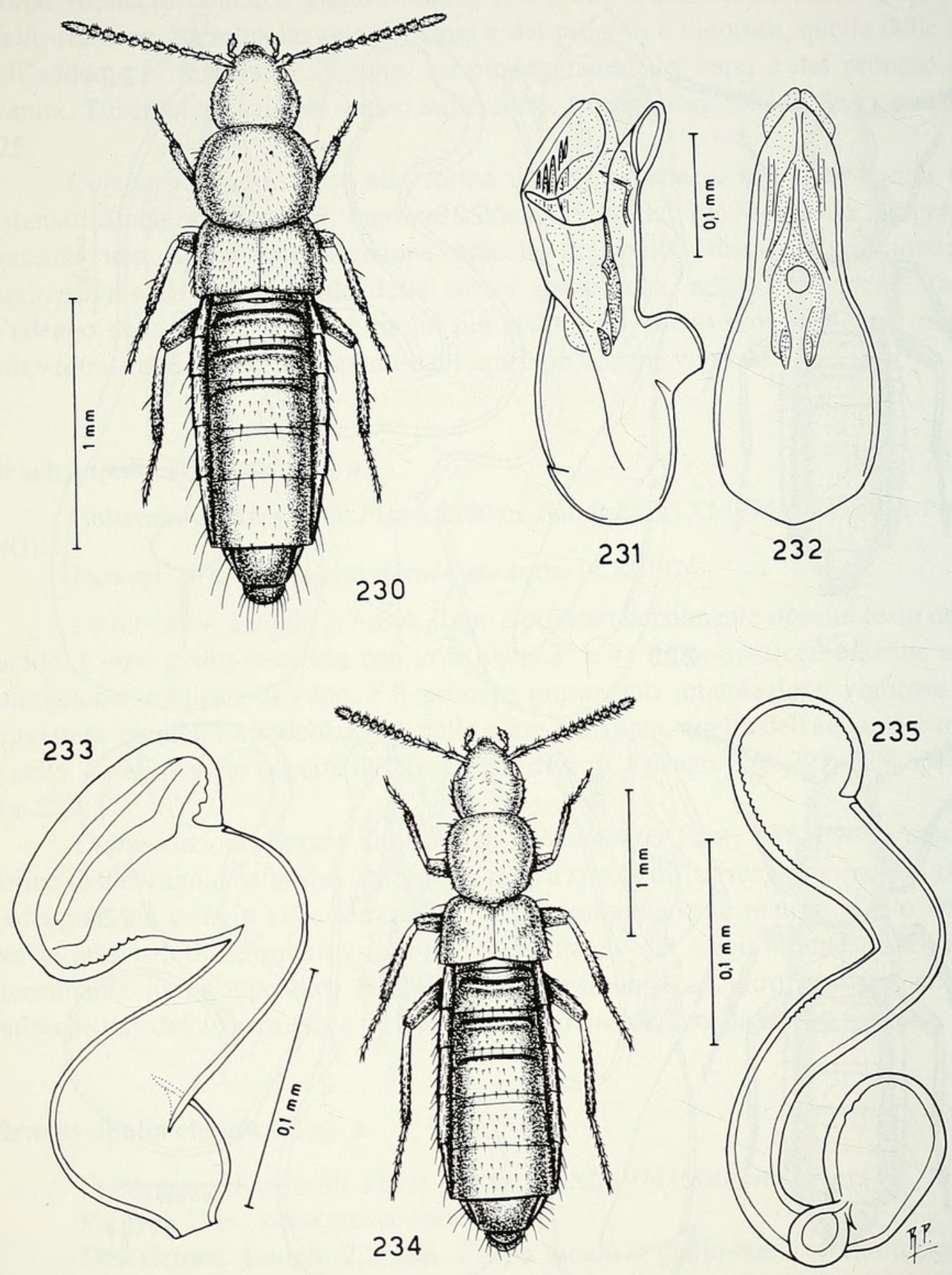

FIGG. 230-235

Habitus, edeago in visione laterale e ventrale e spermateca. 230-233: Brachysipalia elgonicola sp. n.; 234-235: Brachysipalia ruwenzorensis sp. n. 
Brachysipalia ruwenzorensis sp. $\mathrm{n}$.

(Figg. 234-235)

Holotypus \&, Ruwenzori, Kitandara Hut, 13200 ft, I. 1984 (C. Lengeler leg., MG).

Descrizione. Lungh. $3,4 \mathrm{~mm}$. Corpo lucido e rossiccio scuro con uriti liberi $2^{\circ}$, $3^{\circ}, 4^{\circ}$ e metà basale del $5^{\circ}$ bruni; antenne rossicce con i tre antennomeri basali giallorossicci; zampe rossicce. La reticolazione del pronoto è vigorosa, quella sul resto del corpo è netta. Il capo è coperto di tubercoletti distinti. Il pronoto presenta tubercoletti salienti, ma sono assenti sulla linea mediana. Le elitre hanno tubercoletti poco salienti. spermateca fig. 235.

Comparazioni. La forma della spermateca indica anche per questa specie come la precedente, distanza sistematica rispetto le altre specie del genere, per cui non è comparabile con nessuna.

Brachysipalia sanfilippoi sp. $n$.

(Figg. 236-239) Genova).

Holotypus ơ, M. te Kenya, Met. Station, 3050 m, 22.IX.1976 (N. Sanfilippo leg., Mus.

Paratypi: 9 es., stessa provenienza.

Descrizione. Lungh. 2,1 mm. Corpo lucido e giallo, comprese antenne e zampe. La reticolazione del corpo è netta sul disco e svanita al lati e nella zona occipitale. Sul resto del corpo la reticolazione è netta. La punteggiatura ombelicata del capo è distinta. Il pronoto è coperto di punteggiatura finissima: vi sono 4 punti più sviluppati. Le elitre sono coperte di tubercoletti nettamente salienti.

Comparazioni. La nuova specie presenta la spermateca con bulbo prossimale indistinto, mentre in tutte le restanti specie note è da distinto a molto sviluppato. L'edeago mostra reminiscenze con quello di B. kenyamontis Pace, 1985, ma è nettamente meno svilupatto e proporzionalmente più largo in visione ventrale.

Etimologia. Specie dedicata al suo raccoglitore: il noto entomologo genovese Nino Sanfilippo, studioso di Hydrophilidae e per tanti anni segretario della Società Entomologica Italiana.

\section{Brachysipalia viatica sp. $n$.}

(Figg. 240-243)

Holotypus ô, Kenya, Mt. Elgon, 2800 m, 14.XI.1974 (Mahnert \& Perret leg., MG).

Paratypi: 5 es., stessa provenienza.

Descrizione. Lungh. $3,4 \mathrm{~mm}$. Corpo lucido e giallo-rossiccio con uriti liberi $2^{\circ}$, $3^{\circ}, 4^{\circ}$ e $5^{\circ}$ bruni; antenne giallo-rossicce con i tre antennomeri basali e $1^{\prime} 11^{\circ}$ gialli; zampe giallo-rossicce. La reticolazione del capo è distinta, quella del pronoto è svanita e quella delle elitre e dell'addome è netta. La punteggiatura del capo é superficiale, quella del pronoto è indistinta. Tubercoletti nettamente salienti stanno sulle elitre. Edeago figg. 241-242, spermateca fig. 243.

Comparazioni. Specie simile a B. crassa Pace, 1985, del M. Kenya e a B. kenyamontis Pace, 1985. Se ne distingue da entrambe per avere l'edeago ampiamente ricurvo al lato ventrale, con "crista apicalis" e "crista proximalis" nettamente più svilupatte. La spermateca ha bulbo prossimale non così ipertrofico come quello delle due specie citate sopra. 

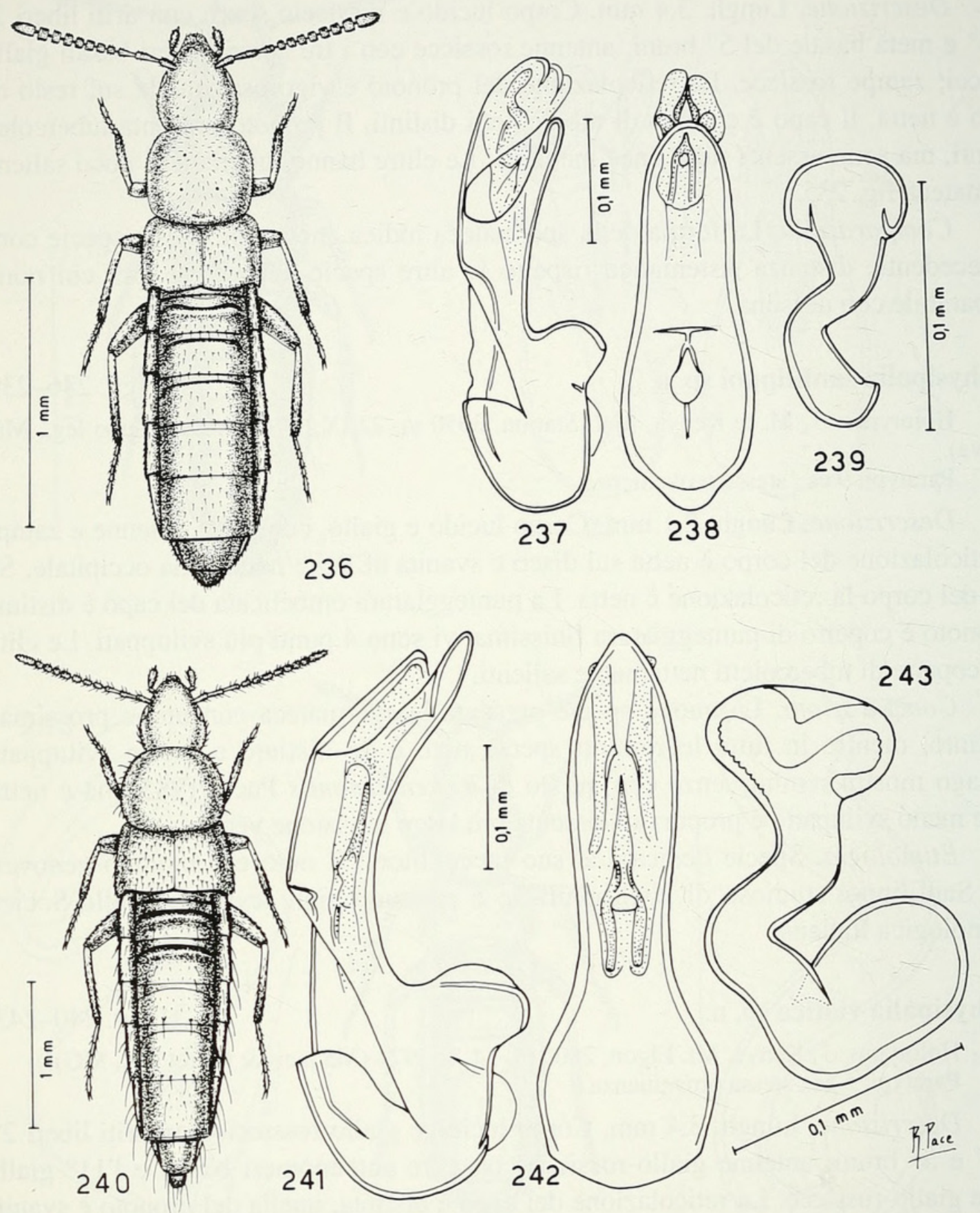

FIGG. 236-243

Habitus, edeago in visione laterale e ventrale e spermateca. 236-239: Brachysipalia sanfilippoi sp. n.; 240-243: Brachysipalia viatica sp. n. 
Brachysipalia embuensis sp. $n$.

(Figg. 244-249) MG).

Holotypus ô, Kenya, Embu, Irangi Forest, 2100 m, 12.X.1977 (Mahnert \& Perret leg.,

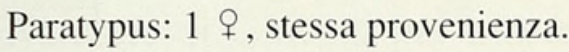

Descrizione. Lungh. 2,2 mm. Corpo lucido e rossiccio con $4^{\circ}$ urite libero bruno; antenne brune con i due antennomeri basali e $1^{\prime} 11^{\circ}$ bruno-rossicci; zampe gialle. La reticolazione del capo è assente, quella del pronoto è distinta. I tubercoletti delle elitre sono molto salienti verso la sutura. Addome non reticolato. Edeago figg. 245-246, spermateca fig. 247.

Comparazioni. La nuova specie ha edeago simile a quello di $B$. franzi Pace, 1985, del Kilimangiaro, ma ha dimensione ridotta e pezzi copulatori del sacco interno di forma diversa: pezzo a uncino assente in franzi. Inoltre la spermateca è meno sviluppata nella nuova specie, sebbene di forma simile a quella di franzi, ha però l'introflessione apicale del bulbo distale, stretta, mentre in franzi è larghissima.

\section{Brachysipalia volans sp. $n$.}

(Figg. 248-249)

Holotypus \&, Kenya, Mt. Elgon, 2700 m, 15.XI.1974 (Mahnert \& Perret leg., MG).

Paratypi: 2 $q$, stessa provenienza, ma $2650 \mathrm{~m}$ e 14.XI.1974.

Descrizione. Lungh. 2,2 mm. Corpo lucido e rossiccio scuro; antenne brunorossicce con antennomero basale rossiccio; zampe giallo-rossicce. Il capo, il pronoto e l'addome sono privi di reticolazione. La reticolazione delle elitre è svanita. La punteggiatura del capo e del pronoto è molto superficiale. Netti tubercoletti stanno sulle elitre.

Comparazioni. La spermateca della nuova specie ha forma e grandezza simili alla spermateca di B. franzi Pace, 1985, del Kilimangiaro, ma l'introflessione apicale del bulbo distale della spermateca stessa della nuova specie, è stretta e profonda, mentre quella di franzi è larghissima e meno profonda. Inoltre le elitre della nuova specie sono appena più corte del pronoto, mentre in franzi sono molto più corte del pronoto. Il pronoto della nuova specie presenta 4 punti discali, assenti in franzi. 


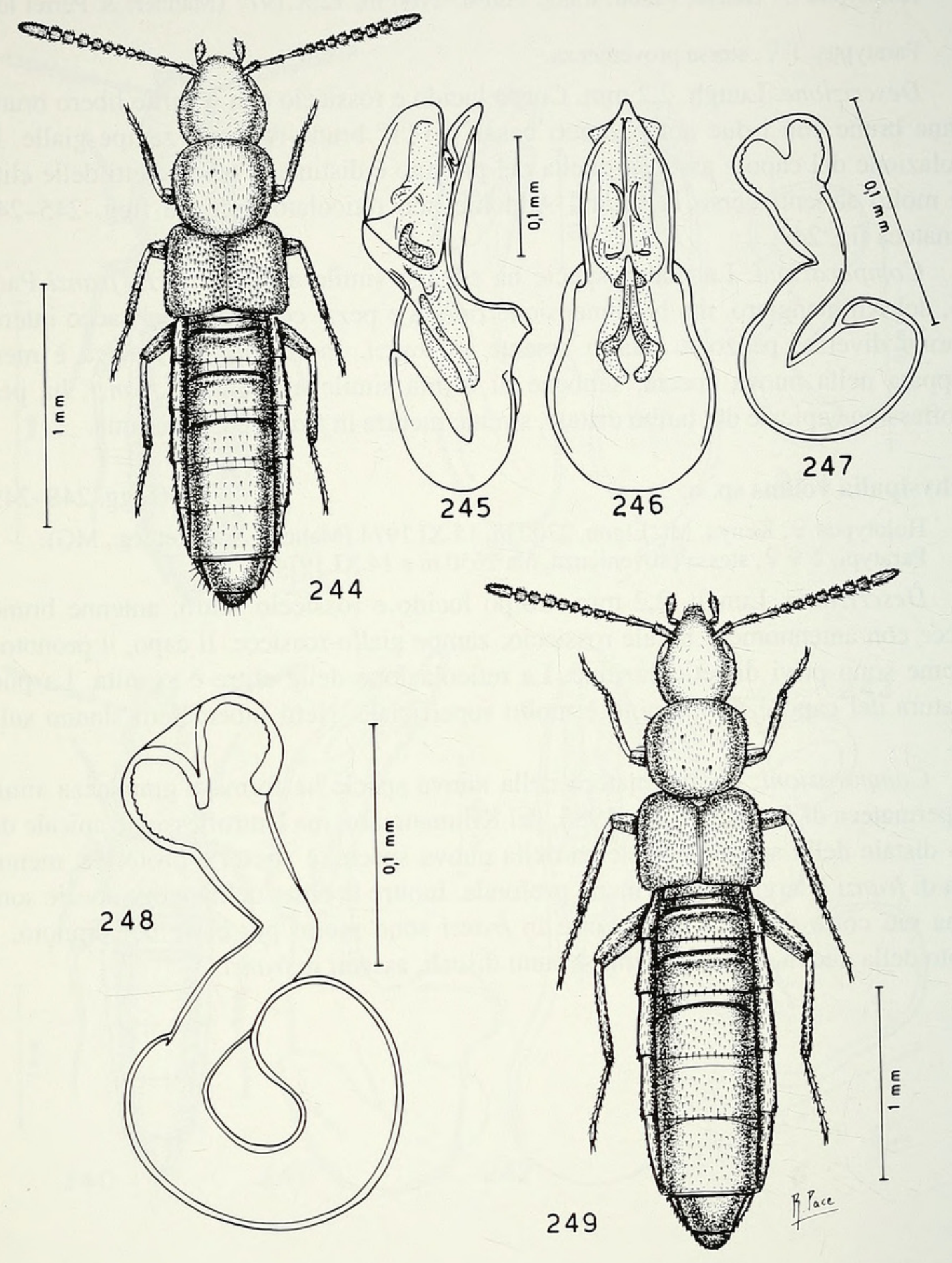

FIGG. 244-249

Habitus, edeago in visione laterale e ventrale e spermateca. 244-247: Brachysipalia embuensis sp. n.; 248-249: Brachysipalia volans sp. n. 


\section{RINGRAZIAMENTI}

Ringrazio molto cordialmente il Dr I. Löbl e il Dr C. Besuchet del Museo di Storia Naturale di Ginevra per avermi affidato in studio il materiale pubblicato nel presente lavoro. Ringrazio per lo stesso motivo il Dr R. Poggi e il Sig. N. Sanfilippo del Museo di Storia Naturale di Genova e il Dr L. Zerche del D.E.I. di Eberswalde. Per il prestito di tipi rigrazio vivamente il Dr L. Baert dell'Institut Royal des Sciences Naturelles de Belgique di Bruxelles, il Dr A.F. Newton del "Field Museum of Natural History" di Chicago e il Dr L. Bartolozzi del Museo Zoologico dell'Università di Firenze.

\section{BIBLIOGRAFIA}

Bernhauer, M. 1901. Ein neuer Termitengast aus Madagaskar. Deutsche ent. Z. 1901: 252.

Bernhauer, M. 1915. Zur Staphylinidenfauna des tropischen Afrika. Annls. hist.-nat. Mus. natn. hung. 13: 95-189.

BERNHAUER, M. 1927. Materiali per lo studio della fauna Eritrea raccolti nel 1901-1903 dal Dr A. Andreini, Staphylinidae. Boll. Soc. ent. Ital. 59: 79-81.

Bernhauer, M. 1931. Entomological Expedition to Abyssinia, 1926-1927: Coleoptera, Staphylinidae. Systematic report by Dr Max Bernhauer. J. Linn. Soc. Lond. Zool. 37: 559-605.

Bernhauer, M. 1934. Neue Kurzflüger von Ruwenzori-Zivu-Gebiet. XXXIV. Beitrag zur afrikanischen Staphylinidenfauna. Rev. Zool. Bot. afr. 25: 206-217.

Bernhauer, M. 1944. Phleophile Staphyliniden aus Ostafrika (Coleoptera). Rev. franç. Ent. 11: $17-21$.

Bernhauer, M. \& Scheerpeltz, O. 1926. Coleopterorum Catalogus. Staphylinidae 4: 499-988, Berlin.

Cameron, M. 1932. New species of Staphylinidae from the Belgian Congo. Bull. Ann. Soc. Ent. Belg. 72: 131-146.

Cameron, M. 1939. The fauna of British India. Coleoptera Staphylinidae 4: 691 pp., London.

CAmERon, M. 1942. New species of Staphylinidae (Col.) collected by the Coryndon Museum Expedition to the Chyulu Hills. Ann. Mag. Nat. Hist. 9: 321-332.

Cameron, M. 1950. Staphylinidae (Coleoptera Polyphaga). Explor. Parc natn. Albert Miss. G. F. de Witte 59: 1-85.

Eichelbaum, F. 1913. Verzeichnis der von mir in den Jahren 1903 und 1904 in Deutsch- und British-Ostafrika eingesammelten Staphylinidae. Arch. Naturg. 79: 114-168.

Fauvel, A. 1900. Staphylinidae nouveaux de Kinchassa (Congo). Rev. Ent. 19: 66-74.

Fauvel, A. 1907. Voyage de M. Ch. Alluaud dans l'Afrique Orientale. Rev. Ent. 26: 10-70.

FENyES, A. 1920. Coleoptera: Fam. Staphylinidae, subfam. Aleocharinae. Genera Insectorum 173: $111-414$.

Jeannel, R. \& Paulian, R. 1945. Mission scientifique de l'Omo. Faune des terriers des ratstaupes, IV: Coléoptères. Mem. Mus. Nat. Hist. 19: 51-147.

KraAtZ, G. 1857. Beiträge zur Kenntniss der Termitophilen. Linnaea Ent. 11: 44-56.

Mulsant, M.E. \& Rey, C. 1873. Description de divers coléoptères brévipennes nouveaux ou peu connus. Opusc. Ent. 15: 147-189.

PACE, R. 1984. Aleocharinae delle Mascarene. Parte II. Rev. suisse Zool. 91: 249-280.

PACE, R. 1985. Aleocharinae raccolte dal Prof. Franz sul Kenya, Kilimangiaro e Monti Aberdare. Fragm. Ent. 18: 115-159. 
PACE, R. 1986. Aleocharinae dell'Africa Orientale (Coleoptera, Staphylinidae). Ann. hist.-nat. Mus. Natn. hung. 78: 83-143.

PACE, R. 1994. Aleocharinae della Sottoregione Africana Orientale al Museo di Ginevra (Coleoptera, Staphylinidae) Parte I. Rev. suisse Zool. 100: 117-193.

ScheErPeltz, O. 1968. Coleoptera Staphylinidae. Cat. faun. Austriae 15. Wien Akad. Wiss.: $1-124$.

Thomson, C.G. 1858. Försök till uppställning af Sveriges Staphyliner. Öfv. Kön. Vet.-Akad. Förh. 15: 27-40.

TotTEnham, C.E. 1957. Coleoptera Staphylinidae: Tachyporinae, Pygosteninae (cont.) and Aleocharinae (part.). Ann. Mus. Congo Tervuren 58: 73-135. 


\section{$2 \mathrm{BHL}$ Biodiversity Heritage Library}

1995. "Aleocharinae della Sottoregione Africana Orientale al Museo di Ginevra (Coleoptera, Staphylinidae) parte 2." Revue suisse de zoologie 102, 779-846. https://doi.org/10.5962/bhl.part.80482.

View This Item Online: https://www.biodiversitylibrary.org/item/128625

DOI: https://doi.org/10.5962/bhl.part.80482

Permalink: https://www.biodiversitylibrary.org/partpdf/80482

\section{Holding Institution}

Smithsonian Libraries

\section{Sponsored by}

Biodiversity Heritage Library

\section{Copyright \& Reuse}

Copyright Status: In Copyright. Digitized with the permission of the rights holder

Rights Holder: Muséum d'histoire naturelle - Ville de Genève License: http://creativecommons.org/licenses/by-nc-sa/3.0/

Rights: https://www.biodiversitylibrary.org/permissions/

This document was created from content at the Biodiversity Heritage Library, the world's largest open access digital library for biodiversity literature and archives. Visit BHL at https://www.biodiversitylibrary.org. 